\title{
Exploration and Development of PPAR Modulators in Health and Disease: An Update of Clinical Evidence
}

\author{
Hong Sheng Cheng ${ }^{1, * \mathbb{C}}$, Wei Ren Tan ${ }^{2}$, Zun Siong Low ${ }^{2}$, Charlie Marvalim ${ }^{1}$, \\ Justin Yin Hao Lee ${ }^{2}$ and Nguan Soon Tan 1,2,*D \\ 1 School of Biological Sciences, Nanyang Technological University Singapore, 60 Nanyang Drive, \\ Singapore 637551, Singapore; CMARVALI001@e.ntu.edu.sg \\ 2 Lee Kong Chian School of Medicine, Nanyang Technological University Singapore, 11 Mandalay Road, \\ Singapore 308232, Singapore; WTAN074@e.ntu.edu.sg (W.R.T.); ZUNSIONG001@e.ntu.edu.sg (Z.S.L.); \\ lee.yinhao@ntu.edu.sg (J.Y.H.L.) \\ * Correspondence: hscheng@ntu.edu.sg (H.S.C.); nstan@ntu.edu.sg (N.S.T.); \\ Tel.: +65-6904-1294 (H.S.C.); +65-6904-1295 (N.S.T.)
}

Received: 30 September 2019; Accepted: 10 October 2019; Published: 11 October 2019

\begin{abstract}
Peroxisome proliferator-activated receptors (PPARs) are nuclear receptors that govern the expression of genes responsible for energy metabolism, cellular development, and differentiation. Their crucial biological roles dictate the significance of PPAR-targeting synthetic ligands in medical research and drug discovery. Clinical implications of PPAR agonists span across a wide range of health conditions, including metabolic diseases, chronic inflammatory diseases, infections, autoimmune diseases, neurological and psychiatric disorders, and malignancies. In this review we aim to consolidate existing clinical evidence of PPAR modulators, highlighting their clinical prospects and challenges. Findings from clinical trials revealed that different agonists of the same PPAR subtype could present different safety profiles and clinical outcomes in a disease-dependent manner. Pemafibrate, due to its high selectivity, is likely to replace other PPAR $\alpha$ agonists for dyslipidemia and cardiovascular diseases. PPAR $\gamma$ agonist pioglitazone showed tremendous promises in many non-metabolic disorders like chronic kidney disease, depression, inflammation, and autoimmune diseases. The clinical niche of PPAR $\beta / \delta$ agonists is less well-explored. Interestingly, dual- or pan-PPAR agonists, namely chiglitazar, saroglitazar, elafibranor, and lanifibranor, are gaining momentum with their optimistic outcomes in many diseases including type 2 diabetes, dyslipidemia, non-alcoholic fatty liver disease, and primary biliary cholangitis. Notably, the preclinical and clinical development for PPAR antagonists remains unacceptably deficient. We anticipate the future design of better PPAR modulators with minimal off-target effects, high selectivity, superior bioavailability, and pharmacokinetics. This will open new possibilities for PPAR ligands in medicine.
\end{abstract}

Keywords: clinical trials; metabolic syndrome; type 2 diabetes mellitus; cancer; non-alcoholic fatty liver diseases; cardiovascular diseases; neurological disorders

\section{Introduction}

Peroxisome proliferator-activated receptors (PPARs) are members of the nuclear receptor superfamily whose physiological functions are linked to metabolism, energy homeostasis, cellular development, and differentiation. Three members of PPARs have been identified, namely PPAR $\alpha$, PPAR $\gamma$, and PPAR $\beta / \delta$. Upon ligand binding, PPARs translocate into the nucleus, where they heterodimerize with retinoid $X$ receptor and bind to peroxisome proliferator response elements (PPREs) to regulate the transcription of target genes [1]. Despite sharing a high degree of structural homology, the three PPAR isoforms have distinct functional roles, tissue distribution, and ligand-binding 
properties [2]. The characteristics of human PPAR $\alpha, \beta / \delta$, and $\gamma$ are well-reviewed [3-5] and will not be elaborated herein.

Owing to their crucial metabolic regulatory roles and excellent druggability, many PPAR agonists have been synthesized for the treatment of metabolic diseases, especially dyslipidemia and type 2 diabetes mellitus (T2DM). For instance, fibrates which are selective PPAR $\alpha$ agonists, are often used in combination with statins to treat atherogenic hyperlipidemia and hypertriglyceridemia [6]. Likewise, thiazolidinediones (TZDs), which are potent PPAR $\gamma$ activators, are used as insulin sensitizers to manage T2DM patients [7]. The clinical success of fibrates and TZDs have not only propelled the development of various PPAR $\alpha$ or $\gamma$ agonists but also sparked the creation of novel PPAR modulators including selective PPAR $\beta / \delta$ activators, dual-PPAR agonists, and pan-PPAR agonists [2]. Aside from dyslipidemia and T2DM, PPARs also have profound implications on other facets of metabolic syndrome (MetS), like diabetic complications, non-alcoholic fatty liver disease (NAFLD), as well as non-metabolic disorders including neurodegenerative diseases, cancers, and inflammatory diseases. As a result, the clinical benefits of PPAR agonists have been assessed in a wide variety of diseases and health complications [8]. Different PPAR agonists and their current clinical statuses are illustrated in Figure 1.

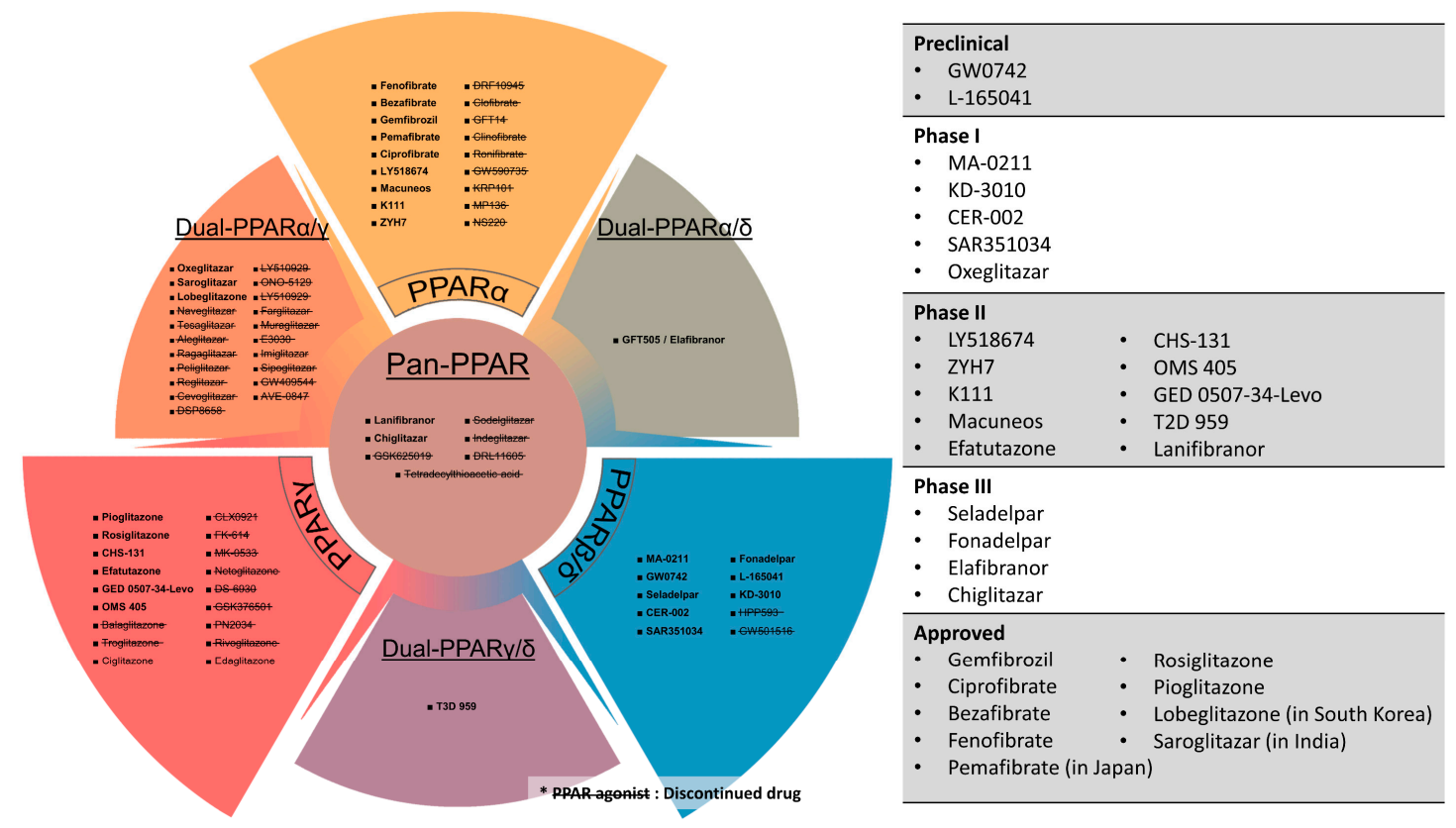

Figure 1. PPAR agonists, their PPAR target(s) and current status in clinical pipeline. Drugs with strikethrough mark (e.g., PPAR agenist) have been discontinued at clinical or preclinical stages.

Undeniably, drugs that target PPARs are of paramount scientific and clinical significance. In the review, we aim to consolidate existing clinical evidence of PPAR agonists and antagonists to highlight their effectiveness, health benefits, clinical prospects, and developmental challenges. Since the lipid-lowering activity of PPAR $\alpha$ agonists and insulin-sensitizing effect of PPAR $\gamma$ agonists are extremely well-established and have been widely exploited to improve dyslipidemia and T2DM [9-12], these aspects will be excluded from this review. Extra emphasis will be placed on new classes of PPAR modulators like dual- and pan-PPAR agonists which are collectively known as "glitazars". Essentially, this review will provide a comprehensive and up-to-date overview of the latest development of PPAR modulators for the treatment of various diseases based on existing clinical data.

\section{Mechanistic Rationales for Targeting PPARs in Various Human Diseases}

PPARs are critical lipid sensors and regulators because of their indispensable roles in various lipid-related bioactivities such as lipid transport, adipocyte differentiation as well as the metabolism of various lipid components like fatty acids, ketone bodies, triglycerides, and cholesterols. Hepatic 
PPAR $\alpha$ stimulates fatty acid catabolism by modulating the expression of lipoprotein lipase (LPL), apolipoprotein genes ( $A P O A 1, A P O A 2$, and $A P O A 5)$, fatty acid transport and oxidation genes (FABP1, FABP3, ACS, ACO, CPT1, and CPT2), as well as genes for HDL metabolism (PLTP) and ketone synthesis (HMGCS2) $[13,14]$. As a result, hepatic PPAR $\alpha$ activation is associated with substantial triglyceride clearance and increased plasma HDL level, underpinning the clinical use of PPAR $\alpha$ agonists to treat hyperlipidemia and cardiovascular disease (CVD). On the other hand, PPAR $\gamma$ selectively promotes lipid uptake and lipogenesis in the adipose tissues, leading to lowered circulating triglycerides and free fatty acids, and insulin resistance [15]. Furthermore, in the adipocytes, genes responsible for insulin-dependent glucose uptake (GLUT4, IRS-1, IRS-2, and c-Cbl associated protein) and adipokines (adiponectin, resistin, leptin, and tumor necrosis factor- $\alpha$ ) are also PPAR $\gamma$ responsive [15]. These adipokines can influence insulin signaling. Consequently, PPAR $\gamma$ activation in adipocytes is sufficient to enhance systemic insulin sensitivity, making PPAR $\gamma$ agonists a potent antidiabetic agent [16]. In contrast to PPAR $\alpha$ and PPAR $\gamma$, much less is known about the regulatory mechanism of PPAR $\beta / \delta$. Aside from driving fatty acid catabolism and energy uncoupling, activation of PPAR $\beta / \delta$ has been demonstrated to favor $\beta$-oxidation over glycolysis in the skeletal muscles, which dramatically enhanced muscle endurance to physical exercises [17]. The stimulatory effect of PPAR $\beta / \delta$ on fatty acid oxidation and mitochondrial activity may help to preserve pancreatic $\beta$-cell function and insulin secretion in the event of prolonged lipotoxicity [18]. In essence, all three PPARs occupy pivotal niches in energy metabolism, rendering their agonists among the most extensively tested drugs for diseases associated with MetS, such as prediabetes, T2DM, obesity, CVD, and atherogenic dyslipidemia, as well as endocrine diseases like polycystic ovarian syndrome (PCOS). Furthermore, the close link between PPARs, metabolism and liver functions also underscores PPARs as potential targets for the liver manifestations: non-alcoholic fatty liver disease (NAFLD), non-alcoholic steatohepatitis (NASH), and primary biliary cholangitis (PBC). Owing to the distinct roles of different PPARs, concomitant activation of multiple PPARs is believed to elicit a superior therapeutic efficacy. Such a speculation leads to the creation of dual- and pan-PPAR agonists which act on two or all PPAR isoforms. The new classes of PPAR modulators are actively being investigated for CVD, T2DM, dyslipidemia, NASH, $\mathrm{PBC}$, and MetS.

There is increasing evidence showing that the cardiovascular benefits of PPAR agonists are attributed, at least in part, to the activation of the endothelial nitric oxide synthase (eNOS) [19]. Under physiological conditions, nitric oxide produced by eNOS acts as a vasodilator and anti-thrombotic agent to safeguard endothelial functions. The activity of eNOS is significantly compromised in CVD and atherosclerosis, resulting in low nitric oxide bioavailability and the disruption of endothelial vasculature. All three subtypes of PPARs can promote eNOS activation. For example, fibrates can enhance nitric oxide biosynthesis by upregulating eNOS expression, stabilizing eNOS mRNA, and stimulating eNOS activation via PI3K, MAPK, and AMPK pathways $[20,21]$. PPAR $\beta / \delta$ and PPAR $\gamma$ also modulate eNOS activity through the PI3K-Akt pathway [22,23]. The stimulatory effect of PPAR $\gamma$ on eNOS activation and stability is also facilitated by other intermediates, including heat shock protein 90, adiponectin, and Src homology region 2-containing protein tyrosine phosphatase 2 [24-26]. Taken together, the effect of PPARs on eNOS and nitric oxide production lays the groundwork for the clinical use of PPAR agonist in CVD and hypertension.

PPARs have also emerged as important regulators of innate immunity and inflammatory response. They form a crucial link between metabolic disorders and chronic low-grade inflammation, which often co-manifest and inseparably intertwine in chronic metabolic diseases. PPARs modulate inflammatory response via various direct and indirect mechanisms [27]. For example, inflammatory mediators and PPAR $\alpha$ ligand, leukotriene B4 can exert a negative feedback mechanism via PPAR $\alpha$ activation to limit its activity and to resolve an inflammatory response [28]. PPAR $\alpha$ also interferes with the proinflammatory

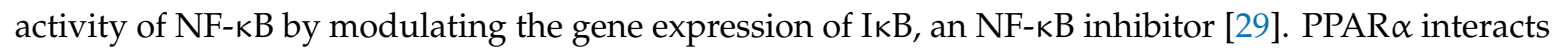
with glucocorticoid receptor $\alpha$ or estrogen receptor to transrepress other proinflammatory transcription factors for anti-inflammatory effects [30,31]. Likewise, the transrepression of inflammatory response 
genes due to ligand-dependent SUMOylation of PPAR $\gamma$ has been observed [32]. Such a post-translation modification of PPAR $\gamma$ reinforces PPAR $\gamma$-nuclear receptor corepressor-histone deacetylase- 3 complexes, thus stabilizing NF- $\mathrm{kB}$ in its repressed, promoter-bound state [32]. In dendritic cells, PPAR $\gamma$ takes part in the regulation of various processes like antigen uptake, cellular activation and maturation, cytokine production, and lipid antigen presentation [33]. Furthermore, macrophage PPAR $\gamma$ can inhibit genes encoding proinflammatory molecules while activating the expression of anti-inflammatory mediators to promote anti-inflammatory effect $[15,27]$. Together with their glucose and lipid regulatory activities, the anti-inflammatory effect of PPAR $\alpha$ and $\gamma$ is beneficial in medical conditions where inflammation is one of the major driving forces of disease exacerbation, such as NASH and atherosclerosis. In hepatitis $C$ infection, insulin resistance and hepatic steatosis appear to benefit viral core protein expression and confer anti-viral drug resistance [34]. Targeting PPARs, which is effective to resolve these abnormalities, can possibly aid in viral and metabolic-related hepatitis. Due to the anti-inflammatory properties, PPARs are also exploited to mitigate acute inflammatory flares in various autoimmune, inflammatory, and infectious diseases, including rheumatoid arthritis, systemic lupus erythematosus (SLE), sepsis, endometriosis, ulcerative colitis, and asthma. Since neuroinflammation has been one of the prominent themes in the pathogenesis for multitudes of neurological diseases, targeting PPARs may also reap beneficial outcome [35-37]. Thus, PPAR agonists are prospective stand-alone or co-administered therapeutic drugs for many neurological or neurodegenerative diseases like amyotrophic lateral sclerosis, multiple sclerosis, cognitive impairment, and Alzheimer's disease as well as mental disorders like depression, addiction, and schizophrenia. Unlike PPAR $\alpha$ and $\gamma$, a role for $\operatorname{PPAR} \beta / \delta$ in inflammation remains controversial. Therefore, the efficacy of PPAR $\beta / \delta$ agonists is rarely examined in inflammatory conditions.

Several PPARs directed processes were linked to either pro- or anti-tumorigenesis. For instance, PPAR $\alpha$ inhibits angiogenesis by hindering endothelial cell proliferation, increasing the expression of angiogenic inhibitors like endostatin and thrombospondin 1, and downregulating VEGF and cytochrome P450 CYP2C [38]. The interaction between PPAR $\alpha$ and NADPH Oxidase 1 also modulates angiogenesis [39]. On the other hand, ligand-activated PPAR $\gamma$ facilitates terminal differentiation, promotes cell cycle arrest, and apoptosis of cancer cells [40]. PPAR $\gamma$ agonists have been shown to regulate the expression of cell cycle mediators like cyclin D1 and cyclin-dependent kinase inhibitors (p21 and p27), resulting in the attenuation of cell cycle progression and proliferation [41-43]. PPAR $\gamma$ agonists also trigger increased apoptotic signaling via the overexpression of pro-apoptotic PTEN, BAX, and BAD, although off-target effects cannot be excluded [44,45]. Moreover, PPAR $\gamma$ also promotes epithelial differentiation and stabilizes the differentiated phenotype by upregulating key proteins like keratins, E-cadherin, alkaline phosphatase, and developmentally-regulated GTP-binding protein $1[40,46]$. The aforementioned anti-tumorigenic properties of PPAR $\alpha$ and $\gamma$ bring about extensive clinical studies that aim to treat malignancy by targeting these nuclear receptors. Again, unlike PPAR $\alpha$ and $\gamma$, the biological function of PPAR $\beta / \delta$ in tumorigenesis remains complex and conflicting. Current evidence supports an oncogenic tendency for PPAR $\beta / \delta$ activation and thus, has raised a question mark over the clinical development and safety of PPAR $\beta / \delta$ agonists.

Essentially, PPARs are integral in various biological processes in energy metabolism, homeostasis, inflammation, cellular proliferation, and differentiation. The multi-functionality, along with the excellent druggability, makes them an ideal therapeutic target for many health conditions. The PPAR-implicated pathways and related diseases are outlined in Figure 2. Next, we will summarize recent clinical evidence of PPAR agonists in various disorders. 


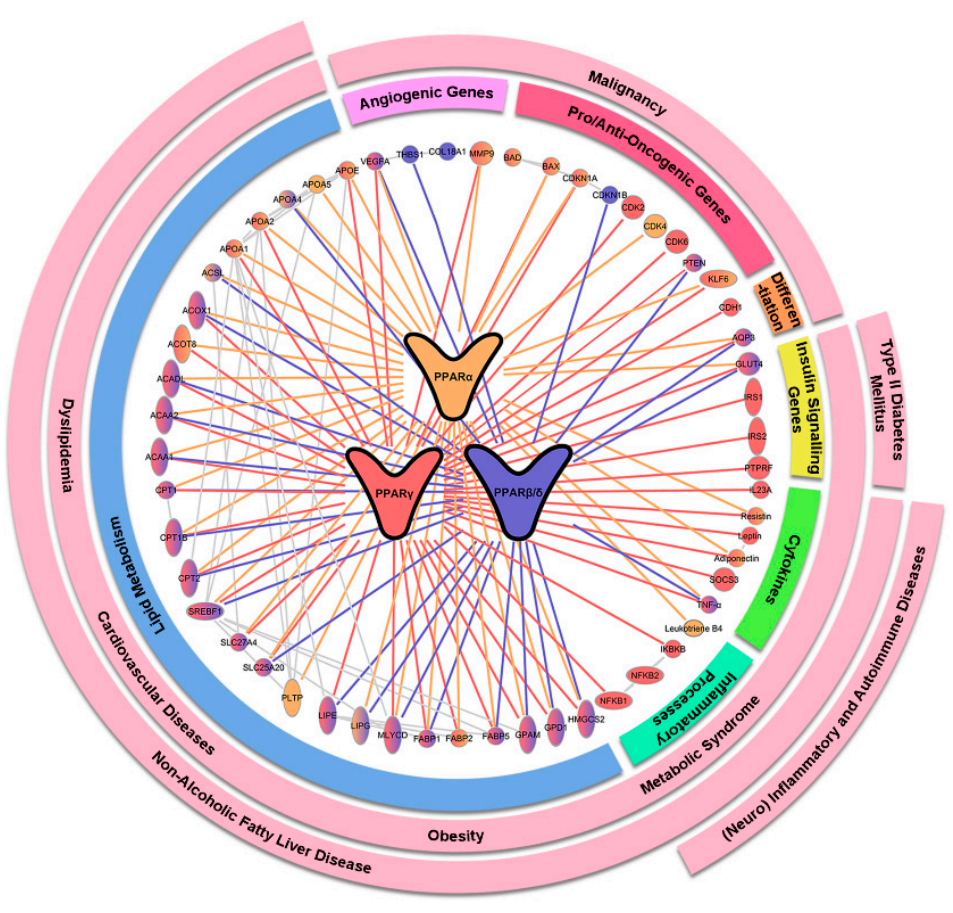

Figure 2. Key target genes and interacting proteins of $\operatorname{PPAR} \alpha, \gamma$, and $\beta / \delta$ and their downstream biological functions and implicated health conditions. Genes and proteins regulated by or interacting with PPAR $\alpha, \gamma$, and $\beta / \delta$ are represented by yellow, red, and blue lines, respectively. The downstream biological functions of the genes are reflected in the innermost circle while the implicated health conditions are highlighted in pink in outer circles.

\section{Type 2 Diabetes Mellitus (T2DM)}

The use of PPAR $\gamma$ agonists in T2DM is arguably one of the earliest clinical applications of PPAR agonists that are built upon the discovery and knowledge of PPARs. The clinical efficacy of $\operatorname{PPAR} \gamma$ agonists as an oral antidiabetic agent is well-established [47-49]. Therefore, such activities and the resultant benefits of both approved and experimental PPAR $\gamma$ agonists, including pioglitazone, rosiglitazone, GSK376501, CHS-131, PN2034, FK614, MK0533, rivoglitazone, and balaglitazone, will not be discussed here.

Despite their clinical feasibility, TZDs have some inherent limitations and side effects [50]. These issues, coupled with the ever-growing prevalence of T2DM, drive the creation of dual- and pan-PPAR agonists with hopes to yield better therapeutic effect and minimize adverse events. This new class of drugs garnering overwhelming enthusiasm from the medical research community. To date, several dual-PPAR $\alpha / \gamma$ agonists have progressed to late-phase clinical trials, including muraglitazar [51-53], tesaglitazar [54-58], aleglitazar [59-61], lobeglitazone [62,63], and MK0767 [64] (NCT00543010; NCT00543361, NCT00543491, NCT00543517, NCT00543738, NCT00543751, NCT00543816, and NCT00543274). All these dual-PPAR $\alpha / \gamma$ agonists effectively normalize glucose- and lipid-abnormalities in T2DM patients when used as mono- or combined therapy with other glucose-lowering drugs. Nevertheless, most of these drugs have tremendous safety concerns. For example, muraglitazar was approved by the United States Food and Drug Administration in 2005 for its use in controlling blood glucose levels in diabetic patients, but a reanalysis of the data suggested that muraglitazar resulted in an excess incidence of the composite end-point of death, major adverse cardiovascular events and congestive heart failure [65]. Likewise, tesaglitazar and aleglitazar are linked to kidney impairment [66-68], whereas MK0767 may be carcinogenic [69]. High risk-to-benefit ratio led to the cessation of further development on muraglitazar, tesaglitazar, aleglitazar, and MK0767. Similarly, other dual-PPAR $\alpha / \gamma$ agonists in early clinical pipeline like naveglitazar (NCT00065312), ONO-5129 (NCT00335712; NCT00212641) and DSP8658 (NCT01042106) also suffered similar setbacks and were 
no longer in development. At the point of penning down this review, lobeglitazone is still under active development for T2DM (NCT02338921; NCT03770052). Long-term animal studies revealed no carcinogenicity with lobeglitazone [70,71], and a Phase III human trial showed comparable efficacy and adverse events between lobeglitazone and pioglitazone in T2DM patients [63]. In 2013, lobeglitazone had been approved for T2DM in South Korea with the tradename "Duvie" and had since been under post-marketing surveillance. The fact that no severe safety issue arises with the drug provides some forms of reassurance to its safety. In short, the creation of dual-PPAR $\alpha / \gamma$ agonists for T2DM is not a fiasco, but future development needs to ensure a desirable safety profile before clinical testing to regain the faith in this pharmacological class.

Compared to dual-PPAR $\alpha / \gamma$ agonists, dual-PPAR $\alpha / \delta$ enjoyed greater success in T2DM. Elafibranor (also known as GFT505), which is a dual-PPAR $\alpha / \delta$ agonist, has shown a potent ameliorative effect on insulin resistance, hyperglycemia and dyslipidemia in obese patients with impaired glucose tolerance without significant safety concern [72,73]. Elafibranor also conferred significant hepatoprotective effect by lowering hepatic lipid deposition and liver enzymes [72]. The unexpected health benefit encouraged the developing company (Genfit) to redirect the research focus of elafibranor towards liver diseases like NAFLD and PBC. Such strategic move successfully placed elafibranor at the forefront of NAFLD drug exploration (see Section 7). Currently, there is no ongoing clinical project on the antidiabetic activity of elafibranor, but its potential in this aspect remains positive.

Several pan-PPAR agonists, including indeglitazar (EUCTR 2005-004227-19; NCT00425919), tetradecylthioacetic acid (NCT00605787), chiglitazar [74,75], and lanifibranor (NCT03459079) have been evaluated for T2DM. Clinical outcomes of most of these drugs are not accessible, but tetradecylthioacetic acid was discontinued due to impaired cardiac performance. The developmental status of indeglitazar is possibly halted, considering that the original developing company (Plexxikon) has been acquired by another pharmaceutical company (Daiichi Sankyo). An exception is chiglitazar which was recently revealed to be well-tolerated and more effective in lowering glycated hemoglobin A1c and restoring insulin sensitivity compared to placebo or sitagliptin based on two Phase III trial $[74,75]$. With chiglitazar and lanifibranor being active in T2DM clinical pipeline, the prospect of pan-PPAR agonists as antidiabetic agents remains optimistic. Furthermore, given the promising clinical outcomes and good safety profile from chiglitazar trial, future studies are likely to emphasize on the long-term drug efficacy in the prevention of diabetic complications, namely nephropathy, retinopathy, and neuropathy.

Although the finding from FIELD study showed that fenofibrate, a PPAR $\alpha$ agonist, has a negligible impact on glycemic control in T2DM patients [76], it did not limit the exploration of fibrates in diabetic complications. In the ACCORD Eye Study, fenofibrate significantly hindered the progression of diabetic retinopathy [77]. A Phase IV trial is currently underway to further validate the retino-protective effect of fenofibrate among T2DM patient (NCT03439345). A separate Phase III trial that aimed to evaluate the efficacy of pemafibrate in diabetic retinopathy was terminated due to subject recruitment issue (NCT03345901). Compared to other synthetic PPAR ligands, the clinical efficacy of PPAR $\beta / \delta$ agonists in T2DM is not well-elaborated. Two Phase II trials were initiated to investigate the effect of GW677954 in diabetic patients (NCT00437164; NCT00196989), but one was prematurely terminated due to carcinogenicity of the drug shown in animal studies. The developing company GlaxoSmithKline has discontinued the PPAR $\beta / \delta$ agonist.

The clinical outcomes of different PPAR agonists in T2DM are summarized in Table 1. Taken together, safety concern remains a considerable obstacle for the clinical development of many novel PPAR agonists, resulting in high attrition of dual- and pan-PPAR agonists as well as PPAR $\beta / \delta$ agonists. However, these setbacks did not stop the exploitation of PPARs for the treatment of T2DM and other diseases. In fact, the inter-drug differences in terms of the side effects suggest that the origin of these unwanted effects is likely off-target reactions that are independent of PPAR. Considering the promising outcomes and good safety profile of chiglitazar, elafibranor, and lobeglitazone, the co-activation of multiple PPARs is still an exciting approach to treat T2DM and its complications. 
Table 1. Summary of the clinical evidence of PPAR agonists in T2DM.

\begin{tabular}{|c|c|c|c|c|c|}
\hline Disease & Target & Drug Name & Clinical Phase (Sample Size) & Main Findings/Primary Endpoint & $\begin{array}{l}\text { Reference/Clinical Trial } \\
\text { Identifier }\end{array}$ \\
\hline \multirow{9}{*}{$\mathrm{T} 2 \mathrm{DM}$} & \multirow{9}{*}{ Dual PPAR $\alpha / \gamma$} & \multirow{2}{*}{ Muraglitazar } & II \& III (1477) & - Reduced glycemic and lipid parameters were dose-dependently & [52] \\
\hline & & & II \& III (3725) & $\begin{array}{l}\text { - Muraglitazar was associated with an excess incidence of the composite } \\
\text { end point of death, major adverse cardiovascular events }\end{array}$ & [65] \\
\hline & & $\begin{array}{l}\text { Muraglitazar + } \\
\text { sulphonylurea }\end{array}$ & III (583) & $\begin{array}{l}\text { - Combined therapy of muraglitazar with sulphonylurea reduced } \\
\text { HbA1c, fasting plasma glucose, and triglycerides more effectively than } \\
\text { sulphonylurea alone. } \\
\text { - Higher rates of congestive heart failure, CVDs, weight gain, and } \\
\text { edema in muraglitazar cohort. }\end{array}$ & [51] \\
\hline & & Muraglitazar + metformin & III (1805) & $\begin{array}{l}\text { - Muraglitazar plus metformin significantly improved } \mathrm{HbA1C} \text {, } \\
\text { triglyceride, and HDL-C levels }\end{array}$ & [53] \\
\hline & & \multirow{2}{*}{ Tesaglitazar } & II (500) & $\begin{array}{l}\text { - Reduced fasting plasma glucose dose-dependently } \\
\text { - Improved markers of glycemic control, atherogenic dyslipidemia, and } \\
\text { measures associated with insulin resistance }\end{array}$ & [55] \\
\hline & & & III-terminated (1707) & $\begin{array}{l}\text { - Tesaglitazar was comparable to pioglitazone in glycemic control } \\
\text { - Tesaglitazar outperformed pioglitazone in improving lipid and } \\
\text { lipoprotein levels }\end{array}$ & [54] \\
\hline & & Tesaglitazar + metformin & III-terminated (555) & $\begin{array}{l}\text { - Tesaglitazar plus metformin reduced } \mathrm{Hb} A 1 \mathrm{C} \text {, fasting plasma glucose, } \\
\text { and insulin levels } \\
\text { - The combined therapy also improved triglycerides, HDL-cholesterol, } \\
\text { and non-HDL-cholesterol } \\
\text { - Higher rate of edema and weight gain in tesaglitazar cohort }\end{array}$ & [56] \\
\hline & & Tesaglitazar + insulin & III-terminated (392) & $\begin{array}{l}\text { - Reduced } \mathrm{HbA1c} \text {, fasting glucose and daily insulin dose } \\
\text { - Improved lipid profile } \\
\text { - Increased serum creatinine }\end{array}$ & [57] \\
\hline & & $\begin{array}{r}\text { Tesaglitazar }+ \\
\text { sulphonylurea }\end{array}$ & III-terminated (568) & $\begin{array}{l}\text { - Improved glycemic control and lipid profile } \\
\text { - Increased serum creatinine dose-dependently }\end{array}$ & [58] \\
\hline
\end{tabular}


Table 1. Cont.

\begin{tabular}{|c|c|c|c|c|c|}
\hline Disease & Target & Drug Name & Clinical Phase (Sample Size) & Main Findings/Primary Endpoint & $\begin{array}{l}\text { Reference/Clinical Trial } \\
\text { Identifier }\end{array}$ \\
\hline \multirow{18}{*}{$\mathrm{T} 2 \mathrm{DM}$} & & \multirow{3}{*}{ Aleglitazar } & II (40) & $\begin{array}{l}\text { - Improved whole-body insulin sensitivity, hepatic insulin resistance } \\
\text { index, and total glucose disposal }\end{array}$ & [59] \\
\hline & & & II (332) & $\begin{array}{l}\text { - Reduced } \mathrm{HbA1c} \text { dose-dependently } \\
\text { - Incidence of edema, hemodilution, and weight gain } \\
\text { increased dose-dependently. }\end{array}$ & [60] \\
\hline & & & III-terminated (591) & $\begin{array}{l}\text { - Improved HbA1c, insulin resistance and lipid variables } \\
\text { - Increased incidence of weight gain and hypoglycemia }\end{array}$ & [61] \\
\hline & & \multirow{2}{*}{ Lobeglitazone } & III (173) & - Improved glycemic control and lipid profile & [62] \\
\hline & & & III (253) & $\begin{array}{l}\text { - Efficacy of lobeglitazone in glucose-lowering was comparable } \\
\text { to pioglitazone }\end{array}$ & [63] \\
\hline & & \multirow{9}{*}{ MK-0767 } & NA (8) & - Improved adiponectin and lipid profile & [64] \\
\hline & & & III-terminated (382) & $\begin{array}{l}\text { - Primary endpoint: Lipid lowering effectiveness of MK0767 compared } \\
\text { to metformin }\end{array}$ & NCT00543361 \\
\hline & & & III-terminated (247) & \multirow{7}{*}{ - NA } & NCT00543010 \\
\hline & & & III-terminated (129) & & NCT00543491 \\
\hline & & & III-terminated (99) & & NCT00543517 \\
\hline & & & III-terminated (114) & & NCT00543738 \\
\hline & & & III-terminated (610) & & NCT00543751 \\
\hline & & & III-terminated (111) & & NCT00543816 \\
\hline & & & III-terminated (100) & & NCT00547274 \\
\hline & & Naveglitazar & II-completed & - NA & NCT00065312 \\
\hline & & \multirow{2}{*}{ ON-5129 } & II-completed (81) & - NA & NCT00335712 \\
\hline & & & II-completed (105) & - Primary endpoint: fasting blood glucose & NCT00212641 \\
\hline & & DSP-8658 & I-completed (40) & - Primary endpoint: Safety assessment & NCT01042106 \\
\hline
\end{tabular}


Table 1. Cont.

\begin{tabular}{|c|c|c|c|c|c|}
\hline Disease & Target & Drug Name & Clinical Phase (Sample Size) & Main Findings/Primary Endpoint & $\begin{array}{l}\text { Reference/Clinical Trial } \\
\text { Identifier }\end{array}$ \\
\hline \multirow{12}{*}{$\mathrm{T} 2 \mathrm{DM}$} & & Lobeglitazone & IV-ongoing (78) & - Primary endpoint: Glycemic target goal achievement rate & NCT02338921 \\
\hline & & & IV-ongoing (174) & - Primary endpoint: Changes of $\mathrm{HbA} 1 \mathrm{c}$ & NCT03770052 \\
\hline & \multirow{2}{*}{ Dual-PPAR $\alpha / \delta$} & \multirow{2}{*}{ Elafibranor } & II (22) & $\begin{array}{l}\text { - Improved peripheral and hepatic insulin sensitivity } \\
\text { - Reduced triglycerides, LDL-cholesterol and liver enzymes }\end{array}$ & [72] \\
\hline & & & II (47) & $\begin{array}{l}\text { - Reduced triglycerides, LDL-cholesterol, } \gamma \text {-glutamyl transferase, } \\
\text { HOMA-IR, glucose, and fructosamine } \\
\text { - Increased HDL-cholesterol }\end{array}$ & [73] \\
\hline & \multirow{6}{*}{ Pan-PPAR } & \multirow{2}{*}{ Indelglitazar } & II-completed (108) & $\begin{array}{l}\text { - Primary endpoint: Changes of fasting plasma glucose, mean plasma } \\
\text { glucose during OGTT and insulin }\end{array}$ & EUCTR 2005-004227-19 \\
\hline & & & II-completed (500) & - Primary endpoint: Fasting plasma glucose & NCT00425919 \\
\hline & & Tetradecylthioacetic acid & II-completed (16) & - Primary endpoint: Plasma lipids & NCT00605787 \\
\hline & & \multirow{2}{*}{ Chiglitazar } & III (535) & $\begin{array}{l}\text { - Reduced } \mathrm{HbA} 1 \mathrm{c} \\
\text { - Incidences of weight gain, edema, and hypoglycemia were relatively } \\
\text { higher in the chiglitazar group }\end{array}$ & [74] \\
\hline & & & III (739) & $\begin{array}{l}\text { - Chiglitazar was comparable to sitagliptin in lowering } \mathrm{HbA} 1 \mathrm{c} \\
\text { - Adverse effects were comparable across different groups }\end{array}$ & [75] \\
\hline & & Lanifibranor & II-ongoing (84) & - Primary endpoint: Intrahepatic triglycerides & NCT03459079 \\
\hline & \multirow[t]{2}{*}{$\operatorname{PPAR} \beta / \delta$} & \multirow{2}{*}{ GW677954 } & II-terminated (1) & $\begin{array}{l}\text { - Primary endpoint: Changes in fluid related parameters as measured } \\
\text { by hematocrit and hemoglobin levels and body weight }\end{array}$ & NCT00437164 \\
\hline & & & II-completed (448) & - Primary endpoint: Changes in $\mathrm{HbA} 1 \mathrm{c}$ & NCT00196989 \\
\hline \multirow{3}{*}{$\begin{array}{l}\text { Diabetic } \\
\text { retinopathy }\end{array}$} & \multirow{3}{*}{ PPAR $\alpha$} & \multirow{2}{*}{ Fenofibrate } & III (3472) & - Reduced diabetic retinopathy progression & [77] \\
\hline & & & IV-ongoing (1060) & $\begin{array}{l}\text { - Primary endpoint: Progression to clinically significant } \\
\text { diabetic retinopathy }\end{array}$ & NCT03439345 \\
\hline & & Pemafibrate & III-terminated (15) & $\begin{array}{l}\text { - Primary endpoint: Diabetic retinopathy worsening or diabetic macular } \\
\text { edema development }\end{array}$ & NCT03345901 \\
\hline
\end{tabular}




\section{Cardiovascular Diseases (CVDs)}

As CVDs are the leading cause of death globally, there is tremendous interest to develop more effective treatment strategies. PPAR agonists are potential CVD drugs given that the leading regulatory role of PPARs in metabolism. New development leading this front are dual or pan-PPAR activators due to their synergistic agonistic effect to multiple PPAR receptors. Unfortunately, in a Phase III clinical trial (AleCardio), treatment with aleglitazar-a dual PPAR $\alpha / \gamma$ agonist, failed to modify cardiovascular risk among T2DM patients but, instead, was associated with severe adverse effects, like heart failure, gastrointestinal hemorrhages, and renal dysfunction [78]. The safety concern and clinical futility prompted its developing company Roche to halt clinical activities of aleglitazar, including another larger Phase III trial (AlePrevent), which had also tested aleglitazar's cardiovascular benefits [79]. Recent post hoc analysis of AleCardio trial data indicates that the concurrent use of clopidogrel (anti-platelet agent) could potentially interfere the metabolism of aleglitazar by inhibiting CYP2C8, subsequently prolonging its clearance and amplifying the toxicity [80]. This finding may serve as supportive evidence to revive the clinical development of aleglitazar, given its outstanding efficacy shown in a Phase II trial [60].

The lipid-lowering effect of PPAR $\alpha$ agonists justifies their clinical development for CVD. As the first fibrate, clofibrate was trialed for CVD in the 1960s, the result of which was disappointing because it did not reduce the incidence of fatal heart attacks and angina, and was linked to the increased onset of gallstones and cholecystectomies [81]. A long-term follow-up study revealed that individuals who had previously exposed to clofibrate and stopped had higher mortality compared to the placebo group [82]. The clinical use of clofibrate has been discontinued. Unlike clofibrate, other PPAR $\alpha$ agonists have been shown to reduce CVD incidence. For instance, bezafibrate improved lipid profile and reduced fibrinogen by $18 \%$, all-cause mortality by $10 \%$, and non-fatal coronary events by $40 \%$ among patients with T2DM, dyslipidemia or existing CVD complications [83-86]. Likewise, the cardiovascular benefits of fenofibrate and gemfibrozil have been repeatedly proven in many clinical trials [76,87-89]. In fact, a recent systematic review concluded that fibrates significantly lower CVD events and myocardial infarction by $16 \%$ and $21 \%$ respectively among subjects without existing CVD issues, strongly pointing out the clinical significance of PPAR $\alpha$ agonists as an effective primary preventive therapy against CVD [90]. Currently, the efficacy of a new PPAR $\alpha$ agonist modulator-pemafibrate in CVD is under clinical testing (CTRI/2017/07/009172). In essence, the beneficial effects of PPAR $\alpha$ agonists in CVD prevention are widely accepted. Nonetheless, it is worth mentioning that their clinical use is often overshadowed by another class of lipid-lowering drugs-statins-which have been shown to exhibit similar, if not superior efficacy compared to fibrates.

The cardioprotective effect of TZDs has also been observed clinically [91]. In diabetic patients, pioglitazone improved myocardial glucose uptake and myocardial perfusion by $75 \%$ and $16 \%$ in addition to the enhanced diastolic and systolic function of the heart [92]. The PROactive study concluded that pioglitazone was beneficial in reducing cardiovascular endpoints, namely cardiovascular death, stroke, non-fatal myocardial infarction, and acute coronary syndrome among

T2DM patients [93-95]. The IRIS trial discovered that the cardioprotective effect of pioglitazone was considerable even in prediabetes patients, whereby a $24 \%$ risk reduction in stroke and myocardial infarction was observed among those treated with pioglitazone compared to placebo [96]. Moreover, in patients who had undergone percutaneous coronary intervention, pioglitazone effectively suppressed in-stent neointimal hyperplasia besides reducing restenosis and incidence of target lesion revascularization [97-100]. Compared to sulfonylurea, the therapeutic effect of pioglitazone in delaying atherosclerotic progression is superior as exemplified by the lower carotid artery intima-media thickness and atheroma volume [101-103]. Although conflicting results about pioglitazone efficacy have been reported in some studies [104-107], a recent meta-analyses of ten randomized control trials (RCTs) reinforced the finding that the treatment with pioglitazone can lower the risk for major cardiovascular events by approximately $26 \%$ [108]. Unlike pioglitazone, the therapeutic effect of rosiglitazone on CVD is modest at best $[109,110]$. In fact, several meta-analyses have also reported a significant causative 
relationship between rosiglitazone use with increased risk of heart failure, myocardial infarction, and other major cardiovascular events, a finding which raised substantial controversy about its clinical application [111-113].

The clinical outcomes of different PPAR agonists in CVD are summarized in Table 2. Overall, in terms of CVD onset, PPAR $\alpha$ agonists generally exhibit a remarkable preventive effect. Pioglitazone, but not rosiglitazone, maybe an excellent drug for primary and secondary prevention of CVD events in T2DM patients, with possible application in those with prediabetes. However, using TZDs as CVD preventive medicines in non-diabetic patients is strongly discouraged considering their adverse effects. The clinical development of dual-PPAR agonist in CVD has ceased.

Table 2. Summary of the clinical evidence of PPAR agonists in CVD.

\begin{tabular}{|c|c|c|c|c|}
\hline Target & Drug Name & $\begin{array}{l}\text { Clinical Phase } \\
\text { (Sample Size) }\end{array}$ & Main Findings/Primary Endpoint & $\begin{array}{l}\text { Reference/Clinical } \\
\text { Trial Identifier }\end{array}$ \\
\hline \multirow{3}{*}{ Dual PPAR $\alpha / \gamma$} & \multirow{3}{*}{ Aleglitazar } & $\begin{array}{l}\text { III-terminated } \\
\quad \text { (7226) }\end{array}$ & $\begin{array}{l}\text { - No effect on lowering CVD risk } \\
\text { - Induced side effects like gastrointestinal } \\
\text { hemorrhages and renal dysfunction }\end{array}$ & [78] \\
\hline & & $\begin{array}{l}\text { III-terminated } \\
\text { (1999) }\end{array}$ & $\begin{array}{l}\text { - Reduced } \mathrm{HbA1c} \text { and blood lipids } \\
\text { Increased incidence of hypoglycemia and } \\
\text { muscular events }\end{array}$ & [79] \\
\hline & & II (332) & $\begin{array}{l}\text { - Lowered } \mathrm{HbA1c} \text { dose-dependently } \\
\text { - Caused edema, hemodilution, and } \\
\text { weight gain }\end{array}$ & [60] \\
\hline \multirow{7}{*}{$\operatorname{PPAR} \alpha$} & \multirow{4}{*}{ Bezafibrate } & NA (1568) & $\begin{array}{l}\text { Did not reduce incidence of coronary } \\
\text { heart disease and stroke } \\
\text { - Reduced incidence of non-fatal } \\
\text { coronary events }\end{array}$ & [83] \\
\hline & & NA (3090) & $\begin{array}{l}\text { - Reduced mortality risk by } 10 \% \\
\text { - Risk reduction was more prominent in } \\
\text { patients with hypertriglyceridemia }\end{array}$ & [84] \\
\hline & & NA (164) & $\begin{array}{l}\text { - Improved lipid profile } \\
\text { - Reduced fibrinogen } \\
\text { - No effect on ultrasound measured } \\
\text { arterial disease }\end{array}$ & [85] \\
\hline & & NA (50) & $\begin{array}{l}\text { - Reduced fibrinogen } \\
\text { - Reduced incidence of angina and left } \\
\text { ventricular failure }\end{array}$ & [86] \\
\hline & Fenofibrate & NA (9795) & $\begin{array}{l}\text { - Improved lipid profile } \\
\text { - Reduced CVD events }\end{array}$ & [87] \\
\hline & Gemfibrozil & NA (4081) & $\begin{array}{l}\text { Improved lipid profile } \\
\text { Reduced incidence of coronary } \\
\text { heart disease }\end{array}$ & [88] \\
\hline & Pemafibrate & III (10000) & $\begin{array}{l}\text { Primary endpoint: Number of patients } \\
\text { with first occurrence of nonfatal MI, } \\
\text { nonfatal ischemic stroke, hospitalization for } \\
\text { unstable angina requiring unplanned } \\
\text { coronary revascularization, or CV death. }\end{array}$ & NCT03071692 \\
\hline
\end{tabular}


Table 2. Cont.

\begin{tabular}{|c|c|c|c|c|}
\hline Target & Drug Name & $\begin{array}{l}\text { Clinical Phase } \\
\text { (Sample Size) }\end{array}$ & Main Findings/Primary Endpoint & $\begin{array}{l}\text { Reference/Clinical } \\
\text { Trial Identifier }\end{array}$ \\
\hline \multirow{18}{*}{$\operatorname{PPAR} \gamma$} & \multirow{15}{*}{ Pioglitazone } & IV (24) & $\begin{array}{l}\text { - Reduced HbA1c and blood pressure } \\
\text { - Enhanced myocardial insulin sensitivity, } \\
\text { systolic function and left ventricular } \\
\text { diastolic function }\end{array}$ & [92] \\
\hline & & III (5238) & $\begin{array}{l}\text { - Reduced CVD events } \\
\text { - Reduced risk of recurrent stroke }\end{array}$ & [93] \\
\hline & & III (5238) & $\begin{array}{l}\text { - Reduced incidence of major adverse } \\
\text { cardiovascular events in long term }\end{array}$ & [94] \\
\hline & & III (5238) & $\begin{array}{l}\text { - Reduced all-cause mortality, non-fatal } \\
\text { myocardial infarction and stroke }\end{array}$ & [95] \\
\hline & & III (3876) & $\begin{array}{l}\text { Reduced risk of stroke and myocardial } \\
\text { infarction among non-diabetic patients } \\
\text { with high CVD risk }\end{array}$ & [96] \\
\hline & & NA (72) & $\begin{array}{l}\text { Reduced neointimal volume and } \\
\text { inflammatory markers } \\
\text { a Increased circulating miRNA-24 and } \\
\text { flow-mediated dilation }\end{array}$ & [97] \\
\hline & & NA (96) & $\begin{array}{l}\text { - Reduced neointimal hyperplasia in } \\
\text { patients with myocardial infarction treated } \\
\text { with primary stent implantation }\end{array}$ & [98] \\
\hline & & NA (97) & $\begin{array}{l}\text { - Suppressed in-stent } \\
\text { neointimal proliferation } \\
\text { - Reduced incidence of target lesion } \\
\text { revascularization after percutaneous } \\
\text { coronary intervention }\end{array}$ & [99] \\
\hline & & NA (28) & $\begin{array}{l}\text { - Reduced in-stent stenosis } \\
\text { - Reduced leptin and endothelial function }\end{array}$ & [100] \\
\hline & & III (462) & $\begin{array}{l}\text { - Pioglitazone was superior to } \\
\text { sulphonylurea in slowing the progression } \\
\text { of carotid artery intima-media thickness }\end{array}$ & [101] \\
\hline & & III (543) & $\begin{array}{l}\text { - Reduced atheroma volume } \\
\text { - Improved lipid profile }\end{array}$ & [102] \\
\hline & & NA (56) & $\begin{array}{l}\text { Reduced atherosclerotic plaque } \\
\text { inflammation more effectively } \\
\text { than sulphonylurea }\end{array}$ & [103] \\
\hline & & NA (120) & $\begin{array}{l}\text { - Lowered the recurrence of stroke, but did } \\
\text { not reach statistical significance }\end{array}$ & [104] \\
\hline & & NA (15) & - Did not enhance antiplatelet effect & [105] \\
\hline & & III (300) & $\begin{array}{l}\text { - Efficacy of pioglitazone in cardiovascular } \\
\text { function was comparable to sulphonylurea }\end{array}$ & [106] \\
\hline & $\begin{array}{l}\text { Pioglitazone + } \\
\text { metformin }\end{array}$ & IV (3028) & $\begin{array}{l}\text { Combined therapy of pioglitazone with } \\
\text { metformin was comparable to combined } \\
\text { therapy of sulphonylurea with metformin } \\
\text { in preventing CVD events }\end{array}$ & [107] \\
\hline & \multirow[t]{2}{*}{ Rosiglitazone } & III (193) & $\begin{array}{l}\text { - No effect on CVD events } \\
\text { Improved glycemic control and } \\
\text { cardiometabolic risk profile }\end{array}$ & [109] \\
\hline & & III (1425) & - Reduced carotid intima-media thickness & [110] \\
\hline
\end{tabular}




\section{Dyslipidemia}

Fibrates are PPAR $\alpha$ agonists which have been long-established as a lipid-lowering agent. Several meta-analyses have demonstrated that fibrates can reduce total cholesterol and triglycerides while increasing high-density cholesterol $[10,114]$, subsequently lowering cardiovascular risk among patients with atherogenic dyslipidemia $[9,115,116]$. Therefore, we will not discuss the clinical efficacy of both approved (fenofibrate, bezafibrate, gemfibrozil) and investigational PPAR $\alpha$ agonists (LY518674, ZYH7, GW590735, K-111) in dyslipidemia. An exception is pemafibrate, which was approved in Japan in 2017 for the treatment of hyperlipidemia. Pemafibrate is marketed as a selective PPAR $\alpha$ modulator due to its superior selectivity for PPAR $\alpha$ and markedly higher potency ( $>2500$-fold) compared to fenofibrate [117]. In Phase III clinical trials, pemafibrate significantly reduced the circulating triglycerides by more than $45 \%$ after $12-24$ weeks of treatment $[118,119]$. The reduction of triglycerides was comparable to fenofibrate at $200 \mathrm{mg} /$ day, but with fewer incidences of adverse effects [118,119]. In patients with T2DM and hypertriglyceridemia, pemafibrate also decreased other lipid components, namely non-HDL and remnant lipoprotein cholesterols, apolipoprotein (Apo) B100, ApoB48, ApoCIII while enhanced insulin sensitivity score, HDL-cholesterols, and ApoA-I levels in the blood circulation [120]. In dyslipidemic patients with CKD, pemafibrate did not adversely affect the kidney function [121]. Thus, given the favorable safety profile and comparable performance to other fibrates, pemafibrate is a superior PPAR $\alpha$ agonist for dyslipidemia.

The lipid-lowering effect of TZDs has been observed in diabetic patients, suggesting a role as a lipid-lowering agent. However, according to Slim et al. (2011), treatment with rosiglitazone for 12 weeks failed to improve hypertriglyceridemia in individuals without diabetes, implying that the hypolipidemic effect is dependent on its insulin-sensitizing properties [122]. As a result, using TZD to treat non-diabetic dyslipidemic patients is not recommended. On the other hand, two PPAR $\beta / \delta$ agonists, namely GW501516 and seladelpar (alternatively known as MBX-8025) have been clinically tested to assess their lipid-lowering activities. Both investigational drugs promote a favorable lipid profile. In healthy subjects, GW501516 significantly lowered fasting plasma triglycerides, ApoB, LDL-cholesterol, and even hepatic fat content $[123,124]$. Later, similar health benefits were observed in two trials with dyslipidemic patients $[125,126]$. Nevertheless, the development of GW501516 was discontinued because of its pro-oncogenic properties observed in animal studies [127]. Like GW501516, seladelpar (50 or $100 \mathrm{mg} /$ day) for eight weeks also performed better than placebo or atorvastatin alone in reversing atherogenic dyslipidemia $[128,129]$. Additionally, seladelpar also improved liver function and was generally well-tolerated [128]. However, larger and longer clinical trials are warranted to yield an in-depth understanding of the clinical efficacy and safety of seladelpar. From these trials, it is clear that different agonists targeting the same PPAR can result in different safety profile and clinical outcomes.

Dyslipidemia often co-manifests with glucose dysregulation, leading to increased risk for prediabetes and T2DM. Thus, several dual PPAR agonists with its dual benefit on glycemic and lipid parameters have also been under clinical development as an anti-dyslipidemia drug. Muraglitazar was the first dual PPAR $\alpha / \gamma$ agonist to be investigated for its lipid-lowering effect in Phase II and III clinical trials (NCT00245388), but the results were not published. In contrast, the safety and efficacy of saroglitazar, a dual PPAR $\alpha / \gamma$ agonist with predominant PPAR $\alpha$ activity, in diabetic dyslipidemia have an optimistic outlook. Two Phase III trials showed that saroglitazar could maintain lipid and glucose homeostasis without common side effects of fibrates and TZDs [130,131]. The drug was granted marketing authorization in India in 2013 for diabetic dyslipidemia not controlled with statins [132]. Thus far, no major serious adverse events have been reported; however, long-term cardiovascular safety has not been established [133]. Future clinical trials of saroglitazar will further establish its place in the management of diabetes, dyslipidemia, and associated cardiovascular risk.

The lipid-modifying effect of elafibranor, which is a dual PPAR $\alpha / \delta$ agonist, has been confirmed in patients with mixed dyslipidemia [73]. Upon oral administration of elafibranor for four weeks, a significant reduction in fasting plasma triglycerides $(-16.7 \%), \gamma$ glutamyl transferase $(-19.9 \%)$, and 
LDL-cholesterol (-11\%), while HDL-cholesterol was elevated by $7.8 \%$ in comparison to placebo [73]. These effects correlated with a reduction in pro-atherogenic apolipoproteins, including ApoB $(-14 \%)$ and an increase in ApoA2 anti-atherogenic HDL particles ( $+18 \%)$. The promising effects of elafibranor on lipid profiles and various liver enzymes have prompted the developing company (Genfit) to repurpose the drug for the treatment of NASH and PBC (see Section 7).

Genetic disorders cause a small subset of dyslipidemia cases. In this context, the effectiveness of fibrate on various familial dyslipidemia and hypercholesterolemia subtypes differs significantly. For instance, fibrates successfully improved hypertriglyceridemia caused by familial dysbetalipoproteinemia, but not those caused by lipoprotein lipase deficiency or glycerol kinase deficiency [134]. The finding is in line with a crossover study which concluded that a four-week regime with bezafibrate lowered triglycerides and increased HDL-cholesterol in those with familial dysbetalipoproteinemia [135]. Bezafibrate also conferred additional benefits when it was used in combination with statins, suggesting that fibrate/statin therapy could be a better standard-of-care in familial dysbetalipoproteinemia [136]. However, bezafibrate failed to improve the clinical symptoms of patients with X-linked adrenoleukodystrophy [137], CPT2, and very long-chain acyl-CoA dehydrogenase deficiency [138]. Apart from that, seladelpar has also completed a Phase II clinical trial as a therapy for homozygous familial hypercholesterolemia. In the 12-week, single-arm, monthly dose escalation (50, 100, and $200 \mathrm{mg} /$ day) study, eight out of 13 participants had a $\geq 20 \%$ LDL-cholesterol decrease from baseline despite the lack of dose response [139]. In patients with familial combined hyperlipidemia, pioglitazone together with conventional lipid-lowering drugs also significantly improved HDL-cholesterols, myocardial glucose disposal, adiponectin, and ALT besides promoting the fat deposition to subcutaneous adipose tissues [140,141]. However, the present findings are based on small sample sizes owing to the rarity of these genetic disorders. Therefore, larger trials are required to validate the results.

For the past two decades, PPAR agonists have been actively tested for HIV-associated dyslipidemia and lipodystrophy syndrome. The underlying cause for the lipid dysregulation is attributable to highly active antiretroviral therapy (HAART), particularly the use of nucleoside reverse-transcriptase inhibitors, non-nucleoside reverse-transcriptase inhibitors, and protease inhibitors [142]. Multiple studies reported a remarkable decline in plasma triglycerides $(>46 \%)$ alongside with amelioration of total cholesterol and HDL-cholesterol levels with the administration of fenofibrate in HAART-treated, HIV-positive subjects [143-148]. Other fibrates, namely bezafibrate and gemfibrozil, also produced similar favorable outcomes which are comparable to statins [149-151]. Fibrates led to more drastic changes in lipid components compared to switching the hyperlipidemia-inducing antiretroviral agents [151]. However, in one study, fibrates failed to modify endothelial function and inflammatory markers in the patients [146]. Gavrila et al. (2005) also demonstrated that fenofibrate did not modulate the blood pressure, glucose, and lipid metabolic parameters, whereas pioglitazone did, over a 12-month regime [152]. Pioglitazone also induced limb fat deposition [153], although one case study suggested that its modulatory effect on subcutaneous fat deposition is limited to non-lipoatrophic regions [154]. In contrast, rosiglitazone had a marginal effect on the lipid profile in HIV-positive patients [155-157]. Thus, its use is not recommended [158]. Interestingly, a pilot study pointed out that tetradecylthioacetic acid (pan-PPAR agonist) exerted a notable suppressive effect on total cholesterol, triglycerides, LDL-cholesterol, LDL/HDL cholesterol ratio, and tumor necrosis factor- $\alpha$ [159]. Fibrates, pioglitazone, and tetradecylthioacetic acid appear to modify lipid profile favorably in HIV patients, but their ability to resolve lipoatrophy is not well-characterized.

To recapitulate, PPAR $\alpha$ agonists will continue to be the backbone of lipid-lowering drugs, especially with the novel selective PPAR $\alpha$ modulator, pemafibrate. The development of seladelpar and dual-PPAR agonists looks wildly exciting considering their optimistic results thus far. The clinical findings of different PPAR agonists in dyslipidemia are summarized in Table 3. Based on the current trend, there will be increasing trials of PPAR agonists on dyslipidemia not only due to lifestyle and metabolism, but also other causes, like genetic disorders, drug-induced, infection, or trauma-related. 
Table 3. Summary of the clinical evidence of PPAR agonists in dyslipidemia.

\begin{tabular}{|c|c|c|c|c|c|}
\hline Disease & Target & Drug Name & Clinical Phase (Sample Size) & Main Findings/Primary Endpoint & $\begin{array}{l}\text { Reference/Clinical Trial } \\
\text { Identifier }\end{array}$ \\
\hline \multirow{11}{*}{ Dyslipidemia } & \multirow{4}{*}{$\operatorname{PPAR} \alpha$} & \multirow{4}{*}{ Pemafibrate } & III (225) & $\begin{array}{l}\text { - Reduced triglycerides and liver enzymes } \\
\text { - Incidence of adverse drug reaction was lower in the pemafibrate group } \\
\text { compared to the fenofibrate group }\end{array}$ & [118] \\
\hline & & & III (526) & $\begin{array}{l}\text { - Pemafibrate were comparable to high-dose fenofibrate }(200 \mathrm{mg} / \text { day }) \\
\text { and superior to low-dose fenofibrate }(100 \mathrm{mg} / \text { day }) \text { in } \\
\text { reducing triglycerides } \\
\text { - Adverse effects of pemafibrate was comparable to placebo }\end{array}$ & [119] \\
\hline & & & III (166) & $\begin{array}{l}\text { - Reduced triglycerides, non-HDL and remnant lipoprotein cholesterol } \\
\text { apolipoprotein (Apo) B100, ApoB48, ApoCIII levels, and HOMA-IR. } \\
\text { - Increased HDL-cholesterol,ApoA-I, and fibroblast growth factor } 21 . \\
\text { - Adverse effects of pemafibrate was comparable to placebo }\end{array}$ & [120] \\
\hline & & & III (189) & $\begin{array}{l}\text { - Decreased triglycerides } \\
\text { - Incidence of adverse events was not associated with estimated } \\
\text { glomerular filtration rate in dyslipidemic patients with CKD. }\end{array}$ & [121] \\
\hline & $\operatorname{PPAR} \alpha, \operatorname{PPAR} \gamma$ & $\begin{array}{l}\text { Rosiglitazone and/or } \\
\text { fenofibrate }\end{array}$ & NA (41) & - Rosiglitazone alone did not affect triglyceride level. & [122] \\
\hline & \multirow{4}{*}{$\operatorname{PPAR} \beta / \delta$} & \multirow[b]{2}{*}{ GW501516 } & II (268) & $\begin{array}{l}\text { - Increased HDL-cholesterol, APOA-I } \\
\text { - Reduced LDL-cholesterol, triglycerides, APOB, free fatty acids }\end{array}$ & [125] \\
\hline & & & IV (13) & $\begin{array}{l}\text { - Decreased plasma triglycerides, fatty acid, APOB-100, APOB-48, and } \\
\text { cholesteryl ester transfer protein activity. } \\
\text { - Decreased VLDL-APOB by increasing its fractional catabolism and of } \\
\text { APOC-III by decreasing its production rate } \\
\text { - Reduced VLDL-to-LDL conversion and LDL-APOB production } \\
\text { - Increased HDL-cholesterol, APOA-II, and LpA-I:A-II concentrations } \\
\text { by increasing APOA-II and LpA-I:A-II production }\end{array}$ & [126] \\
\hline & & Seladelpar & II (181) & $\begin{array}{l}\text { - Reduced APOB-100, LDL-cholesterol, triglycerides, } \\
\text { non-HDL-cholesterol, free fatty acids, liver enzymes and CRP } \\
\text { - Increased HDL-cholesterol } \\
\text { - Reduced number of patients with MetS and higher LDL-cholesterol }\end{array}$ & [128] \\
\hline & & Seladelpar and/or statins & II (166) & $\begin{array}{l}\text { - Reduced small and very small LDL particles, and large VLDL } \\
\text { - Increased large LDL and HDL } \\
\text { - Combined therapy of seladelpar and atorvastatin had complementary } \\
\text { effects in improving lipid profile. }\end{array}$ & [129] \\
\hline & Dual PPAR $\alpha / \gamma$ & Muraglitazar & II \& III-Completed (330) & - Primary endpoint: Percent change of triglycerides from baseline & NCT00245388 \\
\hline & Dual PPAR $\alpha / \delta$ & Elafibranor & II (94) & $\begin{array}{l}\text { - Reduced triglycerides and GGT } \\
\text { - Increased HDL-cholesterol }\end{array}$ & [73] \\
\hline
\end{tabular}


Table 3. Cont

\begin{tabular}{|c|c|c|c|c|c|}
\hline Disease & Target & Drug Name & Clinical Phase (Sample Size) & Main Findings/Primary Endpoint & $\begin{array}{l}\text { Reference/Clinical Trial } \\
\text { Identifier }\end{array}$ \\
\hline \multirow{2}{*}{ Diabetic dyslipidemia } & \multirow{2}{*}{ Dual PPAR $\alpha / \gamma$} & \multirow{2}{*}{ Saroglitazar } & III (109) & $\begin{array}{l}\text { - Reduced triglycerides, LDL, VLDL, total cholesterol, and APOB } \\
\text { - No severe adverse event }\end{array}$ & [130] \\
\hline & & & III (302) & $\begin{array}{l}\text { - Reduced triglycerides, non-HDL-cholesterol, LDL-cholesterol, } \\
\text { VLDL-cholesterol, total cholesterol, APOB, and fasting plasma glucose } \\
\text { - No severe adverse event }\end{array}$ & [131] \\
\hline \multirow{3}{*}{$\begin{array}{c}\text { Familial } \\
\text { dysbetalipoproteinemia }\end{array}$} & \multirow{3}{*}{$\operatorname{PPAR} \alpha$} & Fenofibrate or gemfibrozil & NA (146) & $\begin{array}{l}\text { - Response to fibrate differed based on hypertriglyceridemia subtypes } \\
\text { - Hypertriglyceridemia due to lipoprotein lipase deficiency and glycerol } \\
\text { kinase deficiency did not respond to fibrate } \\
\text { - Palmar xanthomas and hypertriglyceridemia due to APOE resistance } \\
\text { responded well to fibrate }\end{array}$ & [134] \\
\hline & & Bezafibrate & NA (14) & $\begin{array}{l}\text { - Reduced triglycerides and increased HDL-cholesterol } \\
\text { - Changed cholesterol distribution from small- to large-sized LDL and } \\
\text { from large- to small-sized HDL }\end{array}$ & [135] \\
\hline & & Bezafibrate + Statins & NA (15) & $\begin{array}{l}\text { - Bezafibrate with statin reduced post-fat load triglyceride, } \mathrm{APOB} \text { and } \\
\text { estimated glomerular filtration rate. } \\
\text { - Fasting levels of non-HDL-cholesterol, total cholesterol, and } \\
\text { HDL-cholesterol were improved with combined therapy. }\end{array}$ & {$[136]$} \\
\hline $\begin{array}{c}\text { X-linked } \\
\text { adrenoleukodystrophy }\end{array}$ & $\operatorname{PPAR} \alpha$ & Bezafibrate & NA (10) & - No reduction in very-long-chain fatty acids & [137] \\
\hline $\begin{array}{l}\text { CPT II and VLCAD } \\
\text { deficiencies. }\end{array}$ & $\operatorname{PPAR} \alpha$ & Bezafibrate & NA (10) & $\begin{array}{l}\text { - Reduced LDL, triglycerides, and free fatty acids } \\
\text { - No change in palmitate oxidation, fatty acid oxidation and heart rate } \\
\text { during exercise did not improve clinical symptoms in patients with } \\
\text { CPTII and VLCAD deficiencies }\end{array}$ & [138] \\
\hline $\begin{array}{c}\text { Familial } \\
\text { hypercholesterolemia }\end{array}$ & $\operatorname{PPAR} \beta / \delta$ & Seladelpar & II (13) & $\begin{array}{l}\text { - Five patients had a } \geq 20 \% \text { LDL-C decrease from baseline, while } \\
\text { another five had a decrease of }<15 \% \text {. } \\
\text { - Proprotein convertase subtilisin/kexin type } 9 \text { (PCSK9) elevated } \\
\text { by seladelpar. }\end{array}$ & [139] \\
\hline \multirow{2}{*}{$\begin{array}{l}\text { Familial combined } \\
\text { hyperlipidemia }\end{array}$} & \multirow{2}{*}{$\operatorname{PPAR} \gamma$} & \multirow{2}{*}{$\begin{array}{c}\text { Pioglitazone + } \\
\text { lipid-lowering drugs }\end{array}$} & NA (26) & $\begin{array}{l}\text { - Increased whole body glucose disposal, myocardial glucose utilization, } \\
\text { myocardial blood flow, HDL-cholesterol and adiponectin } \\
\text { - Reduced insulin }\end{array}$ & [140] \\
\hline & & & NA (22) & $\begin{array}{l}\text { - Reduced triglycerides, glucose, and ALT } \\
\text { - Increased adiponectin, total and subcutaneous adipose tissues, soleus } \\
\text { intracellular lipids }\end{array}$ & [141] \\
\hline
\end{tabular}


Table 3. Cont

\begin{tabular}{|c|c|c|c|c|c|}
\hline Disease & Target & Drug Name & Clinical Phase (Sample Size) & Main Findings/Primary Endpoint & $\begin{array}{l}\text { Reference/Clinical Tria } \\
\text { Identifier }\end{array}$ \\
\hline \multirow{15}{*}{$\begin{array}{l}\text { HIV-associated } \\
\text { dyslipidemia and } \\
\text { lipodystrophy syndrome }\end{array}$} & \multirow{9}{*}{$\operatorname{PPAR} \alpha$} & Fenofibrate + fish oil & II (100) & $\begin{array}{l}\text { - Combined therapy of fenofibrate and fish oil significantly } \\
\text { reduced triglycerides. }\end{array}$ & [143] \\
\hline & & \multirow{4}{*}{ Fenofibrate } & NA (55) & - Reduced triglycerides & [144] \\
\hline & & & $\mathrm{NA}(36)$ & $\begin{array}{l}\text { - Reduced triglycerides, APOC-III, total cholesterol, APOB, } \\
\text { non-HDL-cholesterol, and triglyceride/APOA1 ratio } \\
\text { - Increased HDL-cholesterol, LDL sizes and LDL resistance to oxidation }\end{array}$ & [145] \\
\hline & & & II (99) & $\begin{array}{l}\text { - Increased HDL-cholesterol } \\
\text { - Brachial flow mediated dilation, CRP, IL-6, and D-dimer } \\
\text { were unaffected. }\end{array}$ & [146] \\
\hline & & & NA (191) & $\begin{array}{l}\text { - Decreased triglycerides and total cholesterol } \\
\text { - Increased non-HDL-cholesterol } \\
\text { - Combined therapy with fenofibrate, niacin, low-saturated-fat diet, } \\
\text { exercise, and exercise led to additional benefits on lipid profile compared } \\
\text { to all monotherapies. }\end{array}$ & [147] \\
\hline & & Fenofibrate + Pravastatin & III (174) & $\begin{array}{l}\text { - Combined therapy of fenofibrate and pravastatin could improve lipid } \\
\text { profile and were well-tolerated. }\end{array}$ & [148] \\
\hline & & \multirow{2}{*}{ Fibrate } & NA (245) & - Reduced triglycerides and total cholesterol & [149] \\
\hline & & & NA (656) & - Reduced triglycerides and total cholesterol & [150] \\
\hline & & Bezafibrate & NA (130) & - Reduced triglycerides, total, and LDL-cholesterol & [151] \\
\hline & $\operatorname{PPAR} \alpha, \operatorname{PPAR} \gamma$ & Fenofibrate, pioglitazone & NA (14) & $\begin{array}{l}\text { - Pioglitazone, but not fenofibrate, improved insulin resistance, blood } \\
\text { pressure, and lipid profile. }\end{array}$ & [152] \\
\hline & \multirow{4}{*}{$\operatorname{PPAR} \gamma$} & Pioglitazone & III (130) & - Increased limb fat deposition, but did not improve lipid profile & [153] \\
\hline & & \multirow{3}{*}{ Rosigltazone } & NA (96) & - No improvement in lipoatrophy & [155] \\
\hline & & & NA (39) & $\begin{array}{l}\text { - Increased subcutaneous and visceral abdominal fat } \\
\text { - Improved insulin sensitivity and adiponectin } \\
\text { - Did not affect CRP and flow-mediated vasodilation }\end{array}$ & [156] \\
\hline & & & II (71) & $\begin{array}{l}\text { - Did not improve carotid intima media thickness, inflammatory } \\
\text { markers and endothelial activation markers }\end{array}$ & [157] \\
\hline & Pan-PPAR & Tetradecylthioacetic acid & NA (10) & $\begin{array}{l}\text { - Tetradecylthioacetic acid with diet intervention reduced total } \\
\text { cholesterol, LDL cholesterol, triglycerides, LDL/HDL cholesterol ratio, } \\
\text { and TNF- } \alpha\end{array}$ & [159] \\
\hline $\begin{array}{l}\text { Dyslipidemia due to } \\
\text { spinal cord injury }\end{array}$ & PPAR $\alpha$ & Fenofibrate & II and III -Completed (23) & $\begin{array}{l}\text { - Primary endpoint: Triglyceride level compared to baseline after two } \\
\text { month fenofibrate treatment }\end{array}$ & NCT02455336 \\
\hline
\end{tabular}




\section{Metabolic Syndrome, Obesity, and Hypertension}

\subsection{Prediabetes and Metabolic Syndrome}

Aside from dyslipidemia, PPAR agonists have been widely proposed as a treatment for various premorbid conditions like obesity, glucose intolerance/insulin resistance, MetS, and prediabetes (Table 4). Elafibranor has been tested in several Phase II clinical studies to evaluate its effectiveness in obese patients with prediabetes [72,73]. Glycemic parameters like insulin resistance score, fasting plasma glucose, fructosamine, peripheral, and hepatic insulin sensitivity were significantly improved with elafibranor ( $80 \mathrm{mg} /$ day) [72,73]. Gene expression analysis of PPAR $\alpha$ and $\delta$ target genes suggested that elafibranor may be a liver-targeted insulin sensitizer [72].

\subsection{Obesity}

The anti-obesity effect of PPAR $\beta / \delta$ agonists, such as GW501516 and GW677954 (also known as sodelglitazar), has also been examined. GW501516 and GW677954 were developed by GlaxoSmithKline. GW677954 should be considered as a pan-PPAR agonist due to its additional activity at PPAR $\alpha$ and $\gamma$. In obese men, GW501516 blunted cholesteryl transfer protein activity and modified the biosynthesis of APOC-III, APOA-II, and LpA-I:A-II, leading to lowered VLDL- and LDL-cholesterols, plasma triglycerides, and fatty acid as well as increased HDL-cholesterol [126]. Further development of both drugs was ceased due to carcinogenicity observed in animal testing.

While various PPAR agonists can effectively improve lipid and glycemic aberrations, their use for weight control is not well-supported. In fact, TZDs increase weight gain [11,160]. TZD-induced weight gain is attributable to increased subcutaneous fat depots due to body fat accumulation and redistribution, and body fluid retention [161]. Furthermore, in one clinical study, individuals given rosiglitazone had lower fasting plasma peptide YY and experienced increased hunger [162]. Such an inhibitory effect on peptide YY, which is an appetite suppressor, may also partly explain TZD-induced weight gain. Like TZDs, the weight-lowering effect of PPAR $\alpha$ agonist in obese patients is marginal unless coupled with other medications like metformin and orlistat $[163,164]$. As such, the clinical use of PPAR agonists for weight control is not recommended based on existing evidence.

\subsection{Hypertension}

Elevated blood pressure is one of the most common comorbidities of obesity and metabolic syndrome. One study reported that fenofibrate could significantly lower blood pressure, heart rate, plasma renin activity, and renal vascular resistance in patients with salt-sensitive hypertension, but not salt-resistant hypertension [165]. Likewise, numerous clinical studies have demonstrated a blood pressure-lowering activity of PPAR $\gamma$ agonists in healthy, obese, and diabetic individuals [166-168]. In hypertensive patients, pioglitazone triggered the reduction of inflammatory markers, like C-reactive protein (CRP), matrix metalloproteinase-2, and -9, besides improving baroreflex sensitivity and left ventricular diastolic function [169-171]. Likewise, favorable changes in endothelial functions, proinflammatory, and prothrombotic biomarkers are also associated with the use of rosiglitazone $[172,173]$. Nonetheless, the underlying mechanism of the anti-hypertensive and vascular protective effects of PPAR $\gamma$ agonists remain unclear. It is postulated that PPAR $\gamma$ agonists may inhibit the renin-angiotensin-aldosterone pathway to lower sodium and water reuptake, but the hypothesis is in contradiction to its edematous effect [174]. Another study concluded that PPAR $\gamma$ in vascular endothelium plays a key role in attenuating vasoconstriction [175]. These findings underpin a combined modulatory effect on renal and vascular function by PPAR $\gamma$ agonists to account for their anti-hypertensive action. While the blood pressure-lowering effect of TZDs and fibrates is modest at best, such activity may confer additional cardiovascular benefits to individuals with insulin resistance and T2DM. 
Table 4. Summary of the clinical evidence of PPAR agonists in MetS, obesity, and hypertension.

\begin{tabular}{|c|c|c|c|c|c|}
\hline Disease & Target & Drug Name & Clinical Phase (Sample Size) & Main Findings/Primary Endpoint & $\begin{array}{l}\text { Reference/Clinical Trial } \\
\text { Identifier }\end{array}$ \\
\hline \multirow[b]{2}{*}{ Prediabetes and MetS } & \multirow[b]{2}{*}{ Dual PPAR $\alpha / \delta$} & \multirow[b]{2}{*}{ Elafibranor } & II (47) & $\begin{array}{l}\text { - Reduced triglycerides, LDL-cholesterol, } \gamma \text {-glutamyl transferase, HOMA-IR, glucose, } \\
\text { and fructosamine } \\
\text { - Increased HDL-cholesterol }\end{array}$ & [73] \\
\hline & & & II (22) & $\begin{array}{l}\text { - Improved hepatic and peripheral insulin sensitivity } \\
\text { - Reduced triglycerides, LDL-cholesterol, liver enzymes } \\
\text { - No activation of PPARs in skeletal muscle, suggesting a liver-targeted action } \\
\text { of elafibranor } \\
\text { - No safety concern }\end{array}$ & [72] \\
\hline \multirow{4}{*}{ Obesity } & $\mathrm{PPAR} \beta / \delta$ & GW501516 & IV (13) & - Increased hepatic removal of VLDL and APOA-II production in obese patients & [126] \\
\hline & $\operatorname{PPAR} \gamma$ & Rosiglitazone & IV (28) & $\begin{array}{l}\text { - Reduced fasting plasma peptide YY3-36 } \\
\text { - No effect on fasting ghrelin }\end{array}$ & [162] \\
\hline & \multirow[t]{2}{*}{ PPAR $\alpha$} & Fenofibrate + metformin & NA (87) & $\begin{array}{l}\text { - Changes in blood pressure, free fatty acid, BMI and HOMA-IR were comparable to } \\
\text { those treated with metformin only } \\
\text { - Combined therapy further decreased fasting and postprandial insulin levels }\end{array}$ & [163] \\
\hline & & Fenofibrate & NA (89) & $\begin{array}{l}\text { - Reduced body weight, BMI, waist circumference, blood pressure, total cholesterol, } \\
\text { LDL-cholesterol, non-HDL-cholesterol, triglyceride and uric acid levels }\end{array}$ & [164] \\
\hline \multirow{7}{*}{ Hypertension } & \multirow{6}{*}{$\operatorname{PPAR} \gamma$} & \multirow{4}{*}{ Pioglitazone } & NA (27) & - Reduced systolic and diastolic blood pressure & [167] \\
\hline & & & NA (149) & $\begin{array}{l}\text { - Reduced CRP } \\
\text { - Increased 24-h blood pressure profile } \\
\text { - Reduced insulin resistance and chronic inflammation }\end{array}$ & [169] \\
\hline & & & III (42) & $\begin{array}{l}\text { - Increased glucose utilization, norepinephrine spillover response, and baroreflex } \\
\text { sensitivity during OGTT } \\
\text { - Reduced triglycerides, insulin level and diastolic blood pressure }\end{array}$ & [170] \\
\hline & & & NA (30) & $\begin{array}{l}\text { - Increased left ventricular diastolic function without causing mass regression } \\
\text { - Increased adiponectin and matrix metalloproteinase-2 }\end{array}$ & [171] \\
\hline & & \multirow[t]{2}{*}{ Rosiglitazone } & NA (24) & $\begin{array}{l}\text { - Decreased 24-h systolic and diastolic blood pressure, insulin, plasminogen activator } \\
\text { inhibitor-1, CRP, LDL- and HDL-cholesterol } \\
\text { - Increased glucose disposal } \\
\text { - No effect on plasma glucose }\end{array}$ & [172] \\
\hline & & & NA (16) & $\begin{array}{l}\text { - No effect on forearm blood flow reactivity } \\
\text { - Attenuated free fatty acid elevation upon triglyceride challenge, which preserved } \\
\text { endothelium-dependent vasodilation }\end{array}$ & [173] \\
\hline & PPAR $\alpha$ & Fenofibrate & NA (31) & $\begin{array}{l}\text { - Did not affect blood pressure in salt-resistant subject } \\
\text { - Reduced diastolic and mean arterial blood pressure in salt-sensitive subjects challenged } \\
\text { by high-salt diet } \\
\text { - Decreased heart rate, plasma renin activity, renal vascular resistance in salt-sensitive, } \\
\text { but not salt-resistance subjects }\end{array}$ & [165] \\
\hline
\end{tabular}




\section{Liver Diseases}

\subsection{Non-Alcoholic Fatty Liver Disease (NAFLD)}

NAFLD is a spectrum of diseases ranging from the alcohol-independent accumulation of fats in the liver (hepatosteatosis) to inflammation (steatohepatitis), liver fibrosis, and cirrhosis [176]. Due to the lack of approved treatment, existing standard-of-care for NAFLD relies primarily on lifestyle modifications. In this context, PPARs, which are vital lipid regulators and promote anti-inflammatory responses, are ideal targets for NAFLD therapy. The importance of PPAR $\alpha$ in NAFLD pathogenesis is demonstrated by a strong negative correlation between PPAR $\alpha$ expression in the liver with NASH severity [177]. However, clinical success with PPAR $\alpha$ agonists is limited. Fenofibrate and gemfibrozil reliably improve liver function, lipid profile, and insulin sensitivity, but have minimal effects on the histopathology in NAFLD [178-180]. Moreover, side effects like impaired kidney function and reversible elevation of serum creatinine and homocysteine are associated with fibrate treatment [181,182]. The occurrence of an adverse incident increases when fibrates are used in combination with certain drugs, particularly gembrozil with cerivastatin, which shows a high incidence rate of rhabdomyolysis [183]. While interest in using fibrates as PPAR $\alpha$ agonist for NAFLD and NASH has dwindled, there is much enthusiasm in selective PPAR alpha modulator (SPPARM $\alpha$ ) such as pemafibrate to enhance clinical efficacy and minimize side effects. An RCT for the use of pemafibrate in NAFLD patients is underway in Japan, and the results will only be available in 2020 (NCT03350165). Given the superior efficacy and safety profile of pemafibrate for dyslipidemia patients when compared to other fibrates (see Section 5), the outcomes of the ongoing NAFLD trial is highly anticipated.

PPAR $\gamma$ may seem like an unlikely target for NAFLD treatment due to their adipocyte-centric expression and functionality. Ironically, pioglitazone is the only pharmacological therapy recognized by the American Association for the Study of Liver Diseases (AASLD) for use in patients with biopsy-proven NASH, irrespective of their diabetic status [184]. Despite no improvement in fibrosis score, the ameliorative effects of pioglitazone on ectopic hepatic lipid deposition, inflammation, histopathology, and liver function were supported by several RCTs [185-189]. Nonetheless, pioglitazone may be a useful drug candidate for early NASH, despite its limited anti-fibrotic activity.

The initial clinical findings of troglitazone, another PPAR $\gamma$ agonist, also showed improved liver enzymes with a marginal improvement in histological scoring [190]. However, troglitazone was withdrawn from the market after it was found to cause hepatitis. The clinical evidence of rosiglitazone for NAFLD suggests only a temporary benefit from rosiglitazone treatment. A pilot study showed that a 48-week rosiglitazone regime significantly reduced hepatocellular ballooning and hepatic necroinflammation but not liver fibrosis in NASH patients [191]. Likewise, a Fatty Liver Improvement with Rosiglitazone Therapy (FLIRT) study found that rosiglitazone treatment for one year could improve hepatic steatosis and insulin sensitivity, but not liver inflammation and fibrosis [192]. Notably, a two-year extension of the study (FLIRT 2) concluded that the benefits of rosiglitazone in NASH were lost [193].

The combined therapy of rosiglitazone and metformin, supplementing exercise and diet modification, could also attenuate NASH progression [194]. Nevertheless, a similar study pointed out that exercise and diet modification had a better treatment response than either rosiglitazone or metformin alone in NASH [195], highlighting the predominant role of lifestyle modification in NASH treatment. Thus, the short-term use of rosiglitazone offers modest benefits for NAFLD patients, but its long-term efficacy is negligible. The diverse efficacy of different PPAR $\gamma$ agonists in NAFLD and NASH reinforces that notion that the activation of the same PPAR subtype by different agonists does not necessarily lead to similar outcomes.

Given the promising efficacy of certain fibrates and TZDs, the concurrent activation of different PPARs becomes an emerging focus in NAFLD therapy. In dyslipidemic patients, dual- and pan-PPAR agonists can lower liver enzymes and hepatic fat content [72,132]. The positive outcomes lead to several NAFLD trials to explore the clinical feasibility of dual- and pan-PPAR agonists. An example 
is GOLDEN-505, a Phase II trial that investigated the effects of different elafibranor (dual PPAR $\alpha / \delta$ agonist) dosages in NASH patients without cirrhosis. A higher proportion of patients on elafibranor (120 mg/day) had lower NAFLD activity score and resolved NASH without fibrosis worsening in addition to the reduction of lipids, glucose, liver enzymes, and inflammatory markers [196]. Elafibranor was well-tolerated, although a slight, reversible increase in serum creatinine was noted [196]. Currently, an ongoing Phase 3 trial (RESOLVE-IT) aims to compare elafibranor to placebo in more than 2000 NASH patients (NCT02704403). The trial is expected to shed more light on the efficacy and long-term safety of the drug.

Saroglitazar, the first approved dual-PPAR $\alpha / \gamma$ agonist (only in India), has also been trialed as a potential drug for NAFLD because of its beneficial effect on fatty liver in diabetic patients with NAFLD [132]. The outcomes of a Phase III trial (GLAZED) comparing saroglitazar to pioglitazone in NAFLD patients is unpublished (NCT02265276). Meanwhile, saroglitazar is also under active clinical investigation for uncomplicated NAFLD and NASH (NCT03061721; NCT03863574) and those that complicated by other medical conditions, like PCOS (NCT03617263) and liver transplantation (NCT03639623). As the first of its kind, and with positive results from dyslipidemia trials, saroglitazar is a new promising drug for the treatment of NAFLD and NASH.

Another promising dual-PPAR $\alpha / \gamma$ agonist for NAFLD is lobeglitazone, which has demonstrated a positive therapeutic effect in T2DM patients (see Section 3). A Phase IV trial reported that lobeglitazone significantly reduced intrahepatic fat content, lipid profile, and liver enzymes in diabetic patients with NAFLD [197]. However, it should be noted that the change in hepatic fat content was determined with Fibroscan ${ }^{\circledR}$ instead of liver histology. Therefore, further RCTs using liver histology as the endpoint are vital to validate the real efficacy of lobeglitazone in NAFLD.

According to preclinical evidence, lanifibranor (also known as IVA337) which is a pan-PPAR agonist, can potentially be the right candidate for NAFLD [198]. In preclinical model of cirrhosis, lanifibranor improves portal hypertension and hepatic fibrosis (to be presented at The Liver Meeting ${ }^{\circledR}$ 2019 in Boston, Massachusetts, USA, November 8-12, 2019). However, its clinical development in NAFLD is lagging elafibranor and saroglitazar. Thus far, there are two ongoing Phase II trials which assess the safety, efficacy, and mechanism of lanifibranor in NAFLD and NASH (NCT03008070; NCT03459079). Nonetheless, if the unique pan-PPAR agonistic activity of lanifibranor can translate into exceptional efficacy with minimal safety concern, the drug is likely to benefit not only patients with NAFLD but also many other chronic metabolic diseases. In summary, the resolution of NASH and NAFLD remains an onerous task. Despite numerous preclinical tests suggesting potential in targeting PPARs, human trials are often disappointing. Currently, there are no approved diabetic therapies expect pioglitazone for NASH, but it has drawbacks. There are also many pharmacological differences between PPAR agonists which could affect its efficacy, thus making it hard to conclude which PPAR is the best for improvement in NASH. However, it seems that the next-generation dual-PPAR or pan-PPAR agonists are presently the most promising way to go about tackling this tall task.

\subsection{Primary Biliary Cholangitis}

PBC is an autoimmune liver disease characterized by the presence of anti-mitochondrial antibodies against pyruvate dehydrogenase complex and a unique bile duct pathology [199]. Patients diagnosed with PBC typically develop extensive liver fibrosis and cirrhosis over a few years, while $15 \%$ of the patients suffer from liver failure after five years [200]. Currently, ursodeoxycholic acid (UDCA) is the only drug approved for PBC, but about a third of patients are non-responders [201]. Various PPAR ligands have thus been trialed as a new therapeutic approach to supplement UDCA. Co-administration of bezafibrate and UDCA to patients who had an incomplete response to UDCA treatment alone, significantly improved hepatic function and reduced liver fibrosis [202-204]. A retrospective cohort study correlated bezafibrate with UDCA combined therapy with reduced risk for liver transplantation and liver-related death [205]. Thus, the combined therapy may improve long-term prognosis of PBC patients. Likewise, the clinical outcomes from another PPAR $\alpha$ agonist, fenofibrate was also optimistic 
as fenofibrate with UDCA could also improve liver biochemistries, leading to a higher complete response rate [206-210]. Taken together, fibrates as adjuvant therapy, aids liver function recovery in PBC patients, particularly among UDCA non-responders. More prolonged and more extensive trials, preferably with histopathological investigation, are warranted to validate the long-term therapeutic effects. Currently, two clinical trials that examine the impacts of bezafibrate in disease progression, quality of life, and cholestatic pruritus intensity are ongoing (NCT02937012; NCT02701166).

In addition to PPAR $\alpha$ agonists, other PPAR modulators are also actively subjected to phase II or III clinical testing as a PBC adjunctive therapy. These drug candidates include seladelpar (NCT03602560; NCT03301506; NCT02955602), elafibranor (NCT03124108), and saroglitazar (NCT03112681). It is worth mentioning that elafibranor was granted Breakthrough Therapy Designation by the U.S. FDA for the treatment of PBC. On the other hand, a Phase II trial featuring seladelpar was terminated early due to overly high elevation of ALT, likely attributable to high seladelpar dosages (50 and $200 \mathrm{mg} /$ day) [211]. Resultantly, three subsequent clinical trials, as mentioned above use lower dosages ( $2-10 \mathrm{mg} /$ day) to minimize untoward events. Considering the clinical success of PPAR $\alpha$ agonists in PBC therapy, the efficacy of other PPAR agonists are also awaited with great expectations. Hence, the outcomes from ongoing trials may help to formulate better therapeutic approaches to treat PBC in the future.

\subsection{Hepatitis $C$}

Hepatitis $\mathrm{C}$ is a form of viral hepatitis caused by the Hepatitis C Virus (HCV) that can increase the risk of cirrhosis and liver cancer. In addition to liver injury, hepatic steatosis and insulin resistance are common manifestations which may aid viral replication and survival [34]. Therefore, PPAR $\gamma$ agonists have been proposed to alleviate these symptoms and delay hepatitis $C$ deterioration. Yet, one-year treatment with farglitazar (PPAR $\gamma$ ) failed to lessen stellate cell activation and fibrosis in chronic hepatitis $C$ patients who did not respond to anti-viral therapy (pegylated interferon alpha/ribavirin) [212]. In a separate trial, pioglitazone also did not confer any benefit to non-responders [213]. Unlike those who are resistant to anti-viral therapy, in treatment-naïve hepatitis $C$ patients, pioglitazone not only reduced HCV RNA after a 14-day course [214] but also resulted in a higher rate of sustained viral response when used in combination with anti-viral therapy [215]. Collectively, by acting on steatosis and insulin resistance, pioglitazone may be beneficial in early stage or treatment-naïve hepatitis $C$ patients, but less effective in those who are resistant to anti-viral therapy. Despite the promising results, clinical development of PPAR $\gamma$ agonists for hepatitis $C$ was stopped when new and more potent pharmacotherapy, direct-acting antivirals, was approved by the FDA in 2011 for hepatitis C treatment [216]. The clinical results of different PPAR agonists in NAFLD, NASH, PBC, and hepatitis C are summarized in Table 5. 
Table 5. Summary of the clinical evidence of PPAR agonists in liver diseases.

\begin{tabular}{|c|c|c|c|c|c|}
\hline Disease & Target & Drug Name & Clinical Phase (Sample Size) & Main Findings/Primary Endpoint & $\begin{array}{l}\text { Reference/Clinical Trial } \\
\text { Identifier }\end{array}$ \\
\hline \multirow{17}{*}{ NAFLD } & \multirow{4}{*}{$\operatorname{PPAR} \alpha$} & Gemfibrozil & NA (46) & - Decreased liver enzymes & [178] \\
\hline & & \multirow[t]{2}{*}{ Fenofibrate } & NA (16) & $\begin{array}{l}\text { Decreased liver enzymes, hepatocellular ballooning degeneration, } \\
\text { and triglycerides }\end{array}$ & [179] \\
\hline & & & NA (27) & - Reduced triglycerides, VLDL, and APOB & [180] \\
\hline & & Pemafibrate & II-ongoing (100) & - Primary endpoint: Hepatic fat fraction and adverse events & NCT03350165 \\
\hline & \multirow{11}{*}{$\operatorname{PPAR} \gamma$} & \multirow{6}{*}{ Pioglitazone } & NA (18) & - Improved biochemical and histological features of NASH & [185] \\
\hline & & & IV (55) & $\begin{array}{l}\text { - Reduced liver enzymes and hepatic fat content } \\
\text { - Improved histological features of NASH }\end{array}$ & [186] \\
\hline & & & NA (74) & $\begin{array}{l}\text { - Reduced liver enzymes } \\
\text { - Reduced hepatocellular injury, Mallory-Denk bodies and fibrosis }\end{array}$ & [187] \\
\hline & & & III (247) & $\begin{array}{l}\text { - Reduced liver enzymes } \\
\text { - Reduced hepatic steatosis and lobular inflammation }\end{array}$ & [188] \\
\hline & & & IV (101) & - Improved biochemical and histological features of NASH & [189] \\
\hline & & & NA (10) & - Improved ALT levels, mild histological improvement & [190] \\
\hline & & \multirow{5}{*}{ Rosiglitazone } & $\mathrm{NA}(30)$ & $\begin{array}{l}\text { - Improved insulin sensitivity } \\
\text { - Decreased in liver enzymes and fat content } \\
\text { - No change to triglyceride level. }\end{array}$ & [191] \\
\hline & & & II (63) & - Improved steatosis, insulin sensitivity and AST/ALT levels & [192] \\
\hline & & & II (44) & $\begin{array}{l}\text { - No improvement in fibrosis, ballooning and steatosis. } \\
\text { - Maintained insulin sensitivity and AST/ALT levels. }\end{array}$ & [193] \\
\hline & & & NA (74) & $\begin{array}{l}\text { - Reduced plasma insulin and improved HOMA-IR score. } \\
\text { - Decrease in AST and ALT } \\
\text { - Improved NAFLD activity score }\end{array}$ & [194] \\
\hline & & & NA (47) & $\begin{array}{l}\text { - No change in rate of steatosis and fibrosis } \\
\text { - Diet together with exercise was superior to rosiglitazone alone. }\end{array}$ & [195] \\
\hline & \multirow{2}{*}{ dual PPAR $\alpha / \delta$} & \multirow{2}{*}{ Elafibranor } & II (276) & - Resolved NASH without fibrosis worsening & [196] \\
\hline & & & III-ongoing (2000) & - Primary endpoint: Achieving resolution of NASH without worsening of fibrosis & NCT02704403 \\
\hline
\end{tabular}


Table 5. Cont.

\begin{tabular}{|c|c|c|c|c|c|}
\hline Disease & Target & Drug Name & Clinical Phase (Sample Size) & Main Findings/Primary Endpoint & $\begin{array}{l}\text { Reference/Clinical Trial } \\
\text { Identifier }\end{array}$ \\
\hline & \multirow{6}{*}{ Dual-PPAR $\alpha / \gamma$} & \multirow{5}{*}{ Saroglitazar } & III-unknown status (100) & - Primary endpoint: Change in NAFLD fibrosis score & NCT02265276 \\
\hline & & & II-ongoing (106) & - Primary endpoint: Percentage change from baseline in serum ALT levels & NCT03061721 \\
\hline & & & II-ongoing (15) & $\begin{array}{l}\text { - Primary endpoint: Change in NAFLD activity score with no worsening } \\
\text { of fibrosis }\end{array}$ & NCT03863574 \\
\hline & & & II-ongoing $(60)$ & - Primary endpoint: Change in hepatic fat content & NCT03617263 \\
\hline & & & II-ongoing (15) & - Primary endpoint: Number of participants with adverse events & NCT03639623 \\
\hline & & Lobeglitazone & IV (38) & $\begin{array}{l}\text { - Reduced hepatic fat content } \\
\text { - Improved glycemic, liver, and lipid profiles }\end{array}$ & [197] \\
\hline & \multirow[t]{2}{*}{ Pan-PPAR } & \multirow[t]{2}{*}{ Lanifibranor } & II-ongoing (225) & $\begin{array}{l}\text { - Primary endpoint: Responder analysis based on the improvement of the SAF } \\
\text { (steatosis: S, activity: A, and fibrosis: F) activity score }\end{array}$ & NCT03008070 \\
\hline & & & II-ongoing (84) & - Primary endpoint: Intrahepatic triglyceride level & NCT03459079 \\
\hline \multirow{15}{*}{ РBC } & \multirow{9}{*}{ PPAR $\alpha$} & \multirow{5}{*}{ Bezafibrate } & III (100) & $\begin{array}{l}\text { - Normalization of bilirubin, liver enzymes, albumin, and plasma } \\
\text { triglyceride levels. }\end{array}$ & [202] \\
\hline & & & NA (16) & - Decreased levels of liver enzymes & [203] \\
\hline & & & $\mathrm{NA}(66)$ & - Improved biliary enzyme parameters & [204] \\
\hline & & & III-ongoing (34) & - Primary endpoint: Complete biochemical response & NCT02937012 \\
\hline & & & III-ongoing (84) & $\begin{array}{l}\text { - Primary endpoint: Proportion of patients with a reduction in itch intensity of } \\
50 \% \text { or more }\end{array}$ & [217] \\
\hline & & \multirow{4}{*}{ Fenofibrate } & II (20) & $\begin{array}{l}\text { - Decrease in liver enzymes, IgM, IL-1, and IL-6 } \\
\text { - No significant decrease in bilirubin }\end{array}$ & [206] \\
\hline & & & NA (22) & $\begin{array}{l}\text { - Decrease in liver enzymes, cholesterol, and TG } \\
\text { - No significant effect on serum bilirubin }\end{array}$ & [208] \\
\hline & & & NA (120) & $\begin{array}{l}\text { - Improvement in ALP, ALT, AST and decompensation, and } \\
\text { transplant-free survival }\end{array}$ & [209] \\
\hline & & & II (10) & - Decrease in total cholesterol, TG, VLDL, LDL, and liver enzymes & [210] \\
\hline & \multirow{4}{*}{$\mathrm{PPAR} \beta / \delta$} & \multirow{4}{*}{ Seladelpar } & III-ongoing (240) & - Primary endpoint: Complete biochemical response & NCT03602560 \\
\hline & & & II \& III-ongoing (356) & - Primary endpoint: Adverse events, and treatment emergent adverse events & NCT03301506 \\
\hline & & & II-ongoing (116) & - Primary endpoint: Serum alkaline phosphatase, adverse events & NCT02955602 \\
\hline & & & II (41) & - Normalization of ALP. Risk of grade 3 increase in aminotransferases & [211] \\
\hline & Dual PPAR $\alpha / \delta$ & Elafibranor & II (45) & - Primary endpoint: Relative change from baseline in serum alkaline phosphatase & NCT03124108 \\
\hline & Dual PPAR $\alpha / \gamma$ & Saroglitazar & II-ongoing (36) & - Primary endpoint: Improvement in ALP levels & NCT03112681 \\
\hline
\end{tabular}


Table 5. Cont

\begin{tabular}{|c|c|c|c|c|c|}
\hline Disease & Target & Drug Name & Clinical Phase (Sample Size) & Main Findings/Primary Endpoint & $\begin{array}{c}\text { Reference/Clinical Trial } \\
\text { Identifier }\end{array}$ \\
\hline \multirow{4}{*}{ Hepatitis C } & \multirow{4}{*}{$\operatorname{PPAR} \gamma$} & Farglitazar & II (265) & - No evidence of antifibrotic activity & {$[212]$} \\
\hline & & \multirow{3}{*}{ Pioglitazone } & II (5) & - No satisfactory viral response. & [213] \\
\hline & & & II (40) & - Decreased serum HCV RNA. & [214] \\
\hline & & & IV (80) & - Increased rapid virologic response & [215] \\
\hline
\end{tabular}




\section{Kidney Diseases}

\subsection{Chronic Kidney Disease (CKD)}

CKD is characterized by persistent, low-grade inflammation of the kidneys, which results in a gradual loss of renal function over time [218]. It is also a common renal complication of many chronic diseases like T2DM, hypertension, and MetS. The inflammatory and metabolic components make PPAR agonists potential drug candidates for CKD. Pioglitazone is well-tolerated in patients with CKD [219]. Indeed, pioglitazone improved the visceral-to-subcutaneous fat deposition, adipokine profile, hepatic insulin sensitivity, and circulating CRP in non-diabetic patients on dialysis [220]. Similar improvements in adiponectin and CRP were also found in obese, diabetic, or insulin-resistant patients with end-stage renal failure (NCT01301027). Furthermore, endothelial function, including flow-mediated dilatation, arterial compliance, and pulse-wave velocity, were not affected by pioglitazone (NCT00586261) and rosiglitazone [221] in CKD patients. A post hoc analysis of PROactive trial revealed that pioglitazone could reduce the incidence of all-cause mortality, myocardial infarction, and stroke in diabetic patients with CKD [222]. Ironically, there was a more significant decline in kidney function in pioglitazone cohort [222]. An ongoing Phase IV trial is looking into the role of pioglitazone in sympathetic nervous system to understand the effect of the PPAR $\gamma$ agonist in lowering cardiovascular risk among CKD patients (NCT03471117). Based on existing evidence, the cardiovascular benefits of pioglitazone in CKD looks optimistic, but the underlying mechanism may not be a direct amelioration of vascular and renal impairment. Future studies should address this question by looking into the effects of TZDs on renal-related endpoints like the progression of kidney disease, glomerular filtration rate, and renal function biomarkers. The outcomes will help to capture the subsets of CKD patients who will truly benefit from the treatment.

\subsection{Other Kidney Diseases}

Apart from CKD, PPAR $\gamma$ agonists have also been trialed in other kidney complication. In renal transplant recipients with newly diagnosed impaired glucose tolerance, pioglitazone reliably improved the insulin sensitivity [223]. This finding was confirmed by another trial that showed pioglitazone significantly reduced carotid intima-media thickness, suggesting a reduction of cardiovascular risk in renal allograft recipients [224]. These results suggest a role for pioglitazone in the management of post-renal transplantation complications.

Maalouf et al. (2019) showed that pioglitazone improved some features of MetS, reduced net acid secretion, and increased urine $\mathrm{pH}$ in patients with uric acid nephrolithiasis, suggesting lower kidney stone formation [225]. Although such treatment is unlikely to replace alkali administration to prevent kidney stone formation, the results established insulin resistance as an important factor of low urine $\mathrm{pH}$. This provides a basis for the use of PPAR $\gamma$ agonists as a treatment for MetS and preventive approach for kidney stone.

A Phase I pilot study was conducted to examine the safety and efficacy of rosiglitazone in resistant focal segmental glomerulosclerosis (NCT00193648). Pioglitazone was also trialed in a Phase II study for autosomal dominant polycystic kidney disease (NCT02697617). The outcomes of both trials remain unpublished. The preliminary results from the above trials will be a dominant factor for further exploration of pioglitazone in other renal-related diseases. Table 6 summarizes the clinical evidence of different PPAR agonists in kidney diseases. 
Table 6. Summary of the clinical evidence of PPAR agonists in kidney diseases.

\begin{tabular}{|c|c|c|c|c|c|}
\hline Disease & Target & Drug Name & $\begin{array}{l}\text { Clinical Phase (Sample } \\
\text { Size) }\end{array}$ & Main Findings/Primary Endpoint & $\begin{array}{c}\text { Reference/Clinical Tria } \\
\text { Identifier }\end{array}$ \\
\hline \multirow{6}{*}{ CKD } & \multirow{6}{*}{$\operatorname{PPAR} \gamma$} & \multirow{5}{*}{ Pioglitazone } & IV (16) & $\begin{array}{l}\text { Decreased the visceral/sub-cutaneous adipose tissue ratio, leptin/adiponectin (L/A) } \\
\text { ratio. Increased insulin sensitivity. }\end{array}$ & {$[220]$} \\
\hline & & & NA-completed (95) & - Primary endpoint: Change in adiponectin and CRP & NCT01301027 \\
\hline & & & NA (75) & $\begin{array}{l}\text { - Halved pioglitazone dosage produces similar glycemic effects with reduced } \\
\text { adverse effects }\end{array}$ & [219] \\
\hline & & & NA-terminated (36) & - Primary endpoint: Change in brachial arterial reactivity & NCT00586261 \\
\hline & & & IV-ongoing (28) & - Primary endpoint: Change in muscle sympathetic nerve activity & NCT03471117 \\
\hline & & Rosiglitazone & NA $(70)$ & - Improvement to insulin sensitivity, hs-CRP, and von Willebrand Factor (vWF). & [221] \\
\hline \multirow{2}{*}{$\begin{array}{l}\text { Renal transplant } \\
\text { complication }\end{array}$} & \multirow{2}{*}{$\operatorname{PPAR} \gamma$} & \multirow{2}{*}{ Pioglitazone } & NA (48) & - Reduced fasting plasma glucose and $\mathrm{HbA1c}$ & [223] \\
\hline & & & NA (83) & - Increase in insulin sensitivity and reduced progression of carotid IMT & [224] \\
\hline Kidney stone & $\operatorname{PPAR} \gamma$ & Pioglitazone & NA (36) & $\begin{array}{l}\text { - Improvement to features of metabolic syndrome, reduced net acid excretion and } \\
\text { increased urine } \mathrm{pH}\end{array}$ & [225] \\
\hline $\begin{array}{l}\text { resistant focal segmental } \\
\text { glomerulosclerosis }\end{array}$ & $\operatorname{PPAR} \gamma$ & Pioglitazone & I-completed (21) & - Primary endpoint: Safety and tolerance & NCT00193648 \\
\hline $\begin{array}{l}\text { Polycystic kidney } \\
\text { disease }\end{array}$ & $\operatorname{PPAR} \gamma$ & Pioglitazone & II-ongoing (18) & - Primary endpoint: Safety and tolerance & NCT02697617 \\
\hline
\end{tabular}




\section{Neurodegenerative Diseases and Neurological Dysfunction}

\subsection{Alzheimer's Disease and Parkinson's Disease}

Expanding interests into metabolic disorders have led to the proposal of how metabolic disorders and Alzheimer's disease have overlapping risk factors, which generated interests of PPAR in Alzheimer's disease. In a pilot Phase II clinical trial conducted on patients with mild Alzheimer's disease and amnestic mild cognitive impairment, a 6-month course of rosiglitazone improved clinical outcomes like better delayed recall, selective attention, and stable plasma level of amyloid $\beta-42$ peptide [226]. The positive outcomes suggest that rosiglitazone may be a novel strategy for cognitive decline, subsequently driving GlaxoSmithKline to spearhead further clinical trials by amassing thousands of subjects that were stratified into APOE $\varepsilon 4$ carriers or non-carriers for the study of extended release rosiglitazone under subsequent REFLECT program. Results from a Phase II trial showed that extended-release rosiglitazone for a year was well-tolerated and could enhance cerebral glucose metabolism, but not displaying clinical improvement in patients with mild to moderate Alzheimer's disease [227]. A larger Phase II trial also concluded that rosiglitazone did not improve cognitive function of patients with mild Alzheimer's disease, although exploratory subgroup analysis revealed that patients without $\mathrm{APOE} \varepsilon 4$ allele, a strong genetic risk factor of Alzheimer's disease, might be more responsive with rosiglitazone [228]. However, further investigation of the efficacy of rosiglitazone in Alzheimer's disease, either as a monotherapy or an adjunctive therapy to acetylcholine esterase inhibitors, in five Phase III clinical trials, did not yield meaningful outcomes in cognition and global function, even when the patients were stratified into APOE $\varepsilon 4$ carriers or non-carriers [229,230]. With many trials done, but no important findings of the potential therapeutics of rosiglitazone on Alzheimer's disease, GlaxoSmithKline has ceased the development of rosiglitazone as Alzheimer's disease therapy.

In a TOMMORROW trial, pioglitazone was tested as a preventive medication for healthy subjects with a strong predisposition to mild cognitive impairment due to Alzheimer's disease. The trial was prematurely terminated due to the lack of efficacy of pioglitazone in preventing the onset of cognitive impairment among high-risk patients (NCT01931566). Other clinical trials that aimed to assess the therapeutic effects of pioglitazone in mild cognitive impairment and Alzheimer's disease also did not identify improvement in cognition, neuropsychiatric symptoms, global function, and daily activities [231,232]. In line with Alzheimer's disease trials, pioglitazone also failed to modify the progression of early Parkinson's disease according to a Phase II trial [233]. Thus far, mounting evidence from past trials strongly points out the ineffectiveness of PPAR $\gamma$ agonists in ameliorating neurodegenerative diseases. Hence, further clinical development in these aspects is not recommended unless stronger evidence, along with concrete pharmacological interaction that supports the use of PPAR $\gamma$ agonists arises. Despite the failure of PPAR $\gamma$ agonists, a new Phase I trial piloting a PPAR $\alpha$ agonist-gemfibrozil, for pre-dementia Alzheimer's patients is on-going (NCT02045056). The study explores the impacts of gemfibrozil on Alzheimer's disease biomarkers like miRNA-107, amyloid $\beta-40$, and -42 peptides in serum, and cerebrospinal fluid. Outcomes of the trial will determine the feasibility of repurposing gemfibrozil as well as other $\operatorname{PPAR} \alpha$ agonist for Alzheimer's disease therapy.

\subsection{Amyotrophic Lateral Sclerosis}

Amyotrophic lateral sclerosis (ALS) is a lethal neurodegenerative disease resultant of motor neuronal death, with clinical presentation of muscle degeneration, paralysis, respiratory distress, and eventual death from respiratory distress. Recent ALS studies involving SOD1 mutant mouse model were indicative of the protective effects of anti-inflammatory compounds in reducing inflammation-induced neuronal death in ALS [234]. Pioglitazone, with its anti-inflammatory properties, may play a neuroprotective role in alleviating ALS. Ironically, pioglitazone's side effect of moderate weight gain may improve survival through rescuing energy deficiency for ALS patients. Despite reported successes of pioglitazone in animal ALS models [235,236], these successes were not observed in the clinical trials 
that piloted pioglitazone in the amelioration of ALS. Dupuis et al. (2012) reported no improvement upon co-administration of $45 \mathrm{mg} /$ day of pioglitazone and $100 \mathrm{mg} /$ day of riluzole when compared to a placebo group, with increased patient death (30:24 by the end of two years) and a hazard ratio of 1.21 at the end of the trial [237]. The trial was prematurely ended on the reason of futility from the adverse events of ALS disease progression, despite well-tolerance of pioglitazone. In another Phase I/II clinical trial, co-administration of riluzole, tretinoin, and pioglitazone did not delay the disease progression of ALS [238]. Existing clinical evidence does not support the use of pioglitazone in ALS treatment. The discrepancy between clinical and preclinical findings may be attributable to the heterogeneity of genetic spectrum of ALS which the SOD1 mutant ALS mice are unable to reproduce.

\subsection{Multiple Sclerosis}

Chronic demyelination in the central nervous system mediated by a targeted autoimmune response and its implications in the disease progression of multiple sclerosis has also been extensively studied via experimental autoimmune encephalomyelitis models [239]. Only limited clinical evidence exists on the potential therapeutics of PPAR $\gamma$ agonists, pioglitazone and CHS-131 (also known as INT-131) for multiple sclerosis. Evidence was based on the inflammatory properties of these agonists in the preclinical model. Pioglitazone or placebo co-administered with interferon $\beta-1 \alpha$ to patients with relapsing-remitting multiple sclerosis showed no clinical improvement or adverse events through expanded disability status scale, despite a promising significant reduction in gray matter atrophy and a positive trend of lower lesion load in subsequent MRI follow-ups [240]. Another PPAR $\gamma$ agonist, CHS-131, was also trialed, with reported lower new contrast-enhanced lesions of $52 \%$ and $21 \%$ in high (3 mg CHS-131/day) and low (1 mg CHS-131/day) dose cohorts, respectively, when compared with placebo [241]. The relapse rate was also lowered by $33 \%$ and $24 \%$ in high- and low-dose cohorts relative to the placebo-treated group [241]. These two trials highlight the potential of PPAR $\gamma$ agonists for multiple sclerosis. The need to upscale these trials to test PPAR $\gamma$ agonists' efficacies and even possible counter-interactions has become increasingly critical, especially when these agonists are more widely applied to patients in the clinical settings for other medical disorders.

\subsection{Other Neurological Disorders}

The efficacy of PPAR agonists was also examined for other neurological disorders like epilepsy (EUCTR 2011-005433-39), post-herpetic neuralgia (NCT01318226), and Friedreich's ataxia (NCT00811681). Adjunctive therapy with fenofibrate for six months markedly reduced seizure frequency in patients with drug-resistant nocturnal frontal lobe epilepsy [242]. ATx08-001 (also known as FK614), a non-TZD PPAR $\gamma$ agonist has been examined for its safety and analgesic properties in individuals with post-herpetic neuralgia (NCT01318226), but no published information regarding the trial outcomes is available. Due to an improved antioxidant mechanism, pioglitazone has also been proposed and trialed as a therapy for Friedreich's ataxia, a rare neurological disorder arising from recessive genetic inheritance of a mutated Frataxin (FXN) gene on chromosome 9q13 (NCT00811681). The data remain unpublished to date, one of the investigators did mention that pioglitazone was unable to improve neurological function in patients with Friedreich's ataxia [243]. While PPAR agonists have been tested in many neurological disorders, the outcomes of most trials are mostly negative or unavailable (Table 7). Hence, future investigation in this aspect is not encouraged unless stronger evidence arises. 
Table 7. Summary of the clinical evidence of PPAR agonists in neurodegenerative diseases and neurological dysfunction.

\begin{tabular}{|c|c|c|c|c|c|}
\hline Disease & Target & Drug Name & $\begin{array}{l}\text { Clinical Phase (Sample } \\
\text { size) }\end{array}$ & Main Findings/Primary Endpoint & $\begin{array}{l}\text { Reference/Clinical Trial } \\
\text { Identifier }\end{array}$ \\
\hline \multirow{11}{*}{ Alzheimer's Disease } & \multirow{10}{*}{$\operatorname{PPAR} \gamma$} & \multirow{7}{*}{ Rosiglitazone } & II (30) & $\begin{array}{l}\text { - Better delayed recall and selective attention } \\
\text { - Stable plasma amyloid } \beta-42 \text { level at } 6^{\text {th }} \text { month }\end{array}$ & [226] \\
\hline & & & II (687) & $\begin{array}{l}\text { - No significant differences of ADAS-Cog at week } 24 \\
\text { - APOE } \varepsilon 4 \text {-negative patients had improved cognitive functions } \\
\text { - Dose-dependent improvement of fasting plasma insulin in APOE } \varepsilon 4 \text {-negative patients }\end{array}$ & [228] \\
\hline & & & II-completed (337) & $\begin{array}{l}\text { - Primary endpoint: Evaluate the long-term safety and tolerability of rosiglitazone-extended } \\
\text { release in subjects with mild to moderate Alzheimer's disease }\end{array}$ & EUCTR2004-000985-12 \\
\hline & & & II (80) & $\begin{array}{l}\text { - Increased cerebral metabolic rate for glucose } \\
\text { - No difference in decrease of whole brain volume } \\
\text { - No difference in clinical outcome measures of ADAS-Cog or CIBIC scores } \\
\text { - No difference in plasma glucose levels }\end{array}$ & [227] \\
\hline & & & II-completed (40) & - Primary endpoint: Frequency of adverse events, safety and tolerability & NCT00381238 \\
\hline & & & III (639) & $\begin{array}{l}\text { - No difference in cognition and global function of APOE- } € 4 \text {-negative subjects } \\
\text { - Well-tolerated }\end{array}$ & [229] \\
\hline & & & III $(1496 ; 1485 ; 1461)$ & - No difference in cognitive function measurements & [230] \\
\hline & & \multirow{3}{*}{ Pioglitazone } & III-terminated (3494) & - Primary endpoint: Time to diagnosis of mild cognitive impairment due to Alzheimer's disease & NCT01931566 \\
\hline & & & II (78) & $\begin{array}{l}\text { - No increase in oxygen uptake, HbA1c, fasting triglycerides, IL-6 levels } \\
\text { - Increased glucose disposal rate } \\
\text { - Decreased fasting insulin level and endurance of exercise } \\
\text { - No difference in cognitive performances } \\
\text { - Significant improvement in ADAS-Cog after endurance exercise }\end{array}$ & [231] \\
\hline & & & II (25) & $\begin{array}{l}\text { - Well-tolerated } \\
\text { - No effect on clinical outcome measures } \\
\text { - No change to blood glucose level in non-diabetic subjects }\end{array}$ & [232] \\
\hline & PPAR $\alpha$ & Gemfibrozil & I-ongoing (72) & - Primary endpoint: Safety, microRNA-107 levels, $\beta$-amyloid 1-40 and -42 levels & NCT02045056 \\
\hline \multirow{2}{*}{ Amyotrophic Lateral Sclerosis } & \multirow[t]{2}{*}{$\operatorname{PPAR} \gamma$} & \multirow{2}{*}{ Pioglitazone } & II (219) & $\begin{array}{l}\text { - Hazard ratio of } 1.21 \text {, with a } 21 \% \text { increase in the pioglitazone group } \\
\text { - No difference in survival, functional rating, quality of life, and slow vital capacity. }\end{array}$ & [237] \\
\hline & & & II (27) & - No effect on tau level & [238] \\
\hline \multirow[t]{2}{*}{ Multiple Sclerosis } & \multirow{2}{*}{$\operatorname{PPAR} \gamma$} & Pioglitazone & $\mathrm{I}(24)$ & $\begin{array}{l}\text { - No improvement in disability status score } \\
\text { - Reduced grey matter volume and fraction loss }\end{array}$ & [240] \\
\hline & & CHS-131 & II (227) & - Dose-dependent reduction in new contrast-enhanced lesions and relapse rates & [241] \\
\hline Drug-resistant Nocturnal Frontal Lobe Epilepsy & PPAR $\alpha$ & Fenofibrate & II (12) & $\begin{array}{l}\text { - Improved subjective measurements of daily seizure diaries and quality of life } \\
\text { - Reduced major events and minor motor events }\end{array}$ & [242] \\
\hline Postherpetic Neuralgia & $\operatorname{PPAR} \gamma$ & ATх08-001/FK614 & II (61) & - Primary endpoint: Sum of the pain intensity difference in 6-h and 12-h pain intensity scores & NCT01318226 \\
\hline Friedreich's Ataxia & $\operatorname{PPAR} \gamma$ & Pioglitazone & III (40) & - No improvement in neurological functions & [243] \\
\hline
\end{tabular}




\section{Psychiatric Disorders}

\subsection{Addiction/Substance Dependency}

Emerging preclinical studies suggested that PPARs can potentially be a target for curbing addiction and substance abuse such as alcoholism as well as drug/cigarette (cocaine, nicotine, and opioid) dependence [244]. These findings spurred pilot clinical trials to determine PPAR agonists in reducing dependencies on these substances. A Phase II clinical trial investigated the effectiveness of fenofibrate on alcoholism (NCT02158273). Measurements on an intention to drink, loss of control, relief craving, urge intensity, and number of drinks after one week associated a minor improvement with fenofibrate, but two other trials that explored the clinical value of gemfibrozil and pioglitazone respectively in alcoholism were terminated (NCT03539432; NCT01631630). Gemfibrozil and pioglitazone were also trialed in several independent clinical trials for nicotine dependence/smoking. Gendy et al. (2018) employed a crossover experimental design (two-week treatment phases separated by one-week washout period) and reported no significant difference between gemfibrozil- and placebo-treated smokers in number of days of abstinence, willingness to opt for de-nicotinized cigarettes, as well as physiological changes and self-reported craving upon exposure to a smoking cue (cigarette) [245]. These findings were in line with that of fenofibrate [246]. Another recent trial on gemfibrozil, however, revealed that gemfibrozil for nine weeks decreased mean exhaled carbon monoxide, but increased the Heaviness of Smoking Index, which is an indicator of the nicotine dependency severity (NCT02638597). Likewise, pioglitazone was found to reduce nicotine craving in heavy smokers [247]. The ameliorative effect of pioglitazone on craving intensity has also been reported in a Phase I/II clinical trial on cocaine abuse [248]. In the study, not only was pioglitazone associated with a significant reduction in self-report craving assessments, but also a notable improvement in white matter integrity [248]. Contradictorily, trials on opioid dependency did not identify any beneficial outcomes with pioglitazone in drug abuse tendency and withdrawal symptoms $[249,250]$. In general, all the trials above had small sample sizes, rendering the efficacy of PPAR $\alpha$ or PPAR $\gamma$ agonists in smoking cessation and substance abuse inconclusive. Reconsiderations for further trials of PPAR $\alpha$ and PPAR $\gamma$ agonists can be made in the perspectives of the somewhat positive results from specific trials.

\subsection{Major Depressive Disorder and Bipolar Depression}

$\operatorname{PPAR} \gamma$ agonists to address mood disorders, especially major depressive disorder and depressive episodes in bipolar disorder, have been tested in a few clinical trials. In a Phase IV trial, an eight-week adjunctive treatment with pioglitazone drastically improved depression symptoms, social functionality, self-reported depression severity, and clinician-rated anxiety severity of patients with bipolar depression [251]. Similar benefits were also obtained with rosiglitazone as an adjunct therapy in bipolar depression, suggesting that PPAR $\gamma$ could potentially modulate mood and emotion [252]. In major depressive disorder, 12-week pioglitazone monotherapy reduced clinician-rated depressive symptoms (NCT00671515). Similarly, combined therapy of pioglitazone and citalopram, which is an antidepressant, also led to a better response, higher remission rate, and frequency of early improvement (reduction of depression scoring within the first two weeks of treatment) compared to citalopram alone [253]. Another trial reported that the anti-depressive effect of pioglitazone was only found in patients with comorbid insulin resistance and appeared more potent in younger patients, implying a linkage between depression and metabolic dysregulation [254]. Indeed, in schizophrenic patients, pioglitazone also significantly improved depressive symptoms and antipsychotics-induced metabolic dysfunction but failed to modify cognitive performance although a regional discrepancy (American and Chinese subjects) in the results was observed [255]. It is speculated that the improvements in depressive symptoms are partly mediated by the anti-inflammatory and metabolic regulatory effect of PPAR $\gamma$, as evidenced by the correlation between depressive symptomatology scoring with a pro-inflammatory cytokine, IL-6 [251], and an adipokine, leptin [256], when pioglitazone was prescribed to patients with bipolar depression. Meanwhile, two trials which investigate the therapeutic effects of pioglitazone 
(EUCTR 2014-003803-31-ES) and bezafibrate (NCT02481245) respectively, in bipolar depression are underway. Existing clinical studies that explore the effects of PPAR $\gamma$ agonists on major depressive disorder and bipolar depression mainly suffer from small sample size. Nonetheless, most of them seem to agree on the potential anti-depressive activity of pioglitazone and rosiglitazone, highlighting the pertinence of further investigation to validate the clinical efficacy.

\subsection{Autism Spectrum Disorder}

In the aspect of autism spectrum disorder, the clinical feasibility of pioglitazone was initially assessed in 25 autistic children in an open-label trial. This results highlighted a significant reduction in irritability, lethargy, stereotypy, and hyperactivity with pioglitazone [257]. Later, the findings of a RCT with pioglitazone as an adjunctive treatment to risperidone also mirrored that of the previous study [258]. Inadequacy in the mode of assessments and dosage safety missing in the earlier studies led to a Phase II clinical trial which concluded that in autistic children, pioglitazone is well-tolerated at $0.75 \mathrm{mg} / \mathrm{kg} / \mathrm{day}$ [259]. Pioglitazone also favorably modifies behavioral symptoms of autistic children, along with a significant reduction of pro-inflammatory IL-6 and increment of anti-inflammatory IL-10 [259]. These trials are indicative of the benefits pioglitazone can confer to the autism spectrum disorder patients, with similar conclusions of upscaling pioglitazone as a mono- or adjuvant therapy in subsequent trials, if any. The clinical outcomes of different PPAR agonists in psychiatric disorders are summarized in Table 8. 
Table 8. Summary of the clinical evidence of PPAR agonists in psychiatric disorders.

\begin{tabular}{|c|c|c|c|c|c|}
\hline Disease & Target & Drug Name & Clinical Phase (Sample Size) & Main Findings/Primary Endpoint & $\begin{array}{l}\text { Reference/Clinical Trial } \\
\text { Identifier }\end{array}$ \\
\hline \multirow{3}{*}{ Alcoholism } & \multirow{2}{*}{$\operatorname{PPAR} \alpha$} & Fenofibrate & II-completed (50) & $\begin{array}{l}\text { - Primary endpoint: Visual Analog Scale of craving to drink and change from } \\
\text { baseline in standard drinks per week }\end{array}$ & NCT02158273 \\
\hline & & Gemfibrozil & II-terminated (3) & - Primary endpoint: Drinks per drinking day and percent days abstinent & NCT03539432 \\
\hline & $\operatorname{PPAR} \gamma$ & Pioglitazone & II-terminated (16) & $\begin{array}{l}\text { - Primary endpoint: Alcohol craving in response to the alcohol cue script, } \\
\text { lipopolysaccharide challenge, and stress script }\end{array}$ & NCT01631630 \\
\hline \multirow{4}{*}{$\begin{array}{c}\text { Nicotine } \\
\text { dependence/Smoking }\end{array}$} & \multirow{3}{*}{ PPAR $\alpha$} & \multirow{2}{*}{ Gemfibrozil } & II (27) & $\begin{array}{l}\text { - No effect on abstinence, number of smoked cigarettes, and choice for } \\
\text { non-nicotinized cigarettes }\end{array}$ & [245] \\
\hline & & & II-completed (16) & $\begin{array}{l}\text { - Decreased mean carbon dioxide exhaled } \\
\text { - Increased mean heaviness of smoking index }\end{array}$ & NCT02638597 \\
\hline & & Fenofibrate & II (38) & $\begin{array}{l}\text { - No difference in days quit, acute smoking reinforcement, and cue-inducing } \\
\text { craving measurements }\end{array}$ & [246] \\
\hline & $\operatorname{PPAR} \gamma$ & Pioglitazone & I/II (42) & $\begin{array}{l}\text { - Increased indicators of abuse potential } \\
\text { - Reduced measures of craving }\end{array}$ & [247] \\
\hline Cocaine dependence & $\operatorname{PPAR} \gamma$ & Pioglitazone & I/II (30) & $\begin{array}{l}\text { - Reducing cocaine craving } \\
\text { - Improved fractional anisotropy values of white matter integrity }\end{array}$ & [248] \\
\hline \multirow[b]{2}{*}{ Opioid dependence } & \multirow[b]{2}{*}{$\operatorname{PPAR} \gamma$} & \multirow[b]{2}{*}{ Pioglitazone } & II (32) & $\begin{array}{l}\text { - No effect on subjective, cognitive, analgesic, and physiological effects } \\
\text { of oxycodone } \\
\text { - No reduction in drug craving and recreational drug use }\end{array}$ & [249] \\
\hline & & & $\mathrm{I}(40)$ & $\begin{array}{l}\text { - No effect on the prevention of opioid withdrawal symptoms } \\
\text { - Increased subjective opiate withdrawal scale score with higher need for } \\
\text { rescue medications } \\
\text { - Did not reduce proinflammatory cytokines in cerebrospinal fluid or plasma }\end{array}$ & [250] \\
\hline \multirow{5}{*}{ Bipolar disorder } & \multirow{4}{*}{$\operatorname{PPAR} \gamma$} & \multirow{3}{*}{ Pioglitazone } & IV (34) & $\begin{array}{l}\text { - Decreased depressive symptoms } \\
\text { - Improved self-reported depressive symptoms and clinician-rated } \\
\text { anxiety scores } \\
\text { - Improved cognitive functions and insulin sensitivity }\end{array}$ & [251] \\
\hline & & & IV (38) & $\begin{array}{l}\text { - No difference in depressive symptoms, response, and remission rates } \\
\text { - No change to mania scores, metabolic and inflammatory markers }\end{array}$ & [256] \\
\hline & & & III-ongoing (60) & - Primary endpoint: Change in the clinical condition & EUCTR 2014-003803-31 \\
\hline & & Rosiglitazone & NA-completed (12) & - Decreased depression severity scoring & [252] \\
\hline & PPAR $\alpha$ & Bezafibrate & II-ongoing (30) & - Primary endpoint: Change in Montgomery-Åsberg Depression Rating Scale & NCT02481245 \\
\hline
\end{tabular}


Table 8. Cont.

\begin{tabular}{|c|c|c|c|c|c|}
\hline Disease & Target & Drug Name & Clinical Phase (Sample Size) & Main Findings/Primary Endpoint & $\begin{array}{l}\text { Reference/Clinical Trial } \\
\text { Identifier }\end{array}$ \\
\hline \multirow{3}{*}{ Major depressive disorder } & \multirow{3}{*}{$\operatorname{PPAR} \gamma$} & \multirow{3}{*}{ Pioglitazone } & II-completed (23) & - Primary endpoint: Change in Depression Symptom Severity & NCT00671515 \\
\hline & & & II/III (50) & $\begin{array}{l}\text { - Improved depression severity score } \\
\text { - Led to earlier improvement with better treatment response } \\
\text { - Higher remission achieved in pioglitazone group }\end{array}$ & [253] \\
\hline & & & IV (37) & $\begin{array}{l}\text { - Significant difference in mean decrease of depression scores in insulin } \\
\text { resistant subjects } \\
\text { - Younger patients with insulin resistance had a greater decline in } \\
\text { depression scoring }\end{array}$ & [254] \\
\hline Schizophrenia & $\operatorname{PPAR} \gamma$ & Pioglitazone & IV (56) & $\begin{array}{l}\text { - Reduced fasting glucose and high density lipoprotein } \\
\text { - Reduced depression symptoms scores, but not cognitive performances } \\
\text { - Subjects from China had no improvement in metabolic parameters and } \\
\text { psychopathology scorings }\end{array}$ & [255] \\
\hline \multirow{3}{*}{ Autism spectrum disorder } & \multirow{3}{*}{$\operatorname{PPAR} \gamma$} & \multirow{3}{*}{ Pioglitazone } & NA (25) & $\begin{array}{l}\text { - Reduced aberrant behaviors like irritability, lethargy, stereotypy } \\
\text { and hyperactivity }\end{array}$ & [257] \\
\hline & & & II (44) & - Reduced irritability, lethargy/social withdrawal, and hyperactivity scores & [258] \\
\hline & & & II (25) & $\begin{array}{l}\text { - Improved behavior scores in global function, social function, irritability, } \\
\text { hyperactivity, repetitive behaviors, and anxiety } \\
\text { - Decreased IL-6 } \\
\text { - Increased IL-10 }\end{array}$ & [259] \\
\hline
\end{tabular}




\section{Autoimmune Diseases}

\subsection{Rheumatoid Arthritis}

The use of TZDs can be extended to treat several autoimmune diseases. In rheumatoid arthritis, drug efficacy in clinical settings was mostly measured by the Disease Activity Score in 28 joints (DAS28) based on CRP level and erythrocyte sedimentation rate (ESR), both of which are inflammatory markers commonly elevated in rheumatoid arthritis, as well as parameters such as Global Health, swollen joint count, and tender joint count. In two randomized, crossover studies, the addition of $45 \mathrm{mg} / \mathrm{day}$ pioglitazone to rheumatoid arthritis patients' baseline disease-modifying antirheumatic drug (DMARD) therapy yielded a significant improvement in patient-reported global health and pain score, along with a significant reduction in the DAS28-CRP level [260,261]. Adjunctive pioglitazone therapy, however, showed no significant changes in DAS28-ESR, swollen joint count, and tender joint count in comparison to the placebo-treated arm [260]. Similarly, another study which used a combination of pioglitazone with methotrexate also reported a significant reduction of DAS28 score and CRP, without significant differences in the swollen joint and tender joint counts [262]. These results suggest that pioglitazone can be a potential adjuvant therapy used in conjunction with other drugs to treat RA.

\subsection{Systemic Lupus Erythematosus}

Pioglitazone was also examined for the treatment of SLE, an autoimmune disease which is highly predisposed to cardiovascular risk [263]. A double-blind RCT with pre-menopausal women with SLE reported a significant reduction of $70.9 \%$ in CRP levels and 34.9\% in serum amyloid A upon a 12-week course with $30 \mathrm{mg} /$ day pioglitazone [264]. Such a marked reduction in inflammation occurred in parallel to other benefits like enhanced insulin sensitivity and improved cholesterol profile, suggesting a potential role of pioglitazone in the treatment of SLE with cardiovascular risk [264]. Currently, there is another ongoing trial examining the efficacy of pioglitazone on vascular function, inflammatory response, and lupus disease activity in SLE patients (NCT02338999). Clearly, the finding from this ongoing trial is highly anticipated as a positive outcome will fuel additional experimental investigation and future trials of pioglitazone in SLE.

\subsection{Other Autoimmune Diseases}

Pioglitazone exhibited a significant reduction in the severity of pulmonary alveolar proteinosis in Csf2 deficient mice, along with an increased ability of cultured macrophages to clear surfactant in vitro. These results prompted an ongoing Phase I/II trial on the treatment of autoimmune pulmonary alveolar proteinosis to stimulate the ability of alveolar macrophages to clear surfactant (NCT03231033), which can provide more insight about the immune-modulatory effect of pioglitazone. On the other hand, lanifibranor (pan-PPAR agonist) has been examined in a Phase II trial for diffuse cutaneous systemic sclerosis, an autoimmune disease of the connective tissues and has extensive complications in skin, kidneys, heart, lungs, and gastrointestinal tract (NCT02503644). Although the detailed results were unpublished, the developing company (Inventiva) announced that lanifibranor failed to improve skin thickness and disease progression. Further development of lanifibranor in diffuse cutaneous systemic sclerosis is discontinued. In short, the clinical results of pioglitazone in autoimmune diseases look promising, whereas the efficacy of other PPAR agonists is rarely investigated. Existing clinical evidence of PPAR agonists in autoimmune diseases are tabulated in Table 9. 
Table 9. Summary of the clinical evidence of PPAR agonists in autoimmune diseases.

\begin{tabular}{|c|c|c|c|c|c|}
\hline Disease & Target & Drug Name & Clinical Phase (Sample Size) & Main Findings/Primary Endpoint & $\begin{array}{l}\text { Reference/Clinical Trial } \\
\text { Identifier }\end{array}$ \\
\hline \multirow{3}{*}{ Rheumatoid arthritis } & \multirow{3}{*}{$\operatorname{PPAR} \gamma$} & \multirow{3}{*}{ Pioglitazone } & NA (34) & $\begin{array}{l}\text { - Reduced CRP and insulin resistance } \\
\text { - No effect on swollen or tender joint count and erythrocyte } \\
\text { sedimentation rate }\end{array}$ & [260] \\
\hline & & & III (143) & $\begin{array}{l}\text { - Reduced pulse wave velocity, but not brachial artery flow } \\
\text { mediated dilatation and microvascular endothelial function } \\
\text { - Reduced disease activity and CRP } \\
\text { - Improved lipid profiles }\end{array}$ & {$[261]$} \\
\hline & & & NA (49) & - Reduced disease activity and CRP & {$[262]$} \\
\hline \multirow{2}{*}{$\begin{array}{l}\text { Systemic Lupus } \\
\text { Erythematosus }\end{array}$} & \multirow[t]{2}{*}{$\operatorname{PPAR} \gamma$} & \multirow[t]{2}{*}{ Pioglitazone } & IV (30) & $\begin{array}{l}\text { - Increased HDL-cholesterol } \\
\text { - Reduced insulin, HOMA-IR, CRP, and amyloid A }\end{array}$ & {$[264]$} \\
\hline & & & I/II-ongoing (88) & - Primary endpoint: vascular function and inflammation & NCT02338999 \\
\hline $\begin{array}{l}\text { Autoimmune pulmonary } \\
\text { alveolar proteinosis }\end{array}$ & $\operatorname{PPAR} \gamma$ & Pioglitazone & I-ongoing (3) & - Primary endpoint: occurrence of adverse events & NCT03231033 \\
\hline $\begin{array}{l}\text { Diffuse cutaneous } \\
\text { systemic sclerosis }\end{array}$ & Pan-PPAR & Lanifibranor & III-completed (145) & $\begin{array}{l}\text { - Primary endpoint: measurement of skin thickness by the } \\
\text { Modified Rodnan Skin Score }\end{array}$ & NCT02503644 \\
\hline
\end{tabular}




\section{Inflammatory and Infectious Diseases}

\subsection{Malaria}

Several clinical studies also evaluated the anti-inflammatory effects of TZDs against various inflammatory and infectious diseases. In a Phase I/II study, patients with uncomplicated Plasmodium falciparum malaria receiving rosiglitazone in addition to standard anti-malaria regimens had significantly faster $50 \%$ and $90 \%$ parasite clearance times as well as a significant reduction in inflammatory responses to infection. However, serum AST or ALT levels did not improve in comparison to placebo-treated patients [265]. In contrast, adjunctive treatment with rosiglitazone in another Phase II trial was not superior to placebo in improving AST, ALT, hematocrit, hemoglobin, mean parasite density, and the median time to parasite clearance, despite its safety and well-tolerance [266]. These studies suggest that rosiglitazone is well-tolerated among malaria patients. Combining rosiglitazone with anti-malaria therapy demonstrated a certain extent of clinical efficacy to attenuate inflammatory response, but the modest effectiveness is unlikely to be translated into clinical use.

\subsection{Ulcerative Colitis}

The clinical efficacy of TZDs was also evaluated in ulcerative colitis, as measured by improvement in the quality of life and disease activity. Patients with mild to moderately active ulcerative colitis showed higher rates of clinical response and remission, and improvement in their quality of life when given rosiglitazone for 12 weeks [267]. Similarly, excellent tolerability and a significant reduction in disease activity were observed when patients with active distal ulcerative colitis were treated with rosiglitazone enema treatment [268]. Indeed, the expression of PPAR $\gamma$ was tremendously suppressed in the inflamed intestinal mucosa, whereas TZD-dependent PPAR $\gamma$ activation could exert a local anti-inflammatory effect in the gut to treat ulcerative colitis [268]. The positive results from clinical studies do support the repurposing of rosiglitazone to treat ulcerative colitis.

\subsection{Asthma}

PPAR $\gamma$ involvement in asthma exacerbation has been observed [269]. Rosiglitazone administered at $4 \mathrm{mg}$ twice daily did not improve the mean FEV1 in asthma patients challenged with allergen inhalation, but was associated with a $15 \%$ reduction in the weighted mean late asthmatic reaction and decreased inflammatory markers [270]. In contrast, pioglitazone did not show significant changes in the lung function, asthma control, airway inflammation, and quality of life in asthma patients [271-273]. In fact, the use of pioglitazone precipitated notable adverse events like increased use of short-acting $\beta 2$-agonists (SABA), fluid retention, and weight gain, rendering the three studies terminated prematurely [271-273]. As such, the lack of efficacy and significant safety concerns exclude the application of TZD for asthma treatment. Nonetheless, these studies highlighted the fact that different TZDs can display vastly different safety profiles.

\subsection{Psoriasis}

Oral administration of TZD has been reported to improve psoriasis, an inflammatory skin disorder. Based on a meta-analysis, pioglitazone was associated with a significant reduction of Psoriasis Area and Severity Index compared to placebo, but such an improvement was not observed in the rosiglitazone-treated cohort [274]. The combined therapy of pioglitazone with acitretin, a retinoid, also led to better improvement in PASI among moderate to severe plaque psoriasis, relative to acitretin therapy only [275]. Although the beneficial effect of pioglitazone is indicated, it should be noted that the conclusion was established based on limited studies, thus highlighting the necessity of further investigation. 


\subsection{Endometriosis}

In three case studies of women with endometriosis, $4 \mathrm{mg} /$ day rosiglitazone showed improvements in the severity of symptoms and pain levels with a reduction in pain medication in two of these patients, with one showing no change [276]. A follow-up trial that used pioglitazone to relieve pain and reduce cytokine levels in endometriosis was prematurely halted (NCT01184144). Evidence for the use of TZDs in endometriosis is limited and inconclusive.

\subsection{Cystic Fibrosis}

The efficacy of pioglitazone was evaluated in the treatment of cystic fibrosis. A 28-day Phase I clinical trial of $30 \mathrm{mg} /$ day pioglitazone did not show any improvement in all of the tested sputum inflammatory mediators in healthy individuals. This finding was believed to be due to the inadequate dose of pioglitazone, short duration of the study, and small sample size [277]. Two single-arm trials that recruited cystic fibrosis patients and examined the effects of pioglitazone on sputum inflammatory markers and airway inflammation have been completed (NCT00719381, NCT00322868). Even though the findings are not published, the results provided in the registered clinical trial database (NCT00322868) showed that one-month treatment with pioglitazone did not modify most of the inflammatory markers, including white cell count, neutrophil count, active elastase, TNF $\alpha$, IL-1 $\beta$, IL-6, and IL-8 in sputum specimens of treated patients. Based on existing evidence, the use of PPAR $\gamma$ agonists to modulate inflammation in cystic fibrosis is not supported.

\subsection{Other Inflammatory and Infectious Diseases}

Other inflammatory diseases that underwent clinical trials with TZDs include sepsis where pioglitazone showed a significant reduction in inflammatory markers: IL-6, IL- 8 , resistin, and TNF- $\alpha$ in patients with severe sepsis or septic shock [278], lung inflammation where Chen et al. (2018) concluded that pioglitazone had no anti-inflammatory effect in healthy volunteers based on ${ }^{18} \mathrm{~F}-\mathrm{FDG}$ PET/CT imaging [279], and chronic granulomatous disease where pioglitazone reduced CRP from 24.4 to $13.1 \mathrm{mg} / \mathrm{L}$ in a five-month old patient [280]. The efficacy of pioglitazone to treat patients with chronic granulomatous disease (NCT03080480), gastric phlogosis due to Helicobacter pylori infection (EUCTR 2005-001218-42), as well as lung inflammation in alcoholic individuals (NCT03060772) is being assessed in ongoing trials. On the other hand, in FFAME trial, fenofibrate failed to attenuate lipopolysaccharide-induced inflammation in healthy individuals [281].

Taken together, PPAR $\gamma$ agonists seem to have some implications in the treatment of certain infectious or inflammatory diseases, including malaria, ulcerative colitis, psoriasis, and septic shock (Table 10). While the successful clinical translation of PPAR $\gamma$ agonists to treat these diseases remains questionable, the anti-inflammatory activity demonstrated is likely to encourage more trials of TZDs in this aspect. Unlike PPAR $\gamma$ agonists, clinical evidence of the anti-inflammatory effect of other PPAR modulators is scarce. 
Table 10. Summary of the clinical evidence of PPAR agonists in inflammatory and infectious diseases.

\begin{tabular}{|c|c|c|c|c|c|}
\hline Disease & Target & Drug Name & Clinical Phase (Sample Size) & Main Findings/Primary Endpoint & $\begin{array}{l}\text { Reference/Clinical Trial } \\
\text { Identifier }\end{array}$ \\
\hline \multirow[b]{2}{*}{ Malaria } & \multirow[b]{2}{*}{$\operatorname{PPAR} \gamma$} & \multirow[b]{2}{*}{ Rosiglitazone } & $\mathrm{I} / \mathrm{II}(140)$ & - Enhanced parasite clearanceReduced inflammatory response & [265] \\
\hline & & & II (30) & $\begin{array}{l}\text { - Rosiglitazone was well-tolerated in children with } \\
\text { uncomplicated malaria }\end{array}$ & [266] \\
\hline \multirow{2}{*}{ Ulcerative colitis } & \multirow{2}{*}{$\operatorname{PPAR} \gamma$} & \multirow{2}{*}{ Rosiglitazone } & II (105) & $\begin{array}{l}\text { - Increased clinical response and quality of lifeMore patients on } \\
\text { rosiglitazone achieved remission }\end{array}$ & [267] \\
\hline & & & NA (14) & - Reduced disease activity scoreIncreased adipophilin level & [268] \\
\hline \multirow{4}{*}{ Asthma } & \multirow{4}{*}{$\operatorname{PPAR} \gamma$} & Rosiglitazone & I (34) & - Mild reduction of late asthmatic reaction & {$[270]$} \\
\hline & & \multirow{3}{*}{ Pioglitazone } & IV (68) & - No effect on asthma control, airway inflammation, and quality of life & [271] \\
\hline & & & II (23) & - No effect on asthma control, lung infection, and exhaled nitric oxide & [272] \\
\hline & & & NA (34) & - No effect on severe asthma & [273] \\
\hline Plaque psoriasis & $\operatorname{PPAR} \gamma$ & Pioglitazone + acitretin & II (41) & - Reduced disease severity score & [275] \\
\hline \multirow[t]{2}{*}{ Endometriosis } & \multirow[t]{2}{*}{$\operatorname{PPAR} \gamma$} & Rosiglitazone & II-terminated (3) & $\begin{array}{l}\text { - Two subjects had less severe symptoms and reduced pain. One patient } \\
\text { had no change. }\end{array}$ & [276] \\
\hline & & Pioglitazone & II and III-withdrawn (20) & - Primary endpoint: Peritoneal cytokine level & NCT01184144 \\
\hline \multirow{3}{*}{ Cystic fibrosis } & \multirow{3}{*}{$\operatorname{PPAR} \gamma$} & \multirow{3}{*}{ Pioglitazone } & NA (20) & $\begin{array}{l}\text { - Slight reduction of persistent influx of neutrophils in sputumNo effect } \\
\text { on sputum inflammatory biomarkers }\end{array}$ & [277] \\
\hline & & & I-completed (24) & $\begin{array}{l}\text { - Primary endpoint: Sputum biomarkers of lung inflammation } \\
\text { and remodeling }\end{array}$ & NCT00719381 \\
\hline & & & NA (21) & - Primary endpoint: Sputum biomarkers of lung inflammation & NCT00322868 \\
\hline Sepsis & $\operatorname{PPAR} \gamma$ & Pioglitazone & I and II (12) & $\begin{array}{l}\text { - Reduced inflammatory cytokinesPioglitazone was considered safe to } \\
\text { critically ill pediatric patients }\end{array}$ & {$[278]$} \\
\hline Lung inflammation & $\operatorname{PPAR} \gamma$ & Pioglitazone & I (18) & - No effect on endotoxin-induced lung inflammation & [279] \\
\hline $\begin{array}{l}\text { Lung inflammation due to } \\
\text { alcoholism }\end{array}$ & $\operatorname{PPAR} \gamma$ & Pioglitazone & II-ongoing (36) & - Primary endpoint: change in phagocytic index of alveolar macrophage & NCT03060772 \\
\hline Chronic granulomatous & $\operatorname{PPAR} \gamma$ & Pioglitazone & I and II-ongoing (100) & $\begin{array}{l}\text { - Primary endpoint: frequency of infections; functional reconstitution of } \\
\text { the NADPH oxidase in circulating cells of the peripheral blood }\end{array}$ & NCT03080480 \\
\hline $\begin{array}{l}\text { Gastric phlogosis due to } H \text {. } \\
\text { pylori infection }\end{array}$ & $\operatorname{PPAR} \gamma$ & Pioglitazone & III-ongoing (80) & - NA & EUCTR 2005-001218-42 \\
\hline Induced endotoxemia & PPAR $\alpha$ & Fenofibrate & NA (36) & - No effect on cytokines, chemokines, and acute-phase proteins & [281] \\
\hline
\end{tabular}




\section{Malignancy}

\subsection{Head and Neck Squamous Cell Carcinoma (HNSCC)}

The aggressive nature of head and neck squamous cell carcinoma (HNSCC) demands better therapeutic options beyond current treatment paradigms. As candidates in the fervent search, pioglitazone and rosiglitazone have been incorporated for the prevention of HNSCC by targeting leukoplakia, which is a precancerous lesion that may develop into squamous cell carcinoma. Currently, two trials have been completed with regards to pioglitazone as monotherapy for HNSCC. In a Phase II trial, 71\% of the subjects with either hyperplastic, dysplastic, or oropharyngeal leukoplakia had a partial response to pioglitazone therapy as characterized by disappearance or reduction of lesions, dysplasia, or hyperplasia [282]. A follow-up trial then demonstrated a superior effect of pioglitazone to placebo (46\% vs. 32\%) despite being terminated early due to slow accrual of patients (NCT00951379). The effectiveness of rosiglitazone on oral leukoplakia was also tested in another study (NCT00369174), but the findings were not released. Additionally, a Phase II clinical trial (NCT02917629) testing the efficacy of pioglitazone on stage I-IV oral cavity or oropharynx cancer is currently actively recruiting. Despite promising results from the completed trials, the scale in these trials may be deemed too small to conclude on the potential of pioglitazone for HNSCC. Larger trials are necessary to draw a conclusion about the clinical advantages of pioglitazone and rosiglitazone in oral leukoplakia and HNSCC.

\subsection{Thyroid Cancer}

Efatutazone (also known as CS-7017 and RS5444), a PPAR $\gamma$ agonist developed by Daiichi Sankyo, has been clinically assessed in anaplastic thyroid carcinoma. The results of a Phase I/II study showed that the adjunct therapy of efatutazone to paclitaxel significantly slowed down disease progression and survival duration in a dose-dependent manner [283]. This promising results led to an ongoing a Phase II study that further investigates the impacts of efatutazone in anaplastic thyroid carcinoma progression (NCT02152137). A small portion of thyroid carcinomas carries an oncogenic paired box 8 (PAX8) and PPAR $\gamma$ fusion protein. In a thyroid cancer patient with such mutation, pioglitazone for 6 months shrank an acetabulum metastatic lesion $(6$ to $3.9 \mathrm{~cm}$ ) and lowered thyroglobulin by 97\% [284]. The benefits were observed even after pioglitazone treatment has ceased for 13 months. While a meaningful conclusion about the efficacy of pioglitazone cannot be drawn from a single case study, the positive result does support follow-up investigations of the PPAR $\gamma$ agonist in this subset of thyroid cancer patients. Rosiglitazone was also assessed for patients with thyroglobulin-positive and radioiodine-negative differentiated thyroid cancer. Five out of 20 subjects given rosiglitazone had a partial treatment response as exemplified by the increased radioiodine uptake while the rest had stable or continual disease progression [285]. No subject had a complete or partial response to rosiglitazone at three month follow-up [285]. It was, therefore, concluded that rosiglitazone is unable to halt the progression of differentiated thyroid cancer.

\subsection{Lung Cancer}

Efatutazone was also tested on non-small cell lung carcinoma (NSCLC) as adjuvant therapy to antineoplastic agents. A Phase I trial showed that a combined therapy of efatutazone, paclitaxel, and carboplatin induced partial responses in 37.5\% (six out of 16) subjects with either metastatic or unresectable NSCLC [286]. A Phase II trial that examined the safety and effectiveness of the combined therapy on progression-free survival in metastatic NSCLC has been completed, but no data has been released (NCT00806286). Likewise, a combined therapy of efatutazone and erlotinib conferred partial responses in 36\% (five out of 14) of the subjects with NSCLC [287]. This was also followed up with a Phase II trial (NCT01101334). Clinical development of efatutazone for NSCLC has been terminated, and the result of the trial was not published. Other PPAR $\gamma$ agonists were also identified for subsequent trials. Pioglitazone was trialed both as a preventive measure and a curative agent. Wigle et al. [288] and Keith et al. [289] examined pioglitazone as a chemoprevention mean for lung carcinoma among 
high-risk smokers or early-stage NSCLC patients. The results revealed reduced cancer cell proliferation with pioglitazone treatment. While the efficacy of PPAR $\gamma$ agonists for NSCLC remains inconclusive, another ongoing study (NCT02852083) may provide an additional perspective for pioglitazone in addressing NSCLC.

\subsection{Colorectal Cancer}

Efatutazone showed some promising results in two clinical trials for colorectal cancer. Subjects who responded to first-line chemotherapy had longer progression-free survival and a higher overall survival rate (NCT00986440). Adjunct therapy of efatutazone to the FOLFIRI chemotherapy regimen (NCT00967616) only achieved a modest improvement in progression-free survival duration [290]. The developing company Daiichi Sankyo has discontinued any further trials on efatutazone against colorectal cancer.

\subsection{Prostate Cancer}

PPAR $\gamma$ agonists as a monotherapy for maintenance therapy was studied during prostate cancer remission. Rosiglitazone did not delay disease progression [291]. A Phase II clinical study in patients with advanced prostate cancer using troglitazone revealed an unexpected prolong stabilization of prostate-specific antigens [292]. This observation suggests that PPAR $\gamma$ may serve as a biological modifier in human prostate cancer. A combined therapy consisting of pioglitazone, imatinib, etoricoxib, dexamethasone, and low-dose treosulfan were evaluated in patients with castration-resistant prostate cancer and found that 23 out of 61 subjects responded to the regimen with mean prostate-specific antigen decreasing by $97 \%$ [293]. Another clinical trial also tested a combined therapy with PPAR $\gamma$ agonist (rosiglitazone/pioglitazone), fenofibrate, and calcitriol in castration-resistant prostate cancer, but was terminated early due to low accrual (EUCTR 2006-001398-44). TZDs may be beneficial to a specific subtype of prostate cancer, and their therapeutic potential in this disease should be further investigated.

\subsection{Blood Cancer (Leukemia, Lymphoma, Myeloma)}

The toxicity and ineffectiveness of many chemotherapeutic drugs require the continued search for better and safer therapeutic drugs. Numerous preclinical trials have highlighted the anticancer potential of many PPAR agonists. A small clinical study reported that the combinational therapy of bezafibrate and medroxyprogesterone acetate has minimal hematological toxicity and a decent treatment effect in acute myeloid leukemia (AML) patients who were not suitable for intensive chemotherapy [294]. Interestingly, the same benefits were no longer observed with the same regime at higher dosage [295]. Pioglitazone is being assessed for AML as a combined therapy with low-dose azacitidine and all-trans-retinoic acid (NCT02942758).

Current trials of PPAR $\gamma$ agonists on chronic myeloid leukemia (CML) often act as a curative add-on to tyrosine kinase inhibitors, which are effective in refractory CML. A few trials have been initiated to study pioglitazone with various tyrosine kinase inhibitors, but their findings remain unknown. The majority of the trials are either at an early stage of recruitment (NCT02767063, NCT02889003), ongoing (NCT02852486), terminated (NCT02730195), or of unknown status (NCT02687425). In a completed Phase II trial, pioglitazone with imatinib malate resulted in long-term suppression of BCR-ABL1 expression in most of the CML patients [296].

A 16-week open label study on cutaneous T-cell lymphoma, using combinational therapy of bexarotene and rosiglitazone in four subjects, showed a reduction in skin scores of scaling in two patients and amelioration of pruritus in three of four subjects [297]. Another clinical trial assessed the feasibility of bezafibrate with medroxyprogesterone acetate as therapeutics for endemic Burkitt's lymphoma, a disease which is associated with chronic malaria. The disease progression and clinical response followed a dose-dependent trend, indicating good efficacy of the combined therapy [298]. The positive results should be validated in larger RCTs to determine its benefits in endemic Burkitt's lymphoma. 
Several PPAR agonists have also been trialed in multiple myeloma patients, including fenofibrate (NCT01965834), efatutazone (NCT01504490), and pioglitazone (EUCTR 2008-002768-32; NCT0101243). The first two of which were terminated early for unclear reasons whereas those that involve pioglitazone are ongoing.

\subsection{Skin Cancer}

Tumor promoting inflammation is a hallmark of cancer. Controlling such inflammatory processes may aid in prolonging progression-free survival in patients with metastatic melanoma. Hart et al. (2016) combined pioglitazone, etoricoxib, low-dose trofosfamide, and temsirolimus for stage IV melanoma, and concluded that the combined therapy could potentially prolong progression-free survival duration [299]. Independently, pioglitazone with rofecoxib in conjunction with low-dose chemotherapy in metastatic melanoma also reached a similar conclusion [300], suggesting that multi-modal therapy that includes PPAR $\gamma$ agonists benefits melanoma patients. Currently, a Phase II clinical trial testing the efficacy of pioglitazone as a monotherapy for skin squamous cell carcinoma is recruiting participants (NCT02347813).

\subsection{Liposarcoma}

PPAR $\gamma$ agonists have been considered as agents for differentiation therapy in liposarcoma [301]. Thus far, mixed clinical results have been reported. In a small pilot study on liposarcoma, troglitazone markedly increased lipid accumulation in the tumor biopsies besides promoting adipocyte differentiation and attenuating tumor cell proliferation [302]. Troglitazone has completed a Phase II study on advanced or metastatic liposarcoma (NCT00003058), but no result is available. In contrast, rosiglitazone did not induce notable histological and clinical response in liposarcoma patients [303]. Another Phase II trial on the effectiveness of rosiglitazone in liposarcoma has been conducted, but no data was released. Overall, sparse findings support the use of TZDs as differentiation therapy in liposarcoma.

\subsection{Breast Cancer}

In refractory breast cancer, troglitazone failed to improve disease progression [304]. A lack of effect was observed in breast cancer patients given short-term rosiglitazone treatment (2-6 weeks). Based on these results, PPAR $\gamma$ agonists have little clinical value in breast cancer therapy [305].

\subsection{Brain Cancer}

Currently, there is limited clinical evidence that supports the use of PPAR agonists against brain-related malignancies. Many clinical trials are still ongoing. One Phase II pilot trial studied rosiglitazone on acromegaly of both macroadenoma and microadenoma in five subjects. Following rosiglitazone treatment ( $20 \mathrm{mg} /$ day), serum insulin-like growth factor- 1 decreased significantly, attributed to inhibition of growth hormone-dependent hepatic synthesis, despite no significant difference in serum growth hormone levels [306]. Two other clinical trials (NCT00612066, NCT00616642) on identifying the potential of rosiglitazone on pituitary tumors had terminated while one is ongoing (NCT03309319). A Phase II clinical trial (NCT01356290) targeting medulloblastoma in children is also currently underway. The primary aim is to evaluate a multidrug anti-angiogenic regimen, which includes fenofibric acid, for medulloblastoma. Minimal conclusions can be derived due to limited clinical data on PPAR agonists for brain-related tumor.

\subsection{Recurrent/Progressive/Metastatic Cancer}

In some clinical trials, PPAR agonists were tested on patients with recurrent or metastatic cancers of different natures. For instance, Robison et al. (2014) employed a multi-drug oral regimen (thalidomide, fenofibrate, celecoxib, low dose of etoposide, and cyclophosphamide) in pediatric 
patients with varying carcinomas, namely high-grade glioma, ependymoma, low-grade glioma, bone tumors, medulloblastoma/primitive neuroectodermal tumor, leukemia, neuroblastoma, and miscellaneous tumors [307]. Only selected cancers like ependymoma and low-grade glioma yielded favorable treatment response [307]. Two other trials that involved multiple carcinoma strata and used pioglitazone (NCT02133625) and efatutazone (NCT00408434) were completed. The former has no published data, whereas the latter showed one patient (with liposarcoma) had sustained partial response, and 12 patients had stable disease out of the 31 recruited subjects [308]. While the trials showed positive results, multi-modal anti-cancer regimens containing PPAR agonists do not appear remarkably effective against recurrent or advanced cancers. The clinical outcomes of different PPAR agonists in various malignancies are summarized in Table 11.

Table 11. Summary of the clinical evidence of PPAR agonists in malignancies.

\begin{tabular}{|c|c|c|c|c|c|}
\hline Disease & Target & Drug Name & $\begin{array}{l}\text { Clinical Phase } \\
\text { (Sample Size) }\end{array}$ & Main Findings/Primary Endpoint & $\begin{array}{l}\text { Reference/Clinical } \\
\text { Trial Identifier }\end{array}$ \\
\hline \multirow{3}{*}{$\begin{array}{l}\text { Cushing's disease/ } \\
\text { Pituitary tumors }\end{array}$} & \multirow{3}{*}{$\operatorname{PPAR} \gamma$} & \multirow{3}{*}{$\begin{array}{l}\text { Rosiglitazone } \\
\text { Rosiglitazone }\end{array}$} & II-terminated (2) & $\begin{array}{l}\text { - Primary endpoint: Number of } \\
\text { treatment responders }\end{array}$ & NCT00612066 \\
\hline & & & II-terminated (1) & $\begin{array}{l}\text { Primary endpoint: Efficacy of rosiglitazone } \\
\text { maleate on Cushing disease }\end{array}$ & NCT00616642 \\
\hline & & & NA-ongoing (24) & $\begin{array}{l}\text { Primary endpoint: Levels of growth hormone, } \\
\text { insulin-like-factor } 1 \text { (IGF-1), and tumor volume }\end{array}$ & NCT03309319 \\
\hline Medullablastoma & $\operatorname{PPAR} \alpha$ & Fenofibrate & II-ongoing (40) & - Primary endpoint: Response rate & NCT01356290 \\
\hline \multirow{3}{*}{ Oral leukoplakia } & \multirow{3}{*}{$\operatorname{PPAR} \gamma$} & \multirow{2}{*}{ Pioglitazone } & II (44) & $\begin{array}{l}\text { Induced clinical and/or histologic response in } \\
15 \text { of } 21 \text { subjects }\end{array}$ & [282] \\
\hline & & & II-terminated (52) & $\begin{array}{l}\text { Primary endpoint: Histologic response and } \\
\text { clinical response }\end{array}$ & NCT00951379 \\
\hline & & Rosiglitazone & II-completed (25) & $\begin{array}{l}\text { - Primary endpoint: Proportion of subjects with } \\
\text { complete or partial response in either clinical or } \\
\text { histological outcomes }\end{array}$ & NCT00369174 \\
\hline $\begin{array}{l}\text { Oral Cavity / } \\
\text { Oropharngeal cancer }\end{array}$ & $\operatorname{PPAR} \gamma$ & Pioglitazone & II-terminated (39) & $\begin{array}{l}\text { - Primary endpoint: Absolute change in } \\
\text { proliferation index (Ki-67) expression }\end{array}$ & NCT02917629 \\
\hline \multirow[t]{2}{*}{$\begin{array}{l}\text { Anaplastic thyroid } \\
\text { carcinoma }\end{array}$} & \multirow[t]{2}{*}{$\operatorname{PPAR} \gamma$} & \multirow[t]{2}{*}{$\begin{array}{l}\text { Efatutazone/ } \\
\text { CS-7017 }\end{array}$} & I (15) & $\begin{array}{l}\text { Dose-dependently increased median time to } \\
\text { disease progression and survival duration } \\
\text { Increased ANGPTL4 levels and } \\
\text { plasma adiponectin }\end{array}$ & [283] \\
\hline & & & II-ongoing (19) & - Primary endpoint: Response rate & NCT02152137 \\
\hline $\begin{array}{l}\text { PAX8-PPAR } \gamma \\
\text { anaplastic thyroid } \\
\text { carcinoma }\end{array}$ & $\operatorname{PPAR} \gamma$ & Pioglitazone & II (1) & $\begin{array}{l}\text { - Reduced acetabular soft tissue metastasis, } \\
\text { thyroglobulin, and severe pain upon } \\
\text { weight bearing }\end{array}$ & [284] \\
\hline $\begin{array}{l}\text { Differentiated } \\
\text { thyroid carcinoma }\end{array}$ & $\operatorname{PPAR} \gamma$ & Rosiglitazone & II (20) & $\begin{array}{l}\text { - Five partial responders, three stable disease } \\
\text { and } 12 \text { progressive disease } \\
\text { - No complete or partial responders }\end{array}$ & [285] \\
\hline \multirow{7}{*}{$\begin{array}{l}\text { Non-small cell lung } \\
\text { carcinoma }\end{array}$} & \multirow{7}{*}{$\operatorname{PPAR} \gamma$} & \multirow{4}{*}{$\begin{array}{l}\text { Efatutazone/ } \\
\text { CS-7017 }\end{array}$} & I (16) & $\begin{array}{l}\text { - Six patients showed partial response, four with } \\
\text { stable disease and six with progressive disease } \\
\text { - Well-tolerated }\end{array}$ & [286] \\
\hline & & & II-completed (111) & $\begin{array}{l}\text { - Primary endpoint: Progression-free } \\
\text { survival rate }\end{array}$ & NCT00806286 \\
\hline & & & I (14) & $\begin{array}{l}\text { - Five patients with partial response, four with } \\
\text { stable disease, six with progressive disease } \\
\text { - Dose-dependently increased of } \\
\text { adiponectin level }\end{array}$ & [287] \\
\hline & & & II-completed (90) & $\begin{array}{l}\text { - Primary endpoint: Proportion of subjects with } \\
\text { progression free survival }\end{array}$ & NCT01101334 \\
\hline & & \multirow[t]{3}{*}{ Pioglitazone } & II (6) & $\begin{array}{l}\text { - Reduced proliferation, inflammatory and } \\
\text { B-cell survival pathway gene expression } \\
\text { - Upregulated complement activation and } \\
\text { chemokine signaling gene expression }\end{array}$ & [288] \\
\hline & & & II (92) & $\begin{array}{l}\text { - No difference in treatment effect } \\
\text { - Decreased cellular proliferation }\end{array}$ & [289] \\
\hline & & & II-ongoing (86) & - Primary endpoint: Progression-free survival & NCT02852083 \\
\hline
\end{tabular}


Table 11. Cont.

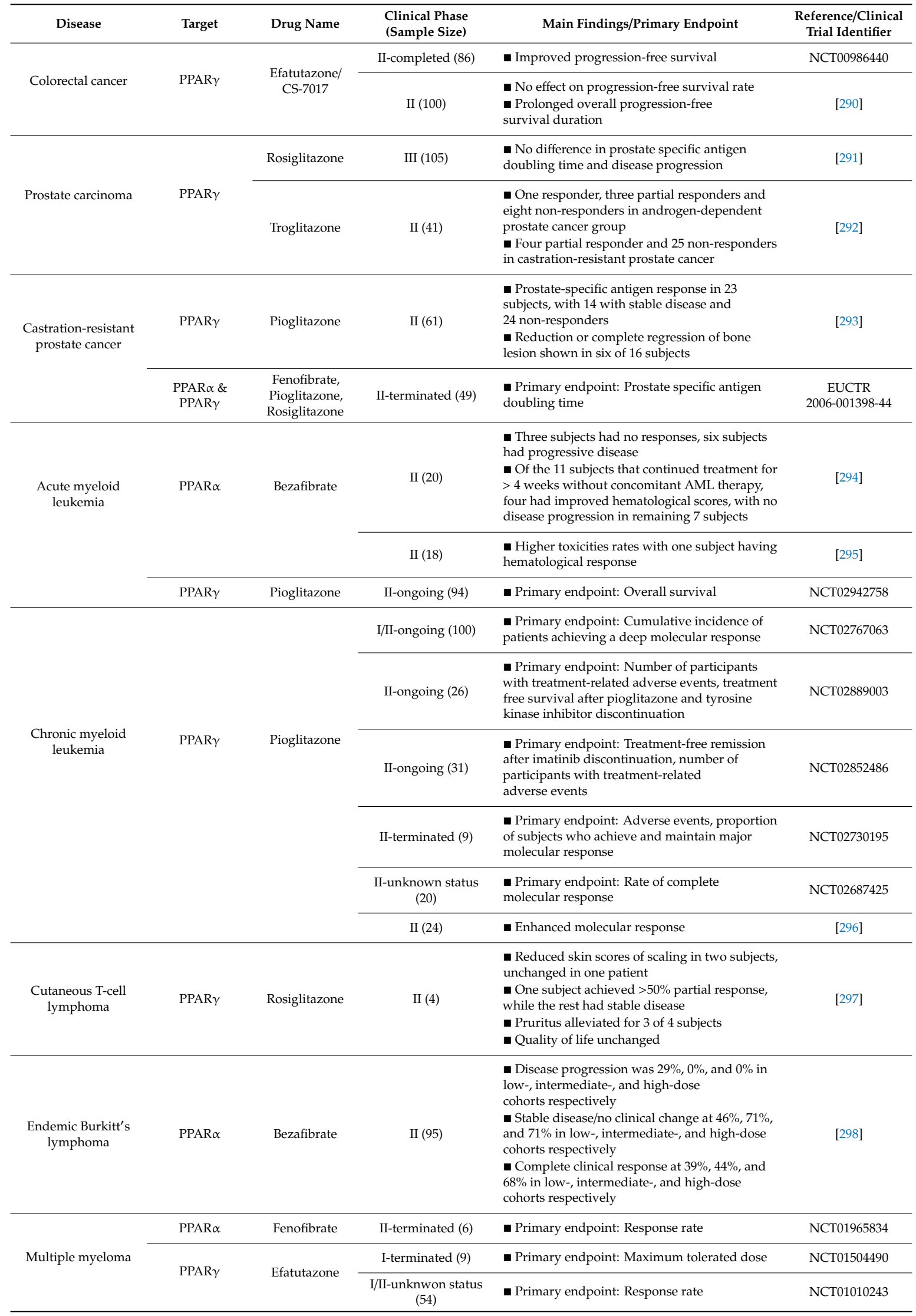


Table 11. Cont.

\begin{tabular}{|c|c|c|c|c|c|}
\hline Disease & Target & Drug Name & $\begin{array}{l}\text { Clinical Phase } \\
\text { (Sample Size) }\end{array}$ & Main Findings/Primary Endpoint & $\begin{array}{l}\text { Reference/Clinical } \\
\text { Trial Identifier }\end{array}$ \\
\hline Melanoma & $\operatorname{PPAR} \gamma$ & Pioglitazone & $\mathrm{I}(6)$ & $\begin{array}{l}\text { - Progression-free survival ranged from } \\
4-13 \text { months } \\
\text { - Four patients with stable disease, one with } \\
\text { mixed response with no objective response in } \\
\text { radiation field, and one partial responder } \\
\text { - Steep decline of melanoma inhibitory activity } \\
\text { and improvement of oncological scores in one } \\
\text { subject with stable disease } \\
\text { - Longer progression-free survival in two } \\
\text { subjects with extensive metastatic liver }\end{array}$ & [299] \\
\hline $\begin{array}{l}\text { Melanoma/Soft } \\
\text { Tissue Sarcoma }\end{array}$ & $\operatorname{PPAR} \gamma$ & Pioglitazone & II (40) & $\begin{array}{l}\text { - Objective response at } 11 \% \text { and disease } \\
\text { stabilization }>6 \text { months at } 11 \% \text { for } \\
\text { melanoma subjects } \\
\text { - Objective response at } 19 \% \text { and disease } \\
\text { stabilization }>6 \text { months at } 14 \% \text { for soft-tissue } \\
\text { sarcoma subjects } \\
\text { - Complete remission in one melanoma subject } \\
\text { and three sarcoma subjects } \\
\text { - Subjects with normal C-reactive protein levels } \\
\text { and subjects with C-reactive levels that } \\
\text { decreased by }>30 \% \text { had prolonged } \\
\text { progression-free survival }\end{array}$ & [300] \\
\hline $\begin{array}{l}\text { Skin squamous cell } \\
\text { carcinoma }\end{array}$ & $\operatorname{PPAR} \gamma$ & Pioglitazone & II-ongoing (40) & $\begin{array}{l}\text { - Primary endpoint: Number of squamous } \\
\text { cell carcinomas }\end{array}$ & NCT02347813 \\
\hline \multirow{3}{*}{ Liposarcoma } & \multirow{3}{*}{$\operatorname{PPAR} \gamma$} & \multirow[t]{2}{*}{ Troglitazone } & II (3) & $\begin{array}{l}\text { Induced intracellular lipid accumulation and } \\
\text { increased expression levels of PPAR } \gamma \text { mRNA }\end{array}$ & [302] \\
\hline & & & II-completed (85) & - NA & NCT00003058 \\
\hline & & Rosiglitazone & II (12) & $\begin{array}{l}\text { Did not induce redifferentiation, reduced } \\
\text { proliferation, and upregulation of PPAR } \gamma, \\
\text { adipsin, and fatty acid binding protein genes }\end{array}$ & [303] \\
\hline $\begin{array}{l}\text { Refractory breast } \\
\text { cancer }\end{array}$ & $\operatorname{PPAR} \gamma$ & Troglitazone & II (22) & - Three patients with stable disease & [304] \\
\hline Breast cancer & $\operatorname{PPAR} \gamma$ & Pioglitazone & I/II (38) & $\begin{array}{l}\text { - No difference in Ki- } 67 \text { expression and } \\
\text { PPAR } \gamma \text { expression } \\
\text { - Improved adiponectin and insulin sensitivity }\end{array}$ & [305] \\
\hline $\begin{array}{l}\text { Acromegaly } \\
\text { (macroadenoma and } \\
\text { microadenoma) }\end{array}$ & $\operatorname{PPAR} \gamma$ & Rosiglitazone & II (5) & $\begin{array}{l}\text { Decreased serum IGF- } 1 \text { at higher dosage of } \\
\text { rosiglitazone ( } 20 \mathrm{mg} / \text { day) } \\
\text { - No change to growth hormone levels }\end{array}$ & [306] \\
\hline $\begin{array}{l}\text { Progressive pediatric } \\
\text { malignancies }\end{array}$ & $\operatorname{PPAR} \alpha$ & Fenofibrate & II (101) & $\begin{array}{l}\text { - Well-tolerance of antiangiogenic } \\
\text { multi-drug treatment } \\
\text { - Induced partial response and stable disease in } \\
\text { ependymoma and low-grade glioma } \\
\text { - Favorable response in miscellaneous central } \\
\text { nervous system (CNS) and non-CNS tumors, } \\
\text { with nine of } 18 \text { having stable disease and five of } \\
18 \text { having partial response } \\
\text { - Increased serum TSP-1 }\end{array}$ & [307] \\
\hline \multirow{2}{*}{$\begin{array}{l}\text { Advanced or } \\
\text { metastatic solid } \\
\text { tumors }\end{array}$} & \multirow[b]{2}{*}{$\operatorname{PPAR} \gamma$} & Pioglitazone & I-completed (28) & $\begin{array}{l}\text { - Primary endpoint: Maximum tolerated dose of } \\
\text { pioglitazone and carboplatin }\end{array}$ & NCT02133625 \\
\hline & & $\begin{array}{l}\text { Efatutazone/ } \\
\text { CS-7017 }\end{array}$ & I (32) & $\begin{array}{l}\text { - Induced sustained partial response in one } \\
\text { patient with myxoid liposarcoma } \\
\text { - Twelve of } 32 \text { patients had stable disease, with } \\
\text { seven of } 12 \text { having a } \geq 81 \text { days stable disease } \\
\text { - Well-tolerated }\end{array}$ & [308] \\
\hline
\end{tabular}

\section{Other Diseases}

\subsection{Polycystic Ovarian Syndrome}

Polycystic ovarian syndrome (PCOS) is an endocrine disorder that may lead to infertility in females. It is closely linked to chronic diseases like obesity, T2DM, and CVD. In PCOS patients, PPAR $\gamma$ agonists improve insulin sensitivity, hyperinsulinemia, glycemic control, and cardiovascular risk factors like lipid profiles and adiponectin level, but did not affect body weight and body mass index [309-313]. Importantly, pioglitazone also led to favorable changes in hirsutism, hyperandrogenism, and pregnancy occurrence $[314,315]$. The overall efficacy of TZDs on hormonal and metabolic dysregulation in PCOS 
females is comparable to metformin [316]. The combined therapy of pioglitazone, metformin with either selective estrogen receptor modulator (clomifene citrate), aromatase inhibitor (letrozole) or antiandrogen (flutamide) also promoted ovulation and lowered excess androgen [317,318]. Although existing studies suffered from small cohort size and short follow-up duration, they suggest that the use of PPAR $\gamma$ agonists can confer promising clinical outcomes in PCOS patients. Clinical trials with larger cohort sizes over a longer term are warranted to elaborate long-term benefits of pioglitazone in PCOS, especially on fertility and pregnancy risk.

\subsection{Muscular Disorders}

Several clinical trials were initiated to explore the clinical prospect of bezafibrate on mitochondrial function in myopathy caused by mitochondrial disorder or neutral lipid storage disease (NCT02398201; EUCTR 2012-002692; NCT01527318). Case studies on two patients with neutral lipid storage disease with myopathy supported the beneficial effects of bezafibrate on tissue lipid accumulation, mitochondrial function, and lipid oxidation, but not on skeletal muscle strength [319]. Additionally, the therapeutic effects of pioglitazone and HPP593 (PPAR $\beta / \delta$ agonist) were also tested in sporadic inclusion body myositis (NCT03440034 and NCT01524406), respectively. While the outcomes from the above trials are not yet available, the findings should shed some light on the safety and clinical efficacy of PPAR agonists in muscular disorders.

\subsection{Burn Injury}

The roles of nuclear receptors are well-implicated in the keratinocyte differentiation and pathological changes of the skin [320]. Conceivably, PPARs, which are members of nuclear receptors, will have unique impact in dermatological conditions. In patients with severe burn injury, a hypermetabolic response, as characterized by elevated cortisol, cytokines, catecholamines, basal energy expenditure, and impaired glucose metabolism, is a common manifestation which can persist up to two years after recovery [321]. Burn patients with hypermetabolism and poor glycemic control had a higher incidence of mortality, infections, and sepsis, but could be rescued with good glucose control [322]. In a Phase II RCT that enrolled pediatric patients with severe burn injury $(n=18)$, fenofibrate significantly improved insulin sensitivity and mitochondrial function [323]. Another larger clinical trial $(n=330)$ is currently on-going to verify the clinical outcomes of fenofibrate as a therapeutic option in thermally-injured patients (NCT02452255).

\subsection{Miscellaneous Health Conditions}

In a proof-of-concept clinical study, fenofibrate showed positive effects in obstructive sleep apnea by decreasing the frequency of oxygen desaturation, apnea, and non-cortical micro-awakenings per hours [324]. Such benefits were not observed with pioglitazone in obstructive sleep apnea, emphasizing the distinct role of each PPAR members [325]. Clinical trials are ongoing for unanticipated diseases, such as sexual dysfunction (NCT00923676) and Huntington's disease (NCT03515213) using fenofibrate. The trial using rosiglitazone to lower the asymmetric dimethylarginine level in critically ill patients revealed no superiority over placebo [326]. The clinical outcomes of different PPAR agonists in PCOS, muscular disorders, burn injury, and other miscellaneous health complications are summarized in Table 12. It is conceivable that many future trials using PPAR agonists (single, dual, and pan) on other diseases will emerge, which further draw attention to the yet undiscovered potential of PPARs. 
Table 12. Summary of the clinical evidence of PPAR agonists in other health complications.

\begin{tabular}{|c|c|c|c|c|c|}
\hline Disease & Target & Drug Name & $\begin{array}{l}\text { Clinical Phase (Sample } \\
\text { Size) }\end{array}$ & Main Findings/Primary Endpoint & $\begin{array}{l}\text { Reference/Clinical Trial } \\
\text { Identifier }\end{array}$ \\
\hline \multirow{4}{*}{ PCOS } & \multirow{4}{*}{$\operatorname{PPAR} \gamma$} & \multirow[t]{2}{*}{ Pioglitazone } & NA (52) & $\begin{array}{l}\text { - Increased body weight, BMI and waist-to-hip ratio } \\
\text { - Increased insulin sensitivity } \\
\text { - Reduced hirsutism, free testoterone, and androstenedione } \\
\text { - Increased pregnancy rate }\end{array}$ & [314] \\
\hline & & & NA (30) & $\begin{array}{l}\text { - Increased insulin sensitivity } \\
\text { - Reduced free androgen index }\end{array}$ & [315] \\
\hline & & $\begin{array}{l}\text { Pioglitazone + flutamide + } \\
\text { metformin }\end{array}$ & NA (34) & $\begin{array}{l}\text { - Reduced androgen } \\
\text { - Improved lipid and glycemic control }\end{array}$ & [317] \\
\hline & & $\begin{array}{l}\text { Pioglitazone + metformin } \\
+ \text { letrozole }\end{array}$ & $\mathrm{I}(50)$ & - Increased ovulation and pregnancy rate & [318] \\
\hline \multirow{3}{*}{$\begin{array}{l}\text { Mitochondrial dysfunction and } \\
\text { myopathy }\end{array}$} & \multirow{3}{*}{ PPAR $\alpha$} & \multirow{3}{*}{ Bezafibrate } & II-completed (6) & - Primary endpoint: respiratory chain enzyme activity & NCT02398201 \\
\hline & & & II-ongoing (24) & $\begin{array}{l}\text { - Primary endpoint: Time interval until a predefined decline in muscle } \\
\text { performance based on walking test }\end{array}$ & EUCTR 2012-002692 \\
\hline & & & NA (2) & $\begin{array}{l}\text { - Reduced cardiac and muscle fat deposition } \\
\text { - Increased fat oxidation }\end{array}$ & [319] \\
\hline $\begin{array}{l}\text { Neutral Lipid Storage Disease } \\
\text { With Myopathy }\end{array}$ & PPAR $\alpha$ & Bezafibrate & IV-completed (6) & $\begin{array}{l}\text { - Primary endpoints: Mitochondrial function, muscular lipid } \\
\text { accumulation, and cardiac function }\end{array}$ & NCT01527318 \\
\hline \multirow{2}{*}{$\begin{array}{l}\text { Sporadic inclusion body } \\
\text { myositis }\end{array}$} & PPAR $\gamma$ & Pioglitazone & I -ongoing (15) & $\begin{array}{l}\text { - Primary endpoint: Peroxisome proliferator-activated receptor gamma } \\
\text { coactivator 1-alpha target gene expression }\end{array}$ & NCT03440034 \\
\hline & $\operatorname{PPAR} \beta / \delta$ & HPP593 & I -terminated (24) & - Primary endpoint: Number and severity of adverse events & NCT01524406 \\
\hline \multirow[t]{2}{*}{ Burn injury } & \multirow[t]{2}{*}{$\operatorname{PPAR} \alpha$} & \multirow[t]{2}{*}{ Fenofibrate } & II (21) & $\begin{array}{l}\text { - Increased glucose uptake, insulin signaling and mitochondrial } \\
\text { glucose oxidation }\end{array}$ & [323] \\
\hline & & & II \& III-ongoing (330) & - Primary endpoint: Glucose metabolism & NCT02452255 \\
\hline \multirow[t]{2}{*}{ Obstructive sleep apnea } & PPAR $\alpha$ & Fenofibrate & II (34) & $\begin{array}{l}\text { - Increased oxygen saturation during sleep } \\
\text { - Reduced obstructive apneas and non-cortical micro-awakenings } \\
\text { per hour }\end{array}$ & [324] \\
\hline & $\operatorname{PPAR} \gamma$ & Pioglitazone & NA (45) & - No effect in quantitative and qualitative sleep measurements & [325] \\
\hline Sexual dysfunction & PPAR $\alpha$ & Fenofibrate & IV-unknown (300) & $\begin{array}{l}\text { - Primary endpoint: International index of erectile dysfunction (IIEF) in } \\
\text { men and Female sexual function index (FSFI) in women }\end{array}$ & NCT00923676 \\
\hline Huntington's disease & PPAR $\alpha$ & Fenofibrate & II-ongoing (20) & $\begin{array}{l}\text { - Primary endpoint: Change in peroxisome proliferator-activated } \\
\text { receptor gamma coactivator 1-alpha }\end{array}$ & NCT03515213 \\
\hline Critically ill patients & $\operatorname{PPAR} \gamma$ & Rosiglitazone & NA (12) & - No effect on asymmetric dimethylarginine in critically ill patients & [326] \\
\hline
\end{tabular}




\section{Clinical Prospects of PPAR Agonists and Antagonists}

In this review, we attempt to consolidate the clinical evidence from past and ongoing trials featuring PPAR modulators. Although the evidence presented herein is by no means exhaustive, it is undeniable that the clinical implications of PPAR agonists span a wide range of health conditions, ranging from metabolic diseases, chronic inflammatory diseases, infections, autoimmune diseases, neurological, and psychiatric disorders, malignancies, etc. Such an extensive implication of PPAR agonists also signifies the crucial modulatory roles of PPARs in diseases with varying pathogeneses. Coupled with the desirable agonistic effect and safety profile of various PPAR agonists, PPARs are undoubtedly one of the most alluring targets in the medical field.

Based on existing clinical evidence, metabolic and endocrine diseases like T2DM, CVD, dyslipidemia, and MetS remain the mainstay of PPAR clinical research. Given the superior efficacy and high selectivity, pemafibrate is expected to overtake conventional PPAR $\alpha$ agonists, in particular, fenofibrate, as the primary fibrate-based lipid-lowering drug in the treatment of dyslipidemia and CVD. Pioglitazone, but not rosiglitazone, will continue to be an important PPAR $\gamma$ agonist for T2DM and CVD prophylaxis among diabetic patients. Despite the setbacks of muraglitazar, tesaglitazar, and aleglitazar, the development of dual- and pan-PPAR agonists in metabolic diseases is gradually gaining momentum, as exemplified by chiglitazar (for T2DM), saroglitazar (for dyslipidemia), and elafibronor (for dyslipidemia). We eagerly await the outcomes of ongoing trials featuring these drugs.

Liver diseases, like NAFLD and PBC, are where dual- and pan-PPAR agonists truly shine. Currently, saroglitazar and elafibranor are in Phase III, whereas lanifibranor is in Phase II for NAFLD. All three drugs show promising results and satisfactory safety profile. Concurrently, elafibranor and saroglitazar are also in the clinical pipeline of PBC. Another drug candidate for PBC is bezafibrate, which is also known to have pan-PPAR agonistic properties. Conceivably, dual- and pan-PPAR agonists are likely to revolutionize the therapeutic paradigm of NAFLD, NASH, and PBC in the future. The feasibility of dual- and pan-PPAR agonists in NAFLD also highlight the potential implications of these drugs in the progression of organ dysfunction caused by ectopic fat deposition in the pancreas, kidneys, and heart.

Pioglitazone is one of, if not the most extensively trialed PPAR agonists. Existing evidence favors the clinical application of pioglitazone in NAFLD, CKD, depressive symptoms, selected autoimmune, and inflammatory diseases, in additional to T2DM and MetS which pioglitazone always thrives in. With the positive efficacy of pioglitazone in these diseases, its clinical utility will likely extend beyond being just an insulin sensitizer. To a lesser extent, PPAR $\alpha$ agonists, especially fenofibrate and bezafibrate, also exhibit pleiotropic beneficial effects in dyslipidemia, CVD, NAFLD, and PBC. Therefore, the future prospect of pioglitazone and fibrates remains full of possibilities even after current therapeutic roles (antidiabetic and lipid-lowering agents, respectively) have been replaced by more effective medications. In comparison, the development of PPAR $\beta / \delta$ agonists (e.g., GW501516 and seladelpar) is relatively slow and limited, which is attributable primarily to the pro-oncogenic activity of many members in this pharmacological class. Hence, future synthetic PPAR $\beta / \delta$ agonists should be subjected to a systematic and thorough inspection to ensure the non-existence of carcinogenicity before any human trials.

Thus far, clinical trials of PPAR agonists on neurological and neurodegenerative disorders are mostly negative, whereas those on malignancies yielded mixed results. The negative or conflicting results are indicative of a knowledge gap in our understanding of the roles of PPARs in these diseases. For instance, it is not uncommon for cancer treatment to exhibit efficacy in a context- or cell type-dependent manner. Likewise, the roles of PPARs in the tumor microenvironment may vary, depending on the physiological cues in the tumor microenvironment, which the current PPAR research paradigm often fails to address. As such, until more insights about the roles of PPARs in neurology and malignancy are established, further trials of PPAR agonists in these fields are not recommended.

We note that synthetic ligands that target the same PPAR subtype may not always possess comparable efficacy, safety profiles, and clinical outcomes. Pioglitazone and rosiglitazone are two compelling examples. Rosiglitazone is associated with significant cardiovascular risk, rendering its 
clinical application highly controversial, whereas pioglitazone continues to show positive activities in many diseases other than T2DM. Such discrepancies can be attributed to the bioavailability, specificity, and pharmacokinetics of the drugs. The inter-drug differences between members of the same class also highlight that the failure of certain investigational PPAR agonists should not stop the creation and development of new agonists. Additionally, while PPAR agonists are widely studied, no clinical evidence is available for PPAR antagonists. Preclinical studies have suggested a role for PPAR $\gamma$ and PPAR $\beta / \delta$ antagonists as anti-obesity and anti-cancer therapy, respectively $[327,328]$. We speculate that exploring the clinical feasibility of PPAR $\beta / \delta$ antagonists in cancer treatment may result in fruitful outcomes considering the involvement of PPAR $\beta / \delta$ in tumorigenesis processes like oxidative stress homeostasis, differentiation of tumor-associated macrophages, angiogenesis, and epithelial-mesenchymal transition [329-331]. Taken together, there is still a great deal of untapped potential in targeting PPARs. Hence, PPAR and their modulators will continue to be a main theme in basic science and clinical research in the years to come.

\section{Concluding Remarks}

PPAR agonists have been clinically tested in a wide range of health conditions with varying degrees of success. Fibrates (PPAR $\alpha$ agonists) and TZDs (PPAR $\gamma$ agonists) remain two of the mainstream therapeutic agents for dyslipidemia, T2DM, and CVD prevention. Pemafibrate will likely replace its predecessors (fenofibrate, gemfibrozil, and bezafibrate) in the treatment of dyslipidemia because of its high selectivity, excellent efficacy, and desirable safety profile. Despite the clinical failures of some dual-PPAR agonists due to notable side effects, other multi-target PPAR activators, especially chiglitazar, saroglitazar, elafibranor, and lanifibranor, are quickly picking up the pace and have displayed outstanding efficacy in T2DM, dyslipidemia, NAFLD, and PBC. Pioglitazone is another noteworthy PPAR agonist that shows a promising effect in many non-metabolic diseases, whereas the clinical implication of PPAR $\beta / \delta$ agonists is less well-understood. Side effects are still a major concern in the design and development of new synthetic PPAR ligands. Future PPAR research should explore methods to minimize the off-target effect of PPAR agonists, as well as the potential of PPAR antagonists, as doing so will open a new repertoire for the exploitation of PPAR ligands in medicine.

Author Contributions: Conceptualization, N.S.T.; data curation, H.S.C. and W.R.T.; writing-original draft preparation, H.S.C., W.R.T., Z.S.L., C.M. and J.Y.H.L.; writing-review and editing, all authors; supervision, N.S.T.; funding acquisition, N.S.T.

Funding: N.S.T.'s work was supported by Nanyang Technological University Start-Up Grant, grant number M4082040.

Acknowledgments: Z.S.L is a recipient of the Lee Kong Chian School of Medicine PhD scholarship.

Conflicts of Interest: The authors declare no conflict of interest.

\section{References}

1. Chan, L.S.A.; Wells, R.A. Cross-talk between PPARs and the partners of RXR: A molecular perspective. PPAR Res. 2009, 2009, 925309. [CrossRef] [PubMed]

2. Tan, C.K.; Zhuang, Y.; Wahli, W. Synthetic and natural peroxisome proliferator-activated receptor (PPAR) agonists as candidates for the therapy of the metabolic syndrome. Expert Opin. Ther. Targets 2017, 21, 333-348. [CrossRef] [PubMed]

3. Mirza, A.Z.; Althagafi, I.I.; Shamshad, H. Role of PPAR receptor in different diseases and their ligands: Physiological importance and clinical implications. Eur. J. Med. Chem. 2019, 166, 502-513. [CrossRef] [PubMed]

4. Bougarne, N.; Weyers, B.; Desmet, S.J.; Deckers, J.; Ray, D.W.; Staels, B.; De Bosscher, K. Molecular actions of PPAR $\alpha$ in lipid metabolism and inflammation. Endocr. Rev. 2018, 39, 760-802. [CrossRef] [PubMed]

5. Tan, N.S.; Vázquez-Carrera, M.; Montagner, A.; Sng, M.K.; Guillou, H.; Wahli, W. Transcriptional control of

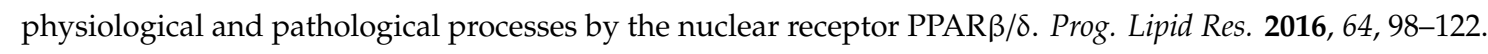
[CrossRef] [PubMed] 
6. Grundy, S.M.; Stone, N.J.; Bailey, A.L.; Beam, C.; Birtcher, K.K.; Blumenthal, R.S.; Braun, L.T.; Ferranti, S.d.; Faiella-Tommasino, J.; Forman, D.E.; et al. 2018 AHA/ACC/AACVPR/AAPA/ABC/ACPM/ ADA/AGS/APhA/ASPC/NLA/PCNA Guideline on the management ofblood cholesterol: A report of the American College of Cardiology/American Heart Association Task Force on Clinical Practice Guidelines. Circulation 2019, 139, e1082-e1143. [PubMed]

7. Inzucchi, S.E.; Bergenstal, R.M.; Buse, J.B.; Diamant, M.; Ferrannini, E.; Nauck, M.; Peters, A.L.; Tsapas, A.; Wender, R.; Matthews, D.R. Management of hyperglycaemia in type 2 diabetes, 2015: A patient-centred approach. Update to a Position Statement of the American Diabetes Association and the European Association for the Study of Diabetes. Diabetologia 2015, 58, 429-442. [CrossRef] [PubMed]

8. Hong, F.; Xu, P.; Zhai, Y. The opportunities and challenges of peroxisome proliferator-activated receptors ligands in clinical drug discovery and development. Int. J. Mol. Sci. 2018, 19, 2189. [CrossRef] [PubMed]

9. Bruckert, E.; Labreuche, J.; Deplanque, D.; Touboul, P.-J.; Amarenco, P. Fibrates effect on cardiovascular risk is greater in patients with high triglyceride levels or atherogenic dyslipidemia profile: A systematic review and meta-analysis. J. Cardiovasc. Pharmacol. 2011, 57, 267-272. [CrossRef]

10. Abourbih, S.; Filion, K.B.; Joseph, L.; Schiffrin, E.L.; Rinfret, S.; Poirier, P.; Pilote, L.; Genest, J.; Eisenberg, M.J. Effect of fibrates on lipid profiles and cardiovascular outcomes: A systematic review. Am. J. Med. 2009, 122, 962.e1-962.e8. [CrossRef]

11. Chiquette, E.; Ramirez, G.; DeFronzo, R. A meta-analysis comparing the effect of thiazolidinediones on cardiovascular risk factors. JAMA Intern. Med. 2004, 164, 2097-2104. [CrossRef] [PubMed]

12. Palmer, S.C.; Mavridis, D.; Nicolucci, A.; Johnson, D.W.; Tonelli, M.; Craig, J.C.; Maggo, J.; Gray, V.; De Berardis, G.; Ruospo, M.; et al. Comparison of clinical outcomes and adverse events associated with glucose-lowering drugs in patients with type 2 diabetes: A meta-analysis. JAMA 2016, 316, 313-324. [CrossRef] [PubMed]

13. Auwerx, J.; Schoonjans, K.; Fruchart, J.-C.; Staels, B. Regulation of triglyceride metabolism by PPARs: Fibrates and thiazolidinediones have distinct effects. J. Atheroscler. Thromb. 1996, 3, 81-89. [CrossRef] [PubMed]

14. Contreras, A.V.; Torres, N.; Tovar, A.R. PPAR- $\alpha$ as a key nutritional and environmental sensor for metabolic adaptation. Adv. Nutr. 2013, 4, 439-452. [CrossRef] [PubMed]

15. Ahmadian, M.; Suh, J.M.; Hah, N.; Liddle, C.; Atkins, A.R.; Downes, M.; Evans, R.M. PPAR $\gamma$ signaling and metabolism: The good, the bad and the future. Nat. Med. 2013, 19, 557-566. [CrossRef] [PubMed]

16. Sugii, S.; Olson, P.; Sears, D.D.; Saberi, M.; Atkins, A.R.; Barish, G.D.; Hong, S.-H.; Castro, G.L.; Yin, Y.-Q.; Nelson, M.C.; et al. PPAR $\gamma$ activation in adipocytes is sufficient for systemic insulin sensitization. Proc. Natl. Acad. Sci. USA 2009, 106, 22504-22509. [CrossRef] [PubMed]

17. Fan, W.; Waizenegger, W.; Lin, C.S.; Sorrentino, V.; He, M.-X.; Wall, C.E.; Li, H.; Liddle, C.; Yu, R.T.; Atkins, A.R.; et al. PPAR $\delta$ promotes running endurance by preserving glucose. Cell Metab. 2017, 25, 1186-1193. [CrossRef] [PubMed]

18. Ravnskjaer, K.; Frigerio, F.; Boergesen, M.; Nielsen, T.; Maechler, P.; Mandrup, S. PPAR $\delta$ is a fatty acid sensor that enhances mitochondrial oxidation in insulin-secreting cells and protects against fatty acid-induced dysfunction. J. Lipid Res. 2010, 51, 1370-1379. [CrossRef]

19. Maccallini, C.; Mollica, A.; Amoroso, R. The positive regulation of eNOS signaling by PPAR agonists in cardiovascular diseases. Am. J. Cardiovasc. Drugs 2017, 17, 273-281. [CrossRef]

20. Wang, Y.; Yang, Q.; Yan, J.T.; Zhao, C.; Cianflone, K.; Wang, D.W. Effects of bezafibrate on the expression of endothelial nitric oxide synthase gene and its mechanisms in cultured bovine endothelial cells. Atherosclerosis 2006, 187, 265-273. [CrossRef]

21. Okayasu, T.; Tomizawa, A.; Suzuki, K.; Manaka, K.-I.; Hattori, Y. PPAR $\alpha$ activators upregulate eNOS activity and inhibit cytokine-induced NF- $\mathrm{B}$ activation through AMP-activated protein kinase activation. Life Sci. 2008, 82, 884-891. [CrossRef] [PubMed]

22. Li, R.; Zhang, H.; Wang, W.; Wang, X.; Huang, Y.; Huang, C.; Gao, F. Vascular insulin resistance in prehypertensive rats: Role of PI3-kinase/Akt/eNOS signaling. Eur. J. Pharmacol. 2010, 628, 140-147. [CrossRef] [PubMed]

23. Quintela, A.M.; Jiménez, R.; Piqueras, L.; Gómez-Guzmán, M.; Haro, J.; Zarzuelo, M.J.; Cogolludo, A.; Sanz, M.J.; Toral, M.; Romero, M.; et al. PPAR $\beta$ activation restores the high glucose-induced impairment of insulin signalling in endothelial cells. Br. J. Pharmacol. 2014, 171, 3089-3102. [CrossRef] [PubMed] 
24. Polikandriotis, J.A.; Mazzella, L.J.; Rupnow, H.L.; Hart, C.M. Peroxisome proliferator-activated receptor $\gamma$ ligands stimulate endothelial nitric oxide production through distinct peroxisome proliferator-activated receptor $\gamma$-dependent mechanisms. Arterioscler. Thromb. Vasc. Biol. 2005, 25, 1810-1816. [CrossRef] [PubMed]

25. Wong, W.T.; Tian, X.Y.; Xu, A.; Yu, J.; Lau, C.W.; Hoo, R.L.; Wang, Y.; Lee, V.W.; Lam, K.S.; Vanhoutte, P.M.; et al. Adiponectin is required for PPAR $\gamma$-mediated improvement of endothelial function in diabetic mice. Cell Metab. 2011, 14, 104-115. [CrossRef] [PubMed]

26. Wakino, S.; Hayashi, K.; Kanda, T.; Tatematsu, S.; Homma, K.; Yoshioka, K.; Takamatsu, I.; Saruta, T. Peroxisome proliferator-activated receptor $\gamma$ ligands inhibit Rho/Rho kinase pathway by inducing protein tyrosine phosphatase SHP-2. Circ. Res. 2004, 95, e45-e55. [CrossRef] [PubMed]

27. Wahli, W.; Michalik, L. PPARs at the crossroads of lipid signaling and inflammation. Trends Endocrinol. Metab. 2012, 23, 351-363. [CrossRef]

28. Devchand, P.R.; Keller, H.; Peters, J.M.; Vazquez, M.; Gonzalez, F.J.; Wahli, W. The PPAR $\alpha-$ leukotriene B4 pathway to inflammation control. Nature 1996, 384, 39-43. [CrossRef]

29. Ibarra-Lara, M.D.L.L.; Sánchez-Aguilar, M.; Soria, E.; Torres-Narváez, J.C.; Del Valle-Mondragón, L.; Cervantes-Pérez, L.G.; Pérez-Severiano, F.; Ramírez-Ortega, M.D.C.; Pastelín-Hernández, G.; Oidor-Chan, V.H.; et al. Peroxisome proliferator-activated receptors (PPAR) downregulate the expression of pro-inflammatory molecules in an experimental model of myocardial infarction. Can. J. Physiol. Pharmacol. 2016, 94, 634-642. [CrossRef]

30. Bougarne, N.; Paumelle, R.; Caron, S.; Hennuyer, N.; Mansouri, R.; Gervois, P.; Staels, B.; Haegeman, G.; De Bosscher, K. PPAR $\alpha$ blocks glucocorticoid receptor $\alpha$-mediated transactivation but cooperates with the activated glucocorticoid receptor $\alpha$ for transrepression on NF-kB. Proc. Natl. Acad. Sci. USA 2009, 106, 7397-7402. [CrossRef]

31. Crisafulli, C.; Bruscoli, S.; Esposito, E.; Mazzon, E.; Di Paola, R.; Genovese, T.; Bramanti, P.; Migliorati, G.; Cuzzocrea, S. PPAR- $\alpha$ contributes to the anti-inflammatory activity of $17 \beta$-estradiol. J. Pharmacol. Exp. Ther. 2009, 331, 796-807. [CrossRef] [PubMed]

32. Pascual, G.; Fong, A.L.; Ogawa, S.; Gamliel, A.; Li, A.C.; Perissi, V.; Rose, D.W.; Willson, T.M.; Rosenfeld, M.G.; Glass, C.K. A SUMOylation-dependent pathway mediates transrepression of inflammatory response genes by PPAR- $\gamma$. Nature 2005, 437, 759-763. [CrossRef] [PubMed]

33. Sazatmari, I.; Rajnavolgyi, E.; Nagy, L. PPAR $\gamma$, a lipid-activated transcription factor as a regulator of dendritic cell function. Ann. N. Y. Acad. Sci. 2006, 1088, 207-218. [CrossRef] [PubMed]

34. Kralj, D.; Jukić, L.V.; Stojsavljević, S.; Duvnjak, M.; Smolić, M.; Čurčić, I.B. Hepatitis C virus, insulin resistance, and steatosis. J. Clin. Transl. Hepatol. 2016, 4, 66-75. [PubMed]

35. Kapadia, R.; Yi, J.-H.; Vemuganti, R. Mechanisms of anti-inflammatory and neuroprotective actions of PPAR-gamma agonists. Front. Biosci. 2008, 13, 1813-1826. [CrossRef] [PubMed]

36. Nisbett, K.E.; Pinna, G. Emerging therapeutic role of PPAR- $\alpha$ in cognition and emotions. Front. Pharmacol. 2018, 9, 998. [CrossRef] [PubMed]

37. Benjamin, R.; Julie, D.; Renaud, J.; Olivier, C.; Pierre, T.; Regis, B. Therapeutic prospects of PPARs in psychiatric disorders: A comprehensive review. Curr. Drug Targets 2013, 14, 724-732.

38. Pozzi, A.; Ibanez, M.R.; Gatica, A.E.; Yang, S.; Wei, S.; Mei, S.; Falck, J.R.; Capdevila, J.H. Peroxisomal proliferator-activated receptor- $\alpha$-dependent inhibition of endothelial cell proliferation and tumorigenesis. J. Biol. Chem. 2007, 282, 17685-17695. [CrossRef]

39. Garrido-Urbani, S.; Jemelin, S.; Deffert, C.; Carnesecchi, S.; Basset, O.; Szyndralewiez, C.; Heitz, F.; Page, P.; Montet, X.; Michalik, L.; et al. Targeting vascular NADPH oxidase 1 blocks tumor angiogenesis through a PPAR $\alpha$ mediated mechanism. PLoS ONE 2011, 6, e14665. [CrossRef]

40. Peters, J.M.; Shah, Y.M.; Gonzalez, F.J. The role of peroxisome proliferator-activated receptors in carcinogenesis and chemoprevention. Nat. Rev. Cancer 2012, 12, 181-195. [CrossRef]

41. Huang, J.-W.; Shiau, C.-W.; Yang, Y.-T.; Kulp, S.K.; Chen, K.-F.; Brueggemeier, R.W.; Shapiro, C.L.; Chen, C.-S. Peroxisome proliferator-activated receptor $\gamma$-independent ablation of cyclin D1 by thiazolidinediones and their derivatives in breast cancer cells. Mol. Pharmacol. 2005, 67, 1342-1348. [CrossRef] [PubMed]

42. Gupta, R.A.; Brockman, J.A.; Sarraf, P.; Willson, T.M.; DuBois, R.N. Target genes of peroxisome proliferator-activated receptor $\gamma$ in colorectal cancer cells. J. Biol. Chem. 2001, 276, 29681-29687. [CrossRef] [PubMed] 
43. Motomura, W.; Okumura, T.; Takahashi, N.; Obara, T.; Kohgo, Y. Activation of peroxisome proliferator-activated receptor $\gamma$ by troglitazone inhibits cell growth through the increase of p27 Kip1 in human pancreatic carcinoma cells. Cancer Res. 2000, 60, 5558-5564. [PubMed]

44. Farrow, B.; Mark Evers, B. Activation of PPAR $\gamma$ increases PTEN expression in pancreatic cancer cells. Biochem. Biophys. Res. Commun. 2003, 301, 50-53. [CrossRef]

45. Bae, M.-A.; Song, B.J. Critical role of c-Jun N-terminal protein kinase activation in troglitazone-induced apoptosis of human hepG2 hepatoma cells. Mol. Pharmacol. 2003, 63, 401-408. [CrossRef] [PubMed]

46. Drori, S.; Girnun, G.D.; Tou, L.; Szwaya, J.D.; Mueller, E.; Kia, X.; Shivdasani, R.A.; Spiegelman, B.M. Hic-5 regulates an epithelial program mediated by PPAR $\gamma$. Genes Dev. 2005, 19, 362-375. [CrossRef] [PubMed]

47. Wang, W.; Zhou, X.; Kwong, J.S.W.; Li, L.; Li, Y.; Sun, X. Efficacy and safety of thiazolidinediones in diabetes patients with renal impairment: A systematic review and meta-analysis. Sci. Rep. 2017, 7, 1717. [CrossRef] [PubMed]

48. Qin, Y.; Wang, X.; Zhang, M. Effect of thiazolidinediones on renal outcomes in diabetic patients with microalbuminuria or macroalbuminuria-A systematic review and meta-analysis. Diabetes 2018, 67, 532-P. [CrossRef]

49. Alam, F.; Islam, M.A.; Mohamed, M.; Ahmad, I.; Kamal, M.A.; Donnelly, R.; Idris, I.; Gan, S.H. Efficacy and safety of pioglitazone monotherapy in type 2 diabetes mellitus: A systematic review and meta-analysis of randomised controlled trials. Sci. Rep. 2019, 9, 5389. [CrossRef]

50. Rizos, C.V.; Elisaf, M.; Mikhailidis, D.P.; Liberopoulos, E.N. How safe is the use of thiazolidinediones in clinical practice? Expert Opin. Drug Saf. 2009, 8, 15-32. [CrossRef]

51. Rubin, C.J.; De Pril, V.; Fiedorek, F.T. Coadministration of muraglitazar plus glyburide: Improvement of glycaemic and lipid profiles in patients with type 2 diabetes. Diabetes Vasc. Dis. Res. 2009, 6, 120-132. [CrossRef] [PubMed]

52. Rubin, C.J.; Viraswami-Appanna, K.; Fiedorek, F.T. Efficacy and safety of muraglitazar: A double-blind, 24-week, dose-ranging study in patients with type 2 diabetes. Diabetes Vasc. Dis. Res. 2009, 6, 205-215. [CrossRef] [PubMed]

53. Rubin, C.J.; Ledeine, J.-M.; Fiedorek, F.T. Improvement of glycaemic and lipid profiles with muraglitazar plus metformin in patients with type 2 diabetes: An active-control trial with glimepiride. Diabetes Vasc. Dis. Res. 2008, 5, 168-176. [CrossRef] [PubMed]

54. Bays, H.; McElhattan, J.; Bryzinski, B.S. A double-blind, randomised trial of tesaglitazar versus pioglitazone in patients with type 2 diabetes mellitus. Diabetes Vasc. Dis. Res. 2007, 4, 181-193. [CrossRef] [PubMed]

55. Goldstein, B.J.; Rosenstock, J.; Anzalone, D.; Tou, C.; Peter Öhman, K. Effect of tesaglitazar, a dual PPAR $\alpha / \gamma$ agonist, on glucose and lipid abnormalities in patients with type 2 diabetes: A 12-week dose-ranging trial. Curr. Med. Res. Opin. 2006, 22, 2575-2590. [CrossRef]

56. Göke, B.; Gause-Nilsson, I.; Persson, A. The effects of tesaglitazar as add-on treatment to metformin in patients with poorly controlled type 2 diabetes. Diabetes Vasc. Dis. Res. 2007, 4, 204-213. [CrossRef]

57. Ratner, R.E.; Parikh, S.; Tou, C. Efficacy, safety and tolerability of tesaglitazar when added to the therapeutic regimen of poorly controlled insulin-treated patients with type 2 diabetes. Diabetes Vasc. Dis. Res. 2007, 4, 214-221. [CrossRef]

58. Wilding, J.P.H.; Gause-Nilsson, I.; Persson, A. Tesaglitazar, as add-on therapy to sulphonylurea, dose-dependently improves glucose and lipid abnormalities in patients with type 2 diabetes. Diabetes Vasc. Dis. Res. 2007, 4, 194-203. [CrossRef]

59. Stirban, A.O.; Andjelkovic, M.; Heise, T.; Nosek, L.; Fischer, A.; Gastaldelli, A.; Herz, M. Aleglitazar, a dual peroxisome proliferator-activated receptor- $\alpha / \gamma$ agonist, improves insulin sensitivity, glucose control and lipid levels in people with type 2 diabetes: Findings from a randomized, double-blind trial. Diabetes Obes. Metab. 2016, 18, 711-715. [CrossRef]

60. Henry, R.R.; Lincoff, A.M.; Mudaliar, S.; Rabbia, M.; Chognot, C.; Herz, M. Effect of the dual peroxisome proliferator-activated receptor- $\alpha / \gamma$ agonist aleglitazar on risk of cardiovascular disease in patients with type 2 diabetes (SYNCHRONY): A phase II, randomised, dose-ranging study. Lancet 2009, 374, 126-135. [CrossRef]

61. Henry, R.R.; Buse, J.B.; Wu, H.; Durrwell, L.; Mingrino, R.; Jaekel, K.; El Azzouzi, B.; Andjelkovic, M.; Herz, M. Efficacy, safety and tolerability of aleglitazar in patients with type 2 diabetes: Pooled findings from three randomized phase III trials. Diabetes Obes. Metab. 2015, 17, 560-565. [CrossRef] [PubMed] 
62. Kim, S.G.; Kim, D.M.; Woo, J.-T.; Jang, H.C.; Chung, C.H.; Ko, K.S.; Park, J.H.; Park, Y.S.; Kim, S.J.; Choi, D.S. Efficacy and safety of lobeglitazone monotherapy in patients with type 2 diabetes mellitus over 24-weeks: A multicenter, randomized, double-blind, parallel-group, placebo controlled trial. PLoS ONE 2014, 9, e92843. [CrossRef] [PubMed]

63. Jin, S.M.; Park, C.Y.; Cho, Y.M.; Ku, B.J.; Ahn, C.W.; Cha, B.S.; Min, K.W.; Sung, Y.A.; Baik, S.H.; Lee, K.W.; et al. Lobeglitazone and pioglitazone as add-ons to metformin for patients with type 2 diabetes: A 24-week, multicentre, randomized, double-blind, parallel-group, active-controlled, phase III clinical trial with a 28-week extension. Diabetes Obes. Metab. 2015, 17, 599-602. [CrossRef] [PubMed]

64. Decochez, K.; Rippley, R.K.; Miller, J.L.; De Smet, M.; Yan, K.X.; Matthijs, Z.; Riffel, K.A.; Song, H.; Zhu, H.; Maynor, H.O.; et al. A dual PPAR $\alpha / \gamma$ agonist increases adiponectin and improves plasma lipid profiles in healthy subjects. Drugs R D 2006, 7, 99-110. [CrossRef] [PubMed]

65. Nissen, S.E.; Wolski, K.; Topol, E.J. Effect of muraglitazar on death and major adverse cardiovascular events in patients with type 2 diabetes mellitus. JAMA 2005, 294, 2581-2586. [CrossRef] [PubMed]

66. Hamrén, B.; Öhman, K.P.; Svensson, M.K.; Karlsson, M.O. Pharmacokinetic-pharmacodynamic assessment of the interrelationships between tesaglitazar exposure and renal function in patients with type 2 diabetes mellitus. J. Clin. Pharmacol. 2012, 52, 1317-1327. [CrossRef]

67. Herz, M.; Gaspari, F.; Perico, N.; Viberti, G.; Urbanowska, T.; Rabbia, M.; Kirk, D.W. Effects of high dose aleglitazar on renal function in patients with type 2 diabetes. Int. J. Cardiol. 2011, 151, 136-142. [CrossRef]

68. Ruilope, L.; Hanefeld, M.; Lincoff, A.M.; Viberti, G.; Meyer-Reigner, S.; Mudie, N.; Wieczorek Kirk, D.; Malmberg, K.; Herz, M. Effects of the dual peroxisome proliferator-activated receptor- $\alpha / \gamma$ agonist aleglitazar on renal function in patients with stage 3 chronic kidney disease and type 2 diabetes: A Phase IIb, randomized study. BMC Nephrol. 2014, 15, 180. [CrossRef]

69. Oleksiewicz, M.B.; Southgate, J.; Iversen, L.; Egerod, F.L. Rat urinary bladder carcinogenesis by dual-acting PPAR agonists. PPAR Res. 2008, 2008, 103167. [CrossRef]

70. Lee, H.S.; Chang, M.; Lee, J.-E.; Kim, W.; Hwang, I.-C.; Kim, D.-H.; Park, H.-K.; Choi, H.-J.; Jo, W.; Cha, S.-W.; et al. Carcinogenicity study of CKD-501, a novel dual peroxisome proliferator-activated receptors $\alpha$ and $\gamma$ agonist, following oral administration to Sprague Dawley rats for 94-101weeks. Regul. Toxicol. Pharmacol. 2014, 69, 207-216. [CrossRef]

71. Moon, K.-S.; Lee, J.-E.; Lee, H.S.; Hwang, I.-C.; Kim, D.-H.; Park, H.-K.; Choi, H.-J.; Jo, W.; Son, W.-C.; Yun, H.-I. CKD-501, a novel selective PPAR $\gamma$ agonist, shows no carcinogenic potential in ICR mice following oral administration for 104 weeks. J. Appl. Toxicol. 2014, 34, 1271-1284. [CrossRef] [PubMed]

72. Cariou, B.; Hanf, R.; Lambert-Porcheron, S.; Zaïr, Y.; Sauvinet, V.; Noël, B.; Flet, L.; Vidal, H.; Staels, B.; Laville, M. Dual Peroxisome Proliferator-Activated Receptor $\alpha / \delta$ agonist GFT505 improves hepatic and peripheral insulin sensitivity in abdominally obese subjects. Diabetes Care 2013, 36, 2923-2930. [CrossRef] [PubMed]

73. Cariou, B.; Zaïr, Y.; Staels, B.; Bruckert, E. Effects of the new dual PPAR $\alpha / \delta$ agonist GFT505 on lipid and glucose homeostasis in abdominally obese patients with combined dyslipidemia or impaired glucose metabolism. Diabetes Care 2011, 34, 2008-2014. [CrossRef] [PubMed]

74. Ji, L.; Song, W.; Fang, H.; Li, W.; Geng, J.; Xu, Y.C.; Wang, Y.; Guo, L.; Cai, H.; Yang, T.; et al. 17-OR: Efficacy and safety of chiglitazar, a novel PPAR $\alpha / \gamma / \mathrm{d}$ pan-agonist, in patients with type 2 diabetes: A randomized, double-blind, placebo-controlled phase 3 superiority trial (CMAP). Diabetes 2019, 68, 17-OR. [CrossRef]

75. Jia, W.; Ma, J.; Miao, H.; Wang, C.; Wang, X.; Li, Q.; Lu, W.; Yang, J.; Zhang, L.; Yang, J.; et al. 18-OR: Efficacy and safety of chiglitazar vs. sitagliptin in patients with type 2 diabetes: A 24-week, randomized, double-blind, noninferiority phase 3 trial (CMAS). Diabetes 2019, 68, 18-OR. [CrossRef] [PubMed]

76. The FIELD Study Investigators. Effects of long-term fenofibrate therapy on cardiovascular events in 9795 people with type 2 diabetes mellitus (the FIELD study): Randomised controlled trial. Lancet 2005, 366, 1849-1861. [CrossRef]

77. Chew, E.Y.; Davis, M.D.; Danis, R.P.; Lovato, J.F.; Perdue, L.H.; Greven, C.; Genuth, S.; Goff, D.C.; Leiter, L.A.; Ismail-Beigi, F.; et al. The effects of medical management on the progression of diabetic retinopathy in persons with type 2 diabetes: The action to control cardiovascular risk in diabetes (ACCORD) Eye Study. Ophthalmology 2014, 121, 2443-2451. [CrossRef] [PubMed] 
78. Lincoff, A.M.; Tardif, J.-C.; Schwartz, G.G.; Nicholls, S.J.; Rydén, L.; Neal, B.; Malmberg, K.; Wedel, H.; Buse, J.B.; Henry, R.R.; et al. Effect of aleglitazar on cardiovascular outcomes after acute coronary syndrome in patients with type 2 diabetes mellitus: The AleCardio randomized clinical trial. JAMA 2014, 311, 1515-1525. [CrossRef]

79. Erdmann, E.; Califf, R.; Gerstein, H.C.; Malmberg, K.; Ruilope, L.; Schwartz, G.G.; Wedel, H.; Volz, D.; Ditmarsch, M.; Svensson, A.; et al. Effects of the dual peroxisome proliferator-activated receptor activator aleglitazar in patients with type 2 diabetes mellitus or prediabetes. Am. Heart J. 2015, 170, 117-122. [CrossRef]

80. Koomen, J.V.; Heerspink, H.J.L.; Schrieks, I.C.; Schwartz, G.G.; Lincoff, A.M.; Nicholls, S.J.; Svensson, A.; Wedel, H.; Weichert, A.; Grobbee, D.E.; et al. Exposure and response analysis of aleglitazar on cardiovascular risk markers and safety outcomes: An analysis of the AleCardio trial. Diabetes Obes. Metab. 2019. [CrossRef]

81. Report from the Committee of Principal Investigators. A co-operative trial in the primary prevention of ischaemic heart disease using clofibrate. Br. Heart J. 1978, 40, 1069-1118. [CrossRef] [PubMed]

82. Report of the Committee of Principal Investigators. WHO cooperative trial on primary prevention of ischaemic heart disease with clofibrate to lower serum cholesterol: Final mortality follow-up. Lancet 1984, 324, 600-604. [CrossRef]

83. Meade, T.; Zuhrie, R.; Cook, C.; Cooper, J. Bezafibrate in men with lower extremity arterial disease: Randomised controlled trial. BMJ 2002, 325, 1139. [CrossRef] [PubMed]

84. Arbel, Y.; Klempfner, R.; Erez, A.; Goldenberg, I.; Benzekry, S.; Shlomo, N.; Fisman, E.Z.; Tenenbaum, A. Bezafibrate for the treatment of dyslipidemia in patients with coronary artery disease: 20-year mortality follow-up of the BIP randomized control trial. Cardiovasc. Diabetol. 2016, 15, 11. [CrossRef] [PubMed]

85. Elkeles, R.S.; Diamond, J.R.; Poulter, C.; Dhanjil, S.; Nicolaides, A.N.; Mahmood, S.; Richmond, W.; Mather, H.; Sharp, P.; Feher, M.D. Cardiovascular outcomes in type 2 diabetes: A double-blind placebo-controlled study of bezafibrate: The St. Mary's, Ealing, Northwick Park Diabetes Cardiovascular Disease Prevention (SENDCAP) Study. Diabetes Care 1998, 21, 641-648. [CrossRef]

86. Madrid-Miller, A.; Moreno-Ruiz, L.; Borrayo-Sánchez, G.; Almeida-Gutiérrez, E.; Martínez-Gómez, D.; Jáuregui-Aguilar, R. Impact of bezafibrate treatment in patients with hyperfibrinogenemia and ST-elevation acute myocardial infarction: A randomized clinical trial. Cir. Cir. 2010, 78, 229-237. [PubMed]

87. d'Emden, M.C.; Jenkins, A.J.; Li, L.; Zannino, D.; Mann, K.P.; Best, J.D.; Stuckey, B.G.A.; Park, K.; Saltevo, J.; Keech, A.C. The FIELD Study Investigators, Favourable effects of fenofibrate on lipids and cardiovascular disease in women with type 2 diabetes: Results from the Fenofibrate Intervention and Event Lowering in Diabetes (FIELD) study. Diabetologia 2014, 57, 2296-2303. [CrossRef]

88. Frick, M.H.; Elo, O.; Haapa, K.; Heinonen, O.P.; Heinsalmi, P.; Helo, P.; Huttunen, J.K.; Kaitaniemi, P.; Koskinen, P.; Manninen, V.; et al. Helsinki Heart Study: Primary-prevention trial with gemfibrozil in middle-aged men with dyslipidemia. N. Engl. J. Med. 1987, 317, 1237-1245. [CrossRef]

89. Michel, P.H. Impact of fenofibrate on type 2 diabetes patients with features of the metabolic syndrome: Subgroup analysis from FIELD. Curr. Cardiol. Rev. 2010, 6, 112-118.

90. Jakob, T.; Nordmann, A.J.; Schandelmaier, S.; Ferreira-González, I.; Briel, M. Fibrates for primary prevention of cardiovascular disease events. Cochrane Database Syst. Rev. 2016, 11, CD009753. [CrossRef]

91. Liu, J.; Wang, L.N. Peroxisome proliferator $\gamma$ activated receptor gamma agonists for preventing recurrent stroke and other vascular events in people with stroke or transient ischaemic attack. Cochrane Database Syst. Rev. 2017, 12, CD010693. [CrossRef] [PubMed]

92. Clarke, G.D.; Solis-Herrera, C.; Molina-Wilkins, M.; Martinez, S.; Merovci, A.; Cersosimo, E.; Chilton, R.J.; Iozzo, P.; Gastaldelli, A.; Abdul-Ghani, M.; et al. Pioglitazone improves left ventricular diastolic function in subjects with diabetes. Diabetes Care 2017, 40, 1530-1536. [CrossRef] [PubMed]

93. Wilcox, R.; Bousser, M.-G.; Betteridge, D.J.; Schernthaner, G.; Pirags, V.; Kupfer, S.; Dormandy, J. Effects of pioglitazone in patients with type 2 diabetes with or without previous stroke. Stroke 2007, 38, 865-873. [CrossRef] [PubMed]

94. Wilcox, R.; Kupfer, S.; Erdmann, E. Effects of pioglitazone on major adverse cardiovascular events in high-risk patients with type 2 diabetes: Results from PROspective pioglitAzone Clinical Trial In macro Vascular Events (PROactive 10). Am. Heart J. 2008, 155, 712-717. [CrossRef] [PubMed] 
95. Dormandy, J.A.; Charbonnel, B.; Eckland, D.J.A.; Erdmann, E.; Massi-Benedetti, M.; Moules, I.K.; Skene, A.M.; Tan, M.H.; Lefèbvre, P.J.; Murray, G.D.; et al. Secondary prevention of macrovascular events in patients with type 2 diabetes in the PROactive Study (PROspective pioglitAzone Clinical Trial In macroVascular Events): A randomised controlled trial. Lancet 2005, 366, 1279-1289. [CrossRef]

96. Kernan, W.N.; Viscoli, C.M.; Furie, K.L.; Young, L.H.; Inzucchi, S.E.; Gorman, M.; Guarino, P.D.; Lovejoy, A.M.; Peduzzi, P.N.; Conwit, R.; et al. Pioglitazone after ischemic stroke or transient ischemic attack. N. Engl. J. Med. 2016, 374, 1321-1331. [CrossRef] [PubMed]

97. Hong, S.J.; Choi, S.C.; Cho, J.Y.; Joo, H.J.; Park, J.H.; Yu, C.W.; Lim, D.-S. Pioglitazone increases circulating microRNA-24 with decrease in coronary neointimal hyperplasia in type 2 diabetic patients-optical coherence tomography analysis. Circ. J. 2015, 79, 880-888. [CrossRef]

98. Kaneda, H.; Shiono, T.; Miyashita, Y.; Takahashi, S.; Taketani, Y.; Domae, H.; Matsumi, J.; Mizuno, S.; Minami, Y.; Sugitatsu, K.; et al. Efficacy and safety of pioglitazone in patients with ST elevation myocardial infarction treated with primary stent implantation. Heart 2009, 95, 1079-1084. [CrossRef]

99. Takagi, T.; Okura, H.; Kobayashi, Y.; Kataoka, T.; Taguchi, H.; Toda, I.; Tamita, K.; Yamamuro, A.; Sakanoue, Y.; Ito, A.; et al. A prospective, multicenter, randomized trial to assess efficacy of pioglitazone on in-stent neointimal suppression in type 2 diabetes: POPPS (Prevention of In-Stent Neointimal Proliferation by Pioglitazone Study). JACC Cardiovasc. Interv. 2009, 2, 524-531. [CrossRef]

100. Nishio, K.; Sakurai, M.; Kusuyama, T.; Shigemitsu, M.; Fukui, T.; Kawamura, K.; Itoh, S.; Konno, N.; Katagiri, T. A randomized comparison of pioglitazone to inhibit restenosis after coronary stenting in patients with type 2 diabetes. Diabetes Care 2006, 29, 101-106. [CrossRef]

101. Mazzone, T.; Meyer, P.M.; Feinstein, S.B.; Davidson, M.H.; Kondos, G.T.; D’Agostino, R.B.; Perez, A.; Provost, J.-C.; Haffner, S.M. Effect of pioglitazone compared with glimepiride on carotid intima-media thickness in type 2 diabetes: A randomized trial. JAMA 2006, 296, 2572-2581. [CrossRef] [PubMed]

102. Nissen, S.E.; Nicholls, S.J.; Wolski, K.; Nesto, R.; Kupfer, S.; Perez, A.; Jure, H.; De Larochellière, R.; Staniloae, C.S.; Mavromatis, K.; et al. Comparison of pioglitazone vs glimepiride on progression of coronary atherosclerosis in patients with type 2 diabetes: The PERISCOPE randomized controlled trial. JAMA 2008, 299, 1561-1573. [CrossRef] [PubMed]

103. Mizoguchi, M.; Tahara, N.; Tahara, A.; Nitta, Y.; Kodama, N.; Oba, T.; Mawatari, K.; Yasukawa, H.; Kaida, H.; Ishibashi, M.; et al. Pioglitazone attenuates atherosclerotic plaque inflammation in patients with impaired glucose tolerance or diabetes: A prospective, randomized, comparator-controlled study using serial FDG PET/CT imaging study of carotid artery and ascending aorta. JACC Cardiovasc. Imaging 2011, 4, 1110-1118. [CrossRef] [PubMed]

104. Tanaka, R.; Yamashiro, K.; Okuma, Y.; Shimura, H.; Nakamura, S.; Ueno, Y.; Tanaka, Y.; Miyamoto, N.; Tomizawa, Y.; Nakahara, T.; et al. Effects of pioglitazone for secondary stroke prevention in patients with impaired glucose tolerance and newly diagnosed diabetes: The J-SPIRIT Study. J. Atheroscler. Thromb. 2015, 22, 1305-1316. [CrossRef] [PubMed]

105. Suryadevara, S.; Ueno, M.; Tello-Montoliu, A.; Ferreiro, J.L.; Desai, B.; Rollini, F.; Box, L.C.; Zenni, M.M.; Guzman, L.A.; Bass, T.A.; et al. Effects of pioglitazone on platelet P2Y12-mediated signalling in clopidogrel-treated patients with type 2 diabetes mellitus. Thromb. Haemost. 2012, 108, 930-936. [CrossRef] [PubMed]

106. Giles, T.D.; Elkayam, U.; Bhattacharya, M.; Perez, A.; Miller, A.B. Comparison of pioglitazone vs glyburide in early heart failure: Insights from a randomized controlled study of patients with type 2 diabetes and mild cardiac disease. Congest. Heart Fail. 2010, 16, 111-117. [CrossRef]

107. Vaccaro, O.; Masulli, M.; Nicolucci, A.; Bonora, E.; Del Prato, S.; Maggioni, A.P.; Rivellese, A.A.; Squatrito, S.; Giorda, C.B.; Sesti, G.; et al. Effects on the incidence of cardiovascular events of the addition of pioglitazone versus sulfonylureas in patients with type 2 diabetes inadequately controlled with metformin (TOSCA.IT): A randomised, multicentre trial. Lancet Diabetes Endocrinol. 2017, 5, 887-897. [CrossRef]

108. de Jong, M.; van der Worp, H.B.; van der Graaf, Y.; Visseren, F.L.J.; Westerink, J. Pioglitazone and the secondary prevention of cardiovascular disease. A meta-analysis of randomized-controlled trials. Cardiovasc. Diabetol. 2017, 16, 134. [CrossRef] 
109. Bertrand, O.F.; Poirier, P.; Rodés-Cabau, J.; Rinfret, S.; Title, L.M.; Dzavik, V.; Natarajan, M.; Angel, J.; Batalla, N.; Alméras, N.; et al. Cardiometabolic effects of rosiglitazone in patients with type 2 diabetes and coronary artery bypass grafts: A randomized placebo-controlled clinical trial. Atherosclerosis 2010, 211, 565-573. [CrossRef]

110. Lonn, E.M.; Gerstein, H.C.; Sheridan, P.; Smith, S.; Diaz, R.; Mohan, V.; Bosch, J.; Yusuf, S.; Dagenais, G.R. Effect of ramipril and of rosiglitazone on carotid intima-media thickness in people with impaired glucose tolerance or impaired fasting glucose: STARR (STudy of Atherosclerosis with Ramipril and Rosiglitazone). J. Am. Coll. Cardiol. 2009, 53, 2028-2035. [CrossRef]

111. Nissen, S.E.; Wolski, K. Effect of rosiglitazone on the risk of myocardial infarction and death from cardiovascular causes. N. Engl. J. Med. 2007, 356, 2457-2471. [CrossRef] [PubMed]

112. Nissen, S.E.; Wolski, K. Rosiglitazone revisited: An updated meta-analysis of risk for myocardial infarction and cardiovascular mortality. JAMA Intern. Med. 2010, 170, 1191-1201. [CrossRef] [PubMed]

113. Cheng, D.; Gao, H.; Li, W. Long-term risk of rosiglitazone on cardiovascular events-A systematic review and meta-analysis. Endokrynol. Pol. 2018, 69, 381-394. [PubMed]

114. Loomba, R.S.; Arora, R. Prevention of cardiovascular disease utilizing fibrates-A pooled meta-analysis. Am. J. Ther. 2010, 17, e182-e188. [CrossRef] [PubMed]

115. Lee, M.; Saver, J.L.; Towfighi, A.; Chow, J.; Ovbiagele, B. Efficacy of fibrates for cardiovascular risk reduction in persons with atherogenic dyslipidemia: A meta-analysis. Atherosclerosis 2011, 217, 492-498. [CrossRef] [PubMed]

116. Tenenbaum, A.; Fisman, E.Z. Fibrates are an essential part of modern anti-dyslipidemic arsenal: Spotlight on atherogenic dyslipidemia and residual risk reduction. Cardiovasc. Diabetol. 2012, 11, 125. [CrossRef] [PubMed]

117. Fruchart, J.-C. Pemafibrate (K-877), a novel selective peroxisome proliferator-activated receptor alpha modulator for management of atherogenic dyslipidaemia. Cardiovasc. Diabetol. 2017, 16, 124. [CrossRef]

118. Ishibashi, S.; Arai, H.; Yokote, K.; Araki, E.; Suganami, H.; Yamashita, S. Efficacy and safety of pemafibrate (K-877), a selective peroxisome proliferator-activated receptor $\alpha$ modulator, in patients with dyslipidemia: Results from a 24-week, randomized, double blind, active-controlled, phase 3 trial. J. Clin. Lipidol. 2018, 12, 173-184. [CrossRef]

119. Arai, H.; Yamashita, S.; Yokote, K.; Araki, E.; Suganami, H.; Ishibashi, S.; K-877 Study Group. Efficacy and safety of Pemafibrate versus fenofibrate in patients with high triglyceride and low HDL cholesterol levels: A multicenter, placebo-controlled, double-blind, randomized trial. J. Atheroscler. Thromb. 2018, 25, 521-538. [CrossRef]

120. Araki, E.; Yamashita, S.; Arai, H.; Yokote, K.; Satoh, J.; Inoguchi, T.; Nakamura, J.; Maegawa, H.; Yoshioka, N.; Tanizawa, Y.; et al. Effects of Pemafibrate, a novel selective PPAR $\alpha$ modulator, on lipid and glucose metabolism in patients with type 2 diabetes and hypertriglyceridemia: A randomized, double-blind, placebocontrolled, phase 3 trial. Diabetes Care 2018, 41, 538-546. [CrossRef]

121. Yokote, K.; Yamashita, S.; Arai, H.; Araki, E.; Suganami, H.; Ishibashi, S. Long-term efficacy and safety of pemafibrate, a novel selective peroxisome proliferator-activated receptor- $\alpha$ modulator (SPPARM $\alpha$ ), in dyslipidemic patients with renal impairment. Int. J. Mol. Sci. 2019, 20, 706. [CrossRef] [PubMed]

122. Slim, A.; Castillo-Rojas, L.; Hulten, E.; Slim, J.N.; Pearce Moore, D.; Villines, T.C. Rosiglitazone and fenofibrate additive effects on lipids. Cholesterol 2011, 2011, 286875. [CrossRef]

123. Sprecher Dennis, L.; Massien, C.; Pearce, G.; Billin Andrew, N.; Perlstein, I.; Willson Timothy, M.; Hassall David, G.; Ancellin, N.; Patterson Scott, D.; Lobe David, C.; et al. Triglyceride:High-density lipoprotein cholesterol effects in healthy subjects administered a peroxisome proliferator activated receptor $\delta$ agonist. Arterioscler. Thromb. Vasc. Biol. 2007, 27, 359-365. [CrossRef] [PubMed]

124. Risérus, U.; Sprecher, D.; Johnson, T.; Olson, E.; Hirschberg, S.; Liu, A.; Fang, Z.; Hegde, P.; Richards, D.; Sarov-Blat, L.; et al. Activation of peroxisome proliferator-activated receptor (PPAR) $\delta$ promotes reversal of multiple metabolic abnormalities, reduces oxidative stress, and increases fatty acid oxidation in moderately obese men. Diabetes 2008, 57, 332-339. [CrossRef] [PubMed]

125. Olson Eric, J.; Pearce Gregory, L.; Jones Nigel, P.; Sprecher Dennis, L. Lipid effects of peroxisome proliferator-activated receptor- $\delta$ agonist GW501516 in subjects with low high-density lipoprotein cholesterol. Arterioscler. Thromb. Vasc. Biol. 2012, 32, 2289-2294. [CrossRef] [PubMed] 
126. Ooi, E.M.M.; Watts, G.F.; Sprecher, D.L.; Chan, D.C.; Barrett, P.H.R. Mechanism of action of a peroxisome proliferator-activated receptor (PPAR)- $\delta$ agonist on lipoprotein metabolism in dyslipidemic subjects with central obesity. J. Clin. Endocrinol. Metab. 2011, 96, E1568-E1576. [CrossRef] [PubMed]

127. Sahebkar, A.; Chew, G.T.; Watts, G.F. New peroxisome proliferator-activated receptor agonists: Potential treatments for atherogenic dyslipidemia and non-alcoholic fatty liver disease. Expert Opin. Pharmacother. 2014, 15, 493-503. [CrossRef]

128. Bays, H.E.; Schwartz, S.; Littlejohn, T., III; Kerzner, B.; Krauss, R.M.; Naim, S.; Wang, X.; Choi, Y.-J.; Roberts, B.K.; Karpf, D.B. MBX-8025, a novel peroxisome proliferator receptor- $\delta$ agonist: Lipid and other metabolic effects in dyslipidemic overweight patients treated with and without atorvastatin. J. Clin. Endocrinol. Metab. 2011, 96, 2889-2897. [CrossRef]

129. Choi, Y.-J.; Roberts, B.K.; Wang, X.; Geaney, J.C.; Naim, S.; Wojnoonski, K.; Karpf, D.B.; Krauss, R.M. Effects of the PPAR- $\delta$ agonist MBX-8025 on atherogenic dyslipidemia. Atherosclerosis 2012, 220, 470-476. [CrossRef]

130. Pai, V.; Paneerselvam, A.; Mukhopadhyay, S.; Bhansali, A.; Kamath, D.; Shankar, V.; Gambhire, D.; Jani, R.H.; Joshi, S.; Patel, P. A multicenter, prospective, randomized, double-blind study to evaluate the safety and efficacy of saroglitazar 2 and $4 \mathrm{mg}$ compared to pioglitazone $45 \mathrm{mg}$ in diabetic dyslipidemia (PRESS V). J. Diabetes Sci. Technol. 2014, 8, 132-141. [CrossRef]

131. Jani, R.H.; Pai, V.; Jha, P.; Mukhopadhyay, G.J.S.; Bhansali, A.; Joshi, S. A multicenter, prospective, randomized, double-blind study to evaluate the safety and efficacy of saroglitazar 2 and $4 \mathrm{mg}$ compared with placebo in type 2 diabetes mellitus patients having hypertriglyceridemia not controlled with atorvastatin therapy (PRESS VI). Diabetes Technol. Ther. 2014, 16, 63-71. [PubMed]

132. Kaul, U.; Parmar, D.; Manjunath, K.; Shah, M.; Parmar, K.; Patil, K.P.; Jaiswal, A. New dual peroxisome proliferator activated receptor agonist-Saroglitazar in diabetic dyslipidemia and non-alcoholic fatty liver disease: Integrated analysis of the real world evidence. Cardiovasc. Diabetol. 2019, 18, 80. [CrossRef] [PubMed]

133. Munigoti, S.; Harinarayan, C. Role of Glitazars in atherogenic dyslipidemia and diabetes: Two birds with one stone? Indian J. Endocrinol. Metab. 2014, 18, 283-287. [CrossRef] [PubMed]

134. Brisson, D.; Méthot, J.; Tremblay, K.; Tremblay, M.; Perron, P.; Gaudet, D. Comparison of the efficacy of fibrates on hypertriglyceridemic phenotypes with different genetic and clinical characteristics. Pharm. Genom. 2010, 20, 742-747. [CrossRef] [PubMed]

135. Kawashiri, M.-A.; Kobayashi, J.; Nohara, A.; Noguchi, T.; Tada, H.; Nakanishi, C.; Inazu, A.; Mabuchi, H.; Yamagishi, M. Impact of bezafibrate and atorvastatin on lipoprotein subclass in patients with type III hyperlipoproteinemia: Result from a crossover study. Clin. Chim. Acta 2011, 412, 1068-1075. [CrossRef] [PubMed]

136. Koopal, C.; Marais, A.D.; Westerink, J.; van der Graaf, Y.; Visseren, F.L.J. Effect of adding bezafibrate to standard lipid-lowering therapy on post-fat load lipid levels in patients with familial dysbetalipoproteinemia. A randomized placebo-controlled crossover trial. J. Lipid Res. 2017, 58, 2180-2187. [CrossRef] [PubMed]

137. Engelen, M.; Tran, L.; Ofman, R.; Brennecke, J.; Moser, A.B.; Dijkstra, I.M.E.; Wanders, R.J.A.; Poll-The, B.T.; Kemp, S. Bezafibrate for X-linked adrenoleukodystrophy. PLoS ONE 2012, 7, e41013. [CrossRef]

138. Ørngreen, M.C.; Madsen, K.L.; Preisler, N.; Andersen, G.; Vissing, J.; Laforêt, P. Bezafibrate in skeletal muscle fatty acid oxidation disorders: A randomized clinical trial. Neurology 2014, 82, 607-613. [CrossRef]

139. Gaudet, D.; Saheb, S.; Bruckert, E.; de Graaf, J.; Langslet, G.; Tardif, J.C.; Bergheanu, S.; Steinberg, A.; Choi, Y.J.; Martin, R.; et al. A pilot study of MBX-8025 in the treatment of homozygous familial hypercholesterolemia (HoFH). Atherosclerosis 2016, 252, e253. [CrossRef]

140. Naoumova, R.P.; Kindler, H.; Leccisotti, L.; Mongillo, M.; Khan, M.T.; Neuwirth, C.; Seed, M.; Holvoet, P.; Betteridge, J.; Camici, P.G. Pioglitazone improves myocardial blood flow and glucose utilization in nondiabetic patients with combined hyperlipidemia: A randomized, double-blind, placebo-controlled study. J. Am. Coll. Cardiol. 2007, 50, 2051-2058. [CrossRef]

141. Thomas, E.L.; Potter, E.; Tosi, I.; Fitzpatrick, J.; Hamilton, G.; Amber, V.; Hughes, R.; North, C.; Holvoet, P.; Seed, M.; et al. Pioglitazone added to conventional lipid-lowering treatment in familial combined hyperlipidaemia improves parameters of metabolic control: Relation to liver, muscle and regional body fat content. Atherosclerosis 2007, 195, e181-e190. [CrossRef] [PubMed] 
142. Viale, P.; Manfredi, R.; Colangeli, V.; Calza, L.; Bon, I.; Re, M.C. Clinical management of dyslipidaemia associated with combination antiretroviral therapy in HIV-infected patients. J. Antimicrob. Chemother. 2016, $71,1451-1465$.

143. Gerber, J.G.; Kitch, D.W.; Fichtenbaum, C.J.; Zackin, R.A.; Charles, S.; Hogg, E.; Acosta, E.P.; Connick, E.; Wohl, D.; Kojic, E.M.; et al. Fish oil and fenofibrate for the treatment of hypertriglyceridemia in HIV-infected subjects on antiretroviral therapy: Results of ACTG A5186. JAIDS J. Acquir. Immune Defic. Syndr. 2008, 47, 459-466. [CrossRef] [PubMed]

144. Rao, A.; D'Amico, S.; Balasubramanyam, A.; Maldonado, M. Fenofibrate is effective in treating hypertriglyceridemia associated with HIV lipodystrophy. Am. J. Med. Sci. 2004, 327, 315-318. [CrossRef] [PubMed]

145. Badiou, S.; Merle De Boever, C.; Dupuy, A.-M.; Baillat, V.; Cristol, J.-P.; Reynes, J. Fenofibrate improves the atherogenic lipid profile and enhances LDL resistance to oxidation in HIV-positive adults. Atherosclerosis 2004, 172, 273-279. [CrossRef] [PubMed]

146. Dubé, M.P.; Komarow, L.; Fichtenbaum, C.J.; Cadden, J.J.; Overton, E.T.; Hodis, H.N.; Currier, J.S.; Stein, J.H. Extended-release niacin versus fenofibrate in HIV-infected participants with low high-density lipoprotein cholesterol: Effects on endothelial function, lipoproteins, and inflammation. Clin. Infect. Dis. 2015, 61, 840-849. [CrossRef] [PubMed]

147. Balasubramanyam, A.; Coraza, I.; Smith, E.O.B.; Scott, L.W.; Patel, P.; Iyer, D.; Taylor, A.A.; Giordano, T.P.; Sekhar, R.V.; Clark, P.; et al. Combination of niacin and fenofibrate with lifestyle changes improves dyslipidemia and hypoadiponectinemia in HIV patients on antiretroviral therapy: Results of "Heart Positive," a randomized, controlled trial. J. Clin. Endocrinol. Metab. 2011, 96, 2236-2247. [CrossRef] [PubMed]

148. Aberg, J.A.; Zackin, R.A.; Brobst, S.W.; Evans, S.R.; Alston, B.L.; Henry, W.K.; Glesby, M.J.; Torriani, F.J.; Yang, Y.; Owens, S.I.; et al. A randomized trial of the efficacy and safety of fenofibrate versus pravastatin in HIV-infected subjects with lipid abnormalities: AIDS Clinical Trials Group Study 5087. AIDS Res. Hum. Retrovir. 2005, 21, 757-767. [CrossRef] [PubMed]

149. Bonnet, F.; Balestre, E.; Thiébaut, R.; Mercié, P.; Dupon, M.; Morlat, P.; Dabis, F.; Groupe d'Epidémiologie Clinique du SIDA en Aquitaine (GECSA). Fibrates or statins and lipid plasma levels in 245 patients treated with highly active antiretroviral therapy. Aquitaine Cohort, France, 1999-2001. HIV Med. 2004, 5, 133-139. [CrossRef] [PubMed]

150. Calza, L.; Manfredi, R.; Chiodo, F. Statins and fibrates for the treatment of hyperlipidaemia in HIV-infected patients receiving HAART. AIDS 2003, 17, 851-859. [CrossRef] [PubMed]

151. Calza, L.; Manfredi, R.; Colangeli, V.; Tampellini, L.; Sebastiani, T.; Pocaterra, D.; Chiodo, F. Substitution of nevirapine or efavirenz for protease inhibitor versus lipid-lowering therapy for the management of dyslipidaemia. AIDS 2005, 19, 1051-1058. [CrossRef] [PubMed]

152. Gavrila, A.; Martin, L.; Mantzoros, C.S.; Moses, A.C.; Hsu, W.; Karchmer, A.W.; Doweiko, J.; Tsiodras, S.; Gautam, S. Improvement in highly active antiretroviral therapy-Induced metabolic syndrome by treatment with pioglitazone but not with fenofibrate: A $2 \times 2$ factorial, randomized, double-blinded, placebo-controlled trial. Clin. Infect. Dis. 2005, 40, 745-749. [CrossRef] [PubMed]

153. Slama, L.; Lanoy, E.; Valantin, M.-A.; Bastard, J.-P.; Chermak, A.; Boutekatjirt, A.; William-Faltaos, D.; Billaud, E.; Molina, J.-M.; Capeau, J.; et al. Effect of pioglitazone on HIV-1-related lipodystrophy: A randomized double-blind placebo-controlled trial (ANRS 113). Antiral Ther. 2008, 13, 67-76.

154. Okada, S.; Konishi, M.; Ishii, H. Pioglitazone therapy for HIV/HAART-associated lipodystrophy syndrome could increase subcutaneous fat mass in non-lipoatrophic but not in lipoatrophic regions. BMJ Case Rep. 2016, 2016, bcr2015213637. [CrossRef] [PubMed]

155. Shen, S.; Walmsley, S.; Kain, K.C.; Cheung, A.; Raboud, J.; Cavalcanti, R.B. A randomized, placebo-controlled trial of rosiglitazone for HIV-related lipoatrophy. J. Infect. Dis. 2007, 195, 1754-1761.

156. van Wijk, J.P.H.; de Koning, E.J.P.; Cabezas, M.C.; op't Roodt, J.; Joven, J.; Rabelink, T.J.; Hoepelman, A.I. Comparison of rosiglitazone and metformin for treating HIV lipodystrophy: A randomized trial. Ann. Intern. Med. 2005, 143, 337-346. [CrossRef]

157. Tungsiripat, M.; El-Bejjani, D.; Rizk, N.; Dogra, V.; O’Riordan, M.A.; Ross, A.C.; Hileman, C.; Storer, N.; Harrill, D.; McComsey, G.A. Carotid intima media thickness, inflammatory markers, and endothelial activation markers in HIV patients with lipoatrophy increased at 48 weeks regardless of use of rosiglitazone or placebo. AIDS Res. Hum. Retrovir. 2011, 27, 295-302. [CrossRef] 
158. Sheth, S.H.; Larson, R.J. The efficacy and safety of insulin-sensitizing drugs in HIV-associated lipodystrophy syndrome: A meta-analysis of randomized trials. BMC Infect. Dis. 2010, 10, 183. [CrossRef]

159. Fredriksen, J.; Ueland, T.; Dyrøy, E.; Halvorsen, B.; Melby, K.; Melbye, L.; Skalhegg, B.S.; Bohov, P.; Skorve, J.; Berge, R.K.; et al. Lipid-lowering and anti-inflammatory effects of tetradecylthioacetic acid in HIV-infected patients on highly active antiretroviral therapy. Eur. J. Clin. Investig. 2004, 34, 709-715. [CrossRef]

160. Chilcott, J.; Tappenden, P.; Jones, M.L.; Wight, J.P. A systematic review of the clinical effectiveness of pioglitazone in the treatment of type 2 diabetes mellitus. Clin. Ther. 2001, 23, 1792-1823. [CrossRef]

161. Ko, K.D.; Kim, K.K.; Lee, K.R. Does weight gain associated with thiazolidinedione use negatively affect cardiometabolic health? J. Obes. Metab. Syndr. 2017, 26, 102-106. [CrossRef]

162. Berberoglu, Z.; Yazici, A.C.; Bayraktar, N.; Demirag, N.G. Rosiglitazone decreases fasting plasma peptide YY3-36 in type 2 diabetic women: A possible role in weight gain? Acta Diabetol. 2012, 49, 115-122. [CrossRef] [PubMed]

163. Li, X.-M.; Li, Y.; Zhang, N.-N.; Xie, Y.-H.; Shi, Y.-Q. Combination therapy with metformin and fenofibrate for insulin resistance in obesity. J. Int. Med. Res. 2011, 39, 1876-1882. [CrossRef] [PubMed]

164. Filippatos, T.D.; Kiortsis, D.N.; Liberopoulos, E.N.; Georgoula, M.; Mikhailidis, D.P.; Elisaf, M.S. Effect of orlistat, micronised fenofibrate and their combination on metabolic parameters in overweight and obese patients with the metabolic syndrome: The FenOrli study. Curr. Med. Res. Opin. 2005, 21, 1997-2006. [CrossRef] [PubMed]

165. Gilbert, K.; Nian, H.; Yu, C.; Luther, J.M.; Brown, N.J. Fenofibrate lowers blood pressure in salt-sensitive but not salt-resistant hypertension. J. Hypertens. 2013, 31, 820-829. [CrossRef]

166. Chetty, V.T.; Sharma, A.M. Can PPAR $\gamma$ agonists have a role in the management of obesity-related hypertension? Vascul. Pharmacol. 2006, 45, 46-53. [CrossRef]

167. Rivas, B.D.; Luque, M.; Martell, N.; Fernández, C.; Fernández-Cruz, A. Pioglitazone decreases ambulatory blood pressure in type 2 diabetics with difficult-to-control hypertension. J. Clin. Hypertens. 2007, 9, 530-537. [CrossRef]

168. Qayyum, R.; Adomaityte, J. A meta-analysis of the effect of thiazolidinediones on blood pressure. J. Clin. Hypertens. 2006, 8, 19-28. [CrossRef]

169. Pfützner, A.; Hanefeld, M.; Dekordi, L.A.; Müller, J.; Kleine, I.; Fuchs, W.; Forst, T. Effect of Pioglitazone and Ramipril on biomarkers of low-grade inflammation and vascular function in nondiabetic patients with increased cardiovascular risk and an activated inflammation: Results from the PIOace study. J. Diabetes Sci. Technol. 2011, 5, 989-998. [CrossRef]

170. Straznicky, N.E.; Grima, M.T.; Sari, C.I.; Eikelis, N.; Lambert, G.W.; Nestel, P.J.; Richards, K.; Dixon, J.B.; Schlaich, M.P.; Lambert, E.A. Pioglitazone treatment enhances the sympathetic nervous system response to oral carbohydrate load in obese individuals with metabolic syndrome. Metabolism 2015, 64, 797-803. [CrossRef]

171. Horio, T.; Suzuki, M.; Suzuki, K.; Takamisawa, I.; Hiuge, A.; Kamide, K.; Takiuchi, S.; Iwashima, Y.; Kihara, S.; Funahashi, T.; et al. Pioglitazone improves left ventricular diastolic function in patients with essential hypertension. Am. J. Hypertens. 2005, 18, 949-957. [CrossRef] [PubMed]

172. Raji, A.; Seely, E.W.; Bekins, S.A.; Williams, G.H.; Simonson, D.C. Rosiglitazone improves insulin sensitivity and lowers blood pressure in hypertensive patients. Diabetes Care 2003, 26, 172-178. [CrossRef] [PubMed]

173. Mittermayer, F.; Schaller, G.; Pleiner, J.; Krzyzanowska, K.; Kapiotis, S.; Roden, M.; Wolzt, M. Rosiglitazone prevents free fatty acid-induced vascular endothelial dysfunction. J. Clin. Endocrinol. Metab. 2007, 92, 2574-2580. [CrossRef] [PubMed]

174. Sugawara, A.; Uruno, A.; Kudo, M.; Matsuda, K.; Yang, C.W.; Ito, S. PPAR $\gamma$ agonist beyond glucose lowering effect. Korean J. Intern. Med. 2011, 26, 19-24. [CrossRef] [PubMed]

175. Ningning, W.; Symons, J.D.; Hui, Z.; Zhanjun, J.; Gonzalez, F.J.; Tianxin, Y. Distinct functions of vascular endothelial and smooth muscle PPAR $\gamma$ in regulation of blood pressure and vascular tone. Toxicol. Pathol. 2009, 37, 21-27. [CrossRef] [PubMed]

176. Sayiner, M.; Koenig, A.; Henry, L.; Younossi, Z.M. Epidemiology of nonalcoholic fatty liver disease and nonalcoholic steatohepatitis in the United States and the rest of the world. Clin. Liver Dis. 2016, 20, 205-214. [CrossRef] [PubMed] 
177. Francque, S.; Verrijken, A.; Caron, S.; Prawitt, J.; Paumelle, R.; Derudas, B.; Lefebvre, P.; Taskinen, M.-R.; Van Hul, W.; Mertens, I.; et al. PPAR $\alpha$ gene expression correlates with severity and histological treatment response in patients with non-alcoholic steatohepatitis. J. Hepatol. 2015, 63, 164-173. [CrossRef]

178. Basaranoglu, M.; Acbay, O.; Sonsuz, A. A controlled trial of gemfibrozil in the treatment of patients with nonalcoholic steatohepatitis. J. Hepatol. 1999, 31, 384. [CrossRef]

179. Fernández-Miranda, C.; Pérez-Carreras, M.; Colina, F.; López-Alonso, G.; Vargas, C.; Solís-Herruzo, J.A. A pilot trial of fenofibrate for the treatment of non-alcoholic fatty liver disease. Dig. Liver Dis. 2008, 40, 200-205. [CrossRef]

180. Fabbrini, E.; Mohammed, B.S.; Korenblat, K.M.; Magkos, F.; McCrea, J.; Patterson, B.W.; Klein, S. Effect of fenofibrate and niacin on intrahepatic triglyceride content, very low-density lipoprotein kinetics, and insulin action in obese subjects with nonalcoholic fatty liver disease. J. Clin. Endocrinol. Metab. 2010, 95, 2727-2735. [CrossRef]

181. Kim, S.; Ko, K.; Park, S.; Lee, D.R.; Lee, J. Effect of fenofibrate medication on renal function. Korean J. Fam. Med. 2017, 38, 192-198. [CrossRef] [PubMed]

182. Davidson, M.H.; Armani, A.; McKenney, J.M.; Jacobson, T.A. Safety considerations with fibrate therapy. Am. J. Cardiol. 2007, 99, S3-S18. [CrossRef] [PubMed]

183. Jacobson, T.A. Myopathy with statin-fibrate combination therapy: Clinical considerations. Nat. Rev. Endocrinol. 2009, 5, 507-518. [CrossRef] [PubMed]

184. Chalasani, N.; Younossi, Z.; Lavine, J.E.; Charlton, M.; Cusi, K.; Rinella, M.; Harrison, S.A.; Brunt, E.M.; Sanyal, A.J. The diagnosis and management of nonalcoholic fatty liver disease: Practice guidance from the American Association for the Study of Liver Diseases. Hepatology 2018, 67, 328-357. [CrossRef] [PubMed]

185. Promrat, K.; Lutchman, G.; Uwaifo, G.I.; Freedman, R.J.; Soza, A.; Heller, T.; Doo, E.; Ghany, M.; Premkumar, A.; Park, Y.; et al. A pilot study of pioglitazone treatment for nonalcoholic steatohepatitis. Hepatology 2004, 39, 188-196. [CrossRef] [PubMed]

186. Belfort, R.; Harrison, S.A.; Brown, K.; Darland, C.; Finch, J.; Hardies, J.; Balas, B.; Gastaldelli, A.; Tio, F.; Pulcini, J.; et al. A placebo-controlled trial of pioglitazone in subjects with nonalcoholic steatohepatitis. N. Engl. J. Med. 2006, 355, 2297-2307. [CrossRef] [PubMed]

187. Aithal, G.P.; Thomas, J.A.; Kaye, P.V.; Lawson, A.; Ryder, S.D.; Spendlove, I.; Austin, A.S.; Freeman, J.G.; Morgan, L.; Webber, J. Randomized, placebo-controlled trial of pioglitazone in nondiabetic subjects with nonalcoholic steatohepatitis. Gastroenterology 2008, 135, 1176-1184. [CrossRef] [PubMed]

188. Sanyal, A.J.; Chalasani, N.; Kowdley, K.V.; McCullough, A.; Diehl, A.M.; Bass, N.M.; Neuschwander-Tetri, B.A.; Lavine, J.E.; Tonascia, J.; Unalp, A.; et al. Pioglitazone, vitamin E, or placebo for nonalcoholic steatohepatitis. N. Engl. J. Med. 2010, 362, 1675-1685. [CrossRef] [PubMed]

189. Cusi, K.; Orsak, B.; Bril, F.; Lomonaco, R.; Hecht, J.; Ortiz-Lopez, C.; Tio, F.; Hardies, J.; Darland, C.; Musi, N.; et al. Long-term pioglitazone treatment for patients with nonalcoholic steatohepatitis and prediabetes or type 2 diabetes mellitus: A randomized trial. Ann. Intern. Med. 2016, 165, 305-315. [CrossRef] [PubMed]

190. Caldwell, S.H.; Hespenheide, E.E.; Redick, J.A.; Iezzoni, J.C.; Battle, E.H.; Sheppard, B.L. A pilot study of a thiazolidinedione, troglitazone, in nonalcoholic steatohepatitis. Am. J. Gastroenterol. 2001, 96, 519-525. [CrossRef] [PubMed]

191. Neuschwander-Tetri, B.A.; Brunt, E.M.; Wehmeier, K.R.; Oliver, D.; Bacon, B.R. Improved nonalcoholic steatohepatitis after 48 weeks of treatment with the PPAR- $\gamma$ ligand rosiglitazone. Hepatology 2003, 38, 1008-1017. [CrossRef] [PubMed]

192. Ratziu, V.; Giral, P.; Jacqueminet, S.; Charlotte, F.; Hartemann-Heurtier, A.; Serfaty, L.; Podevin, P.; Lacorte, J.M.; Bernhardt, C.; Bruckert, E.; et al. Rosiglitazone for nonalcoholic steatohepatitis: One-year results of the randomized placebo-controlled Fatty Liver Improvement with Rosiglitazone Therapy (FLIRT) Trial. Gastroenterology 2008, 135, 100-110. [CrossRef] [PubMed]

193. Ratziu, V.; Charlotte, F.; Bernhardt, C.; Giral, P.; Halbron, M.; LeNaour, G.; Hartmann-Heurtier, A.; Bruckert, E.; Poynard, T.; Group, L.S. Long-term efficacy of rosiglitazone in nonalcoholic steatohepatitis: Results of the fatty liver improvement by rosiglitazone therapy (FLIRT 2) extension trial. Hepatology 2010, 51, 445-453. [CrossRef] [PubMed] 
194. Idilman, R.; Mizrak, D.; Corapcioglu, D.; Bektas, M.; Doganay, B.; Sayki, M.; Coban, S.; Erden, E.; Soykan, I.; Emral, R.; et al. Clinical trial: Insulin-sensitizing agents may reduce consequences of insulin resistance in individuals with non-alcoholic steatohepatitis. Aliment. Pharmacol. Ther. 2008, 28, 200-208. [CrossRef] [PubMed]

195. Akyüz, F.; Demir, K.; Özdil, S.; Aksoy, N.; Poturoğlu, Ş.; İbrişim, D.; Kaymakoğlu, S.; Beşışık, F.; Boztaş, G.; Çakaloğlu, Y.; et al. The effects of rosiglitazone, metformin, and diet with exercise in nonalcoholic fatty liver disease. Dig. Dis. Sci. 2007, 52, 2359-2367. [CrossRef] [PubMed]

196. Ratziu, V.; Harrison, S.A.; Francque, S.; Bedossa, P.; Lehert, P.; Serfaty, L.; Romero-Gomez, M.; Boursier, J.; Abdelmalek, M.; Caldwell, S.; et al. Elafibranor, an agonist of the peroxisome proliferator-activated receptor $-\alpha$ and $-\delta$, induces resolution of nonalcoholic steatohepatitis without fibrosis worsening. Gastroenterology 2016, 150, 1147-1159. [CrossRef] [PubMed]

197. Lee, Y.-H.; Kim, J.H.; Kim, S.R.; Jin, H.Y.; Rhee, E.-J.; Cho, Y.M.; Lee, B.-W. Lobeglitazone, a novel thiazolidinedione, improves non-alcoholic fatty liver disease in type 2 diabetes: Its efficacy and predictive factors related to responsiveness. J. Korean Med. Sci. 2017, 32, 60-69. [CrossRef] [PubMed]

198. Wettstein, G.; Luccarini, J.-M.; Poekes, L.; Faye, P.; Kupkowski, F.; Adarbes, V.; Defrêne, E.; Estivalet, C.; Gawronski, X.; Jantzen, I.; et al. The new-generation pan-peroxisome proliferator-activated receptor agonist IVA337 protects the liver from metabolic disorders and fibrosis. Hepatol. Commun. 2017, 1, 524-537. [CrossRef] [PubMed]

199. Gershwin, M.E.; Ansari, A.A.; Mackay, I.R.; Nakanuma, Y.; Nishio, A.; Rowley, M.J.; Coppel, R.L. Primary biliary cirrhosis: An orchestrated immune response against epithelial cells. Immunol. Rev. 2000, 174, $210-225$. [CrossRef]

200. Lindor, K.D.; Gershwin, M.E.; Poupon, R.; Kaplan, M.; Bergasa, N.V.; Heathcote, E.J. Primary biliary cirrhosis. Hepatology 2009, 50, 291-308. [CrossRef]

201. Corpechot, C.; Carrat, F.; Bahr, A.; Chrétien, Y.; Poupon, R.-E.; Poupon, R. The effect of ursodeoxycholic acid therapy on the natural course of primary biliary cirrhosis. Gastroenterology 2005, 128, 297-303. [CrossRef] [PubMed]

202. Corpechot, C.; Chazouillères, O.; Rousseau, A.; Le Gruyer, A.; Habersetzer, F.; Mathurin, P.; Goria, O.; Potier, P.; Minello, A.; Silvain, C.; et al. A placebo-controlled trial of bezafibrate in primary biliary cholangitis. N. Engl. J. Med. 2018, 378, 2171-2181. [CrossRef] [PubMed]

203. Itakura, J.; Izumi, N.; Nishimura, Y.; Inoue, K.; Ueda, K.; Nakanishi, H.; Tsuchiya, K.; Hamano, K.; Asahina, Y.; Kurosaki, M.; et al. Prospective randomized crossover trial of combination therapy with bezafibrate and UDCA for primary biliary cirrhosis. Hepatol. Res. 2004, 29, 216-222. [CrossRef] [PubMed]

204. Iwasaki, S.; Ohira, H.; Nishiguchi, S.; Zeniya, M.; Kaneko, S.; Onji, M.; Ishibashi, H.; Sakaida, I.; Kuriyama, S.; Ichida, T.; et al. The efficacy of ursodeoxycholic acid and bezafibrate combination therapy for primary biliary cirrhosis: A prospective, multicenter study. Hepatol. Res. 2008, 38, 557-564. [CrossRef]

205. Honda, A.; Tanaka, A.; Kaneko, T.; Komori, A.; Abe, M.; Inao, M.; Namisaki, T.; Hashimoto, N.; Kawata, K.; Takahashi, A.; et al. Bezafibrate improves GLOBE and UK-PBC scores and long-term outcomes in patients with primary biliary cholangitis. Hepatology 2019. [CrossRef] [PubMed]

206. Levy, C.; Peter, J.A.; Nelson, D.R.; Keach, J.; Petz, J.; Cabrera, R.; Clark, V.; Firpi, R.J.; Morelli, G.; Soldevila-Pico, C.; et al. Pilot study: Fenofibrate for patients with primary biliary cirrhosis and an incomplete response to ursodeoxycholic acid. Aliment. Pharmacol. Ther. 2011, 33, 235-242. [CrossRef] [PubMed]

207. Grigorian, A.Y.; Mardini, H.E.; Corpechot, C.; Poupon, R.; Levy, C. Fenofibrate is effective adjunctive therapy in the treatment of primary biliary cirrhosis: A meta-analysis. Clin. Res. Hepatol. Gastroenterol. 2015, 39, 296-306. [CrossRef]

208. Han, X.F.; Wang, Q.X.; Liu, Y.; You, Z.R.; Bian, Z.L.; Qiu, D.K.; Ma, X. Efficacy of fenofibrate in Chinese patients with primary biliary cirrhosis partially responding to ursodeoxycholic acid therapy. J. Dig. Dis. 2012, 13, 219-224. [CrossRef]

209. Cheung, A.C.; Lapointe-Shaw, L.; Kowgier, M.; Meza-Cardona, J.; Hirschfield, G.M.; Janssen, H.L.A.; Feld, J.J. Combined ursodeoxycholic acid (UDCA) and fenofibrate in primary biliary cholangitis patients with incomplete UDCA response may improve outcomes. Aliment. Pharmacol. Ther. 2016, 43, 283-293. [CrossRef]

210. Liberopoulos, E.N.; Florentin, M.; Elisaf, M.S.; Mikhailidis, D.P.; Tsianos, E. Fenofibrate in primary biliary cirrhosis: A pilot study. Open Cardiovasc. Med. J. 2010, 4, 120-126. [CrossRef] 
211. Jones, D.; Boudes, P.F.; Swain, M.G.; Bowlus, C.L.; Galambos, M.R.; Bacon, B.R.; Doerffel, Y.; Gitlin, N.; Gordon, S.C.; Odin, J.A.; et al. Seladelpar (MBX-8025), a selective PPAR- $\delta$ agonist, in patients with primary biliary cholangitis with an inadequate response to ursodeoxycholic acid: A double-blind, randomised, placebo-controlled, phase 2, proof-of-concept study. Lancet Gastroenterol. Hepatol. 2017, 2, 716-726. [CrossRef]

212. McHutchison, J.; Goodman, Z.; Patel, K.; Makhlouf, H.; Rodriguez-Torres, M.; Shiffman, M.; Rockey, D.; Husa, P.; Chuang, W.L.; Levine, R.; et al. Farglitazar lacks antifibrotic activity in patients with chronic hepatitis C infection. Gastroenterology 2010, 138, 1365-1373. [CrossRef]

213. Overbeck, K.; Genné, D.; Golay, A.; Negro, F. Pioglitazone in chronic hepatitis C not responding to pegylated interferon- $\alpha$ and ribavirin. J. Hepatol. 2008, 49, 295-298. [CrossRef] [PubMed]

214. Chojkier, M.; Elkhayat, H.; Sabry, D.; Donohue, M.; Buck, M. Pioglitazone decreases hepatitis C viral load in overweight, treatment naïve, genotype 4 infected-patients: A pilot study. PLoS ONE 2012, 7, e31516. [CrossRef] [PubMed]

215. Hsu, C.-S.; Hsu, S.-J.; Lin, H.H.; Tseng, T.-C.; Wang, C.-C.; Chen, D.-S.; Kao, J.-H. A pilot study of add-on oral hypoglycemic agents in treatment-naïve genotype- 1 chronic hepatitis $C$ patients receiving peginterferon alfa-2b plus ribavirin. J. Formos. Med. Assoc. 2014, 113, 716-721. [CrossRef] [PubMed]

216. Vachon, M.-L.; Dieterich, D.T. The era of direct-acting antivirals has begun: The beginning of the end for HCV? Semin. Liver Dis. 2011, 31, 399-409. [CrossRef] [PubMed]

217. Bolier, R.; de Vries, E.S.; Parés, A.; Helder, J.; Kemper, E.M.; Zwinderman, K.; Elferink, R.P.O.; Beuers, U.; van Buuren, H.R.; Drenth, J.P.; et al. Fibrates for the treatment of cholestatic itch (FITCH): Study protocol for a randomized controlled trial. Trials 2017, 18, 230. [CrossRef] [PubMed]

218. Mihai, S.; Codrici, E.; Popescu, I.D.; Enciu, A.-M.; Albulescu, L.; Necula, L.G.; Mambet, C.; Anton, G.; Tanase, C. Inflammation-related mechanisms in chronic kidney disease prediction, progression, and outcome. J. Immunol. Res. 2018, 2018, 2180373. [CrossRef]

219. Satirapoj, B.; Watanakijthavonkul, K.; Supasyndh, O. Safety and efficacy of low dose pioglitazone compared with standard dose pioglitazone in type 2 diabetes with chronic kidney disease: A randomized controlled trial. PLoS ONE 2018, 13, e0206722. [CrossRef] [PubMed]

220. Zanchi, A.; Tappy, L.; Lê, K.-A.; Bortolotti, M.; Theumann, N.; Halabi, G.; Gauthier, T.; Mathieu, C.; Tremblay, S.; Bertrand, P.C.; et al. Pioglitazone improves fat distribution, the adipokine profile and hepatic insulin sensitivity in non-diabetic end-stage renal disease subjects on maintenance dialysis: A randomized cross-over pilot study. PLoS ONE 2014, 9, e109134. [CrossRef] [PubMed]

221. Chan, D.T.; Watts, G.F.; Irish, A.B.; Dogra, G.K. Rosiglitazone does not improve vascular function in subjects with chronic kidney disease. Nephrol. Dial. Transplant. 2011, 26, 3543-3549. [CrossRef] [PubMed]

222. Schneider, C.A.; Ferrannini, E.; DeFronzo, R.; Schernthaner, G.; Yates, J.; Erdmann, E. Effect of pioglitazone on cardiovascular outcome in diabetes and chronic kidney disease. J. Am. Soc. Nephrol. 2008, 19, 182-187. [CrossRef] [PubMed]

223. Werzowa, J.; Hecking, M.; Haidinger, M.; Lechner, F.; Döller, D.; Pacini, G.; Stemer, G.; Pleiner, J.; Frantal, S.; Säemann, M.D. Vildagliptin and pioglitazone in patients with impaired glucose tolerance after kidney transplantation: A randomized, placebo-controlled clinical trial. Transplantation 2013, 95, 456-462. [CrossRef] [PubMed]

224. Han, S.J.; Hur, K.Y.; Kim, Y.S.; Kang, E.S.; Kim, S.I.; Kim, M.S.; Kwak, J.Y.; Kim, D.J.; Choi, S.H.; Cha, B.S.; et al. Effects of pioglitazone on subclinical atherosclerosis and insulin resistance in nondiabetic renal allograft recipients. Nephrol. Dial. Transplant. 2009, 25, 976-984. [CrossRef] [PubMed]

225. Maalouf, N.M.; Poindexter, J.R.; Adams-Huet, B.; Moe, O.W.; Sakhaee, K. Increased production and reduced urinary buffering of acid in uric acid stone formers is ameliorated by pioglitazone. Kidney Int. 2019, 95, 1262-1268. [CrossRef] [PubMed]

226. Watson, G.S.; Cholerton, B.A.; Reger, M.A.; Baker, L.D.; Plymate, S.R.; Asthana, S.; Fishel, M.A.; Kulstad, J.J.; Green, P.S.; Cook, D.G.; et al. Preserved cognition in patients with early Alzheimer disease and amnestic mild cognitive impairment during treatment with rosiglitazone: A preliminary study. Am. J. Geriatr. Psychiatry 2005, 13, 950-958. [CrossRef] [PubMed]

227. Tzimopoulou, S.; Cunningham, V.J.; Nichols, T.E.; Searle, G.; Brid, N.P.; Mistry, P.; Dixon, I.J.; Hallett, W.A.; Whitcher, B.; Brown, A.P.; et al. A multi-center randomized proof-of-concept clinical trial applying $\left[{ }^{18} \mathrm{~F}\right]$ FDG-PET for evaluation of metabolic therapy with rosiglitazone XR in mild to moderate Alzheimer's disease. J. Alzheimers Dis. 2010, 22, 1241-1256. [CrossRef] 
228. Risner, M.E.; Saunders, A.M.; Altman, J.F.B.; Ormandy, G.C.; Craft, S.; Foley, I.M.; Zvartau-Hind, M.E.; Hosford, D.A.; Roses, A.D.; Group for the Rosiglitazone in Alzheimer's Disease Study. Efficacy of rosiglitazone in a genetically defined population with mild-to-moderate Alzheimer's disease. Pharm. J. 2006, 6, 246-254. [CrossRef]

229. Gold, M.; Alderton, C.; Zvartau-Hind, M.; Egginton, S.; Saunders, A.M.; Irizarry, M.; Craft, S.; Landreth, G.; Linnamägi, Ü.; Sawchak, S. Rosiglitazone monotherapy in mild-to-moderate Alzheimer's disease: Results from a randomized, double-blind, placebo-controlled phase III study. Dement. Geriatr. Cogn. Disord. 2010, 30, 131-146. [CrossRef]

230. Harrington, C.; Sawchak, S.; Chiang, C.; Davies, J.; Donovan, C.; Saunders, A.M.; Irizarry, M.; Jeter, B.; Zvartau-Hind, M.; van Dyck, C.; et al. Rosiglitazone does not improve cognition or global function when used as adjunctive therapy to AChE inhibitors in mild-to-moderate Alzheimers disease: Two phase 3 studies. Curr. Alzheimer Res. 2011, 8, 592-606. [CrossRef]

231. Hildreth, K.L.; Van Pelt, R.E.; Moreau, K.L.; Grigsby, J.; Hoth, K.F.; Pelak, V.; Anderson, C.A.; Parnes, B.; Kittelson, J.; Wolfe, P.; et al. Effects of pioglitazone or exercise in older adults with mild cognitive impairment and insulin resistance: A pilot study. Dement. Geriatr. Cogn. Disord. Extra 2015, 5, 51-63. [CrossRef] [PubMed]

232. Geldmacher, D.S.; Fritsch, T.; McClendon, M.J.; Landreth, G. A randomized pilot clinical trial of the safety of pioglitazone in treatment of patients with Alzheimer disease. JAMA Neurol. 2011, 68, 45-50. [CrossRef] [PubMed]

233. NINDS Exploratory Trials in Parkinson Disease (NET-PD) FS-ZONE Investigators. Pioglitazone in early Parkinson's disease: A phase 2, multicentre, double-blind, randomised trial. Lancet Neurol. 2015, 14, 795-803. [CrossRef]

234. Dutta, K.; Patel, P.; Julien, J.-P. Protective effects of Withania somnifera extract in SOD1G93A mouse model of amyotrophic lateral sclerosis. Exp. Neurol. 2018, 309, 193-204. [CrossRef] [PubMed]

235. Schütz, B.; Reimann, J.; Dumitrescu-Ozimek, L.; Kappes-Horn, K.; Landreth, G.E.; Schürmann, B.; Zimmer, A.; Heneka, M.T. The oral antidiabetic pioglitazone protects from neurodegeneration and amyotrophic lateral sclerosis-like symptoms in superoxide dismutase-G93A transgenic mice. J. Neurosci. 2005, 25, 7805-7812. [CrossRef] [PubMed]

236. Joardar, A.; Menzl, J.; Podolsky, T.C.; Manzo, E.; Estes, P.S.; Ashford, S.; Zarnescu, D.C. PPAR gamma activation is neuroprotective in a Drosophila model of ALS based on TDP-43. Hum. Mol. Genet. 2014, 24, 1741-1754. [CrossRef] [PubMed]

237. Dupuis, L.; Dengler, R.; Heneka, M.T.; Meyer, T.; Zierz, S.; Kassubek, J.; Fischer, W.; Steiner, F.; Lindauer, E.; Otto, M.; et al. A randomized, double blind, placebo-controlled trial of pioglitazone in combination with riluzole in amyotrophic lateral sclerosis. PLoS ONE 2012, 7, e37885. [CrossRef]

238. Levine, T.D.; Bowser, R.; Hank, N.C.; Gately, S.; Stephan, D.; Saperstein, D.S.; Van Keuren-Jensen, K. A pilot trial of pioglitazone $\mathrm{HCl}$ and tretinoin in ALS: Cerebrospinal fluid biomarkers to monitor drug efficacy and predict rate of disease progression. Neurol. Res. Int. 2012, 2012, 582075. [CrossRef]

239. Höftberger, R.; Leisser, M.; Bauer, J.; Lassmann, H. Autoimmune encephalitis in humans: How closely does it reflect multiple sclerosis? Acta Neuropathol. Commun. 2015, 3, 80. [CrossRef] [PubMed]

240. Kaiser, C.C.; Shukla, D.K.; Stebbins, G.T.; Skias, D.D.; Jeffery, D.R.; Stefoski, D.; Katsamakis, G.; Feinstein, D.L. A pilot test of pioglitazone as an add-on in patients with relapsing remitting multiple sclerosis. J. Neuroimmunol. 2009, 211, 124-130. [CrossRef]

241. Weinstein, D.; Boyko, A.; Pugliese, L.; Tang, H.; Lanfear, D.; Zivadinov, R.; Finck, B. CHS-131, A novel once daily oral treatment, decreased lesion burden of patients with relapsing-remitting course of multiple sclerosis (RRMS) in a randomized, double-blind, phase 2b, multicenter study (S50.002). Neurology 2017, 88, S50.002.

242. Puligheddu, M.; Melis, M.; Pillolla, G.; Milioli, G.; Parrino, L.; Terzano, G.M.; Aroni, S.; Sagheddu, C.; Marrosu, F.; Pistis, M.; et al. Rationale for an adjunctive therapy with fenofibrate in pharmacoresistant nocturnal frontal lobe epilepsy. Epilepsia 2017, 58, 1762-1770. [CrossRef] [PubMed]

243. Kearney, M.; Orrell, R.W.; Fahey, M.; Brassington, R.; Pandolfo, M. Pharmacological treatments for Friedreich ataxia. Cochrane Database Syst. Rev. 2016, 2016, CD007791. [CrossRef] [PubMed]

244. Foll, B.L.; Ciano, P.D.; Leigh, V.P.; Steven, R.G.; Roberto, C. Peroxisome proliferator-activated receptor (PPAR) agonists as promising new medications for drug addiction: Preclinical evidence. Curr. Drug Targets 2013, 14, 768-776. [CrossRef] [PubMed] 
245. Gendy, M.N.S.; Di Ciano, P.; Kowalczyk, W.J.; Barrett, S.P.; George, T.P.; Heishman, S.; Le Foll, B. Testing the PPAR hypothesis of tobacco use disorder in humans: A randomized trial of the impact of gemfibrozil (a partial PPAR $\alpha$ agonist) in smokers. PLoS ONE 2018, 13, e0201512. [CrossRef] [PubMed]

246. Perkins, K.A.; Karelitz, J.L.; Michael, V.C.; Fromuth, M.; Conklin, C.A.; Chengappa, K.N.R.; Hope, C.; Lerman, C. Initial evaluation of fenofibrate for efficacy in aiding smoking abstinence. Nicotine Tob. Res. 2015, 18, 74-78. [CrossRef] [PubMed]

247. Jones, J.D.; Comer, S.D.; Metz, V.E.; Manubay, J.M.; Mogali, S.; Ciccocioppo, R.; Martinez, S.; Mumtaz, M.; Bisaga, A. Pioglitazone, a PPAR $\gamma$ agonist, reduces nicotine craving in humans, with marginal effects on abuse potential. Pharmacol. Biochem. Behav. 2017, 163, 90-100. [CrossRef] [PubMed]

248. Schmitz, J.M.; Green, C.E.; Hasan, K.M.; Vincent, J.; Suchting, R.; Weaver, M.F.; Moeller, F.G.; Narayana, P.A.; Cunningham, K.A.; Dineley, K.T.; et al. PPAR-gamma agonist pioglitazone modifies craving intensity and brain white matter integrity in patients with primary cocaine use disorder: A double-blind randomized controlled pilot trial. Addiction 2017, 112, 1861-1868. [CrossRef] [PubMed]

249. Jones, J.D.; Sullivan, M.A.; Manubay, J.M.; Mogali, S.; Metz, V.E.; Ciccocioppo, R.; Comer, S.D. The effects of pioglitazone, a PPAR $\gamma$ receptor agonist, on the abuse liability of oxycodone among nondependent opioid users. Physiol. Behav. 2016, 159, 33-39. [CrossRef] [PubMed]

250. Schroeder, J.R.; Phillips, K.A.; Epstein, D.H.; Jobes, M.L.; Furnari, M.A.; Kennedy, A.P.; Heilig, M.; Preston, K.L. Assessment of pioglitazone and proinflammatory cytokines during buprenorphine taper in patients with opioid use disorder. Psychopharmacology (Berl) 2018, 235, 2957-2966. [CrossRef]

251. Kemp, D.E.; Schinagle, M.; Gao, K.; Conroy, C.; Ganocy, S.J.; Ismail-Beigi, F.; Calabrese, J.R. PPAR- $\gamma$ agonism as a modulator of mood: Proof-of-concept for pioglitazone in bipolar depression. CNS Drugs 2014, 28, 571-581. [CrossRef] [PubMed]

252. Rasgon, N.L.; Kenna, H.A.; Williams, K.E.; Powers, B.; Wroolie, T.; Schatzberg, A.F. Rosiglitazone add-on in treatment of depressed patients with insulin resistance: A pilot study. Sci. World J. 2010, 10, 321-328. [CrossRef] [PubMed]

253. Sepanjnia, K.; Modabbernia, A.; Ashrafi, M.; Modabbernia, M.-J.; Akhondzadeh, S. Pioglitazone adjunctive therapy for moderate-to-severe major depressive disorder: Randomized double-blind placebo-controlled trial. Neuropsychopharmacology 2012, 37, 2093-2100. [CrossRef] [PubMed]

254. Lin, K.W.; Wroolie, T.E.; Robakis, T.; Rasgon, N.L. Adjuvant pioglitazone for unremitted depression: Clinical correlates of treatment response. Psychiatry Res. 2015, 230, 846-852. [CrossRef] [PubMed]

255. Smith, R.C.; Jin, H.; Li, C.; Bark, N.; Shekhar, A.; Dwivedi, S.; Mortiere, C.; Lohr, J.; Hu, Q.; Davis, J.M. Effects of pioglitazone on metabolic abnormalities, psychopathology, and cognitive function in schizophrenic patients treated with antipsychotic medication: A randomized double-blind study. Schizophr. Res. 2013, 143, 18-24. [CrossRef] [PubMed]

256. Aftab, A.; Kemp, D.E.; Ganocy, S.J.; Schinagle, M.; Conroy, C.; Brownrigg, B.; D'Arcangelo, N.; Goto, T.; Woods, N.; Serrano, M.B.; et al. Double-blind, placebo-controlled trial of pioglitazone for bipolar depression. J. Affect. Disord. 2019, 245, 957-964. [CrossRef]

257. Boris, M.; Kaiser, C.C.; Goldblatt, A.; Elice, M.W.; Edelson, S.M.; Adams, J.B.; Feinstein, D.L. Effect of pioglitazone treatment on behavioral symptoms in autistic children. J. Neuroinflamm. 2007, 4, 3. [CrossRef] [PubMed]

258. Ghaleiha, A.; Rasa, S.M.; Nikoo, M.; Farokhnia, M.; Mohammadi, M.-R.; Akhondzadeh, S. A pilot double-blind placebo-controlled trial of pioglitazone as adjunctive treatment to risperidone: Effects on aberrant behavior in children with autism. Psychiatry Res. 2015, 229, 181-187. [CrossRef] [PubMed]

259. Capano, L.; Dupuis, A.; Brian, J.; Mankad, D.; Genore, L.; Hastie Adams, R.; Smile, S.; Lui, T.; Odrobina, D.; Foster, J.A.; et al. A pilot dose finding study of pioglitazone in autistic children. Mol. Autism 2018, 9, 59. [CrossRef] [PubMed]

260. Ormseth, M.J.; Oeser, A.M.; Cunningham, A.; Bian, A.; Shintani, A.; Solus, J.; Tanner, S.B.; Stein, C.M. Peroxisome proliferator-activated receptor $\gamma$ agonist effect on rheumatoid arthritis: A randomized controlled trial. Arthrit. Res. Ther. 2013, 15, R110. [CrossRef]

261. Marder, W.; Khalatbari, S.; Myles, J.D.; Hench, R.; Lustig, S.; Yalavarthi, S.; Parameswaran, A.; Brook, R.D.; Kaplan, M.J. The peroxisome proliferator activated receptor- $\gamma$ pioglitazone improves vascular function and decreases disease activity in patients with rheumatoid arthritis. J. Am. Heart Assoc. 2013, 2, e000441. [CrossRef] [PubMed] 
262. Shahin, D.; Toraby, E.E.; Abdel-Malek, H.; Boshra, V.; Elsamanoudy, A.Z.; Shaheen, D. Effect of peroxisome proliferator-activated receptor gamma agonist (pioglitazone) and methotrexate on disease activity in rheumatoid arthritis (experimental and clinical study). Clin. Med. Insights Arthrit. Musculoskelet. Disord. 2011, 4, 1-10. [CrossRef] [PubMed]

263. Knight, J.S.; Kaplan, M.J. Cardiovascular disease in lupus: Insights and updates. Curr. Opin. Rheumatol. 2013, 25, 597-605. [CrossRef] [PubMed]

264. Juárez-Rojas, J.; Medina-Urrutia, A.; Jorge-Galarza, E.; Caracas-Portilla, N.; Posadas-Sánchez, R.; Cardoso-Saldaña, G.; Goycochea-Robles, M.; Silveira, L.; Lino-Pérez, L.; Mas-Oliva, J.; et al. Pioglitazone improves the cardiovascular profile in patients with uncomplicated systemic lupus erythematosus: A double-blind randomized clinical trial. Lupus 2012, 21, 27-35. [CrossRef]

265. Boggild, A.K.; Krudsood, S.; Patel, S.N.; Serghides, L.; Tangpukdee, N.; Katz, K.; Wilairatana, P.; Liles, W.C.; Looareesuwan, S.; Kain, K.C. Use of peroxisome proliferator-activated receptor $\gamma$ agonists as adjunctive treatment for Plasmodium falciparum malaria: A randomized, double-blind, placebo-controlled trial. Clin. Infect. Dis. 2009, 49, 841-849. [CrossRef] [PubMed]

266. Varo, R.; Crowley, V.M.; Sitoe, A.; Madrid, L.; Serghides, L.; Bila, R.; Mucavele, H.; Mayor, A.; Bassat, Q.; Kain, K.C. Safety and tolerability of adjunctive rosiglitazone treatment for children with uncomplicated malaria. Malar. J. 2017, 16, 215. [CrossRef]

267. Lewis, J.D.; Lichtenstein, G.R.; Deren, J.J.; Sands, B.E.; Hanauer, S.B.; Katz, J.A.; Lashner, B.; Present, D.H.; Chuai, S.; Ellenberg, J.H.; et al. Rosiglitazone for active ulcerative colitis: A randomized placebo-controlled trial. Gastroenterology 2008, 134, 688-695. [CrossRef]

268. Pedersen, G.; Brynskov, J. Topical rosiglitazone treatment improves ulcerative colitis by restoring peroxisome proliferator-activated receptor- $\gamma$ activity. Am. J. Gastroenterol. 2010, 105, 1595-1603. [CrossRef]

269. Benayoun, L.; Letuve, S.; Druilhe, A.; Boczkowski, J.; Dombret, M.-C.; Mechighel, P.; Megret, J.; Leseche, G.; Aubier, M.; Pretolani, M. Regulation of peroxisome proliferator-activated receptor $\gamma$ expression in human asthmatic airways. Am. J. Respir. Crit. Care Med. 2001, 164, 1487-1494. [CrossRef]

270. Richards, D.B.; Bareille, P.; Lindo, E.L.; Quinn, D.; Farrow, S.N. Treatment with a peroxisomal proliferator activated receptor gamma agonist has a modest effect in the allergen challenge model in asthma: A randomised controlled trial. Respir. Med. 2010, 104, 668-674. [CrossRef]

271. Anderson, J.R.; Mortimer, K.; Pang, L.; Smith, K.M.; Bailey, H.; Hodgson, D.B.; Shaw, D.E.; Knox, A.J.; Harrison, T.W. Evaluation of the PPAR- $\gamma$ agonist pioglitazone in mild asthma: A double-blind randomized controlled trial. PLoS ONE 2016, 11, e0160257. [CrossRef] [PubMed]

272. Dixon, A.E.; Subramanian, M.; DeSarno, M.; Black, K.; Lane, L.; Holguin, F. A pilot randomized controlled trial of pioglitazone for the treatment of poorly controlled asthma in obesity. Respir. Res. 2015, 16, 143. [CrossRef] [PubMed]

273. Kaler, M.; Barochia, A.V.; Weir, N.A.; Cuento, R.A.; Stylianou, M.; Roth, M.J.; Filie, A.C.; Vaughey, E.C.; Nathan, S.D.; Levine, S.J. A randomized, placebo-controlled, double-blinded, crossover trial of pioglitazone for severe asthma. J. Allergy Clin. Immunol. 2017, 140, 1716-1718. [CrossRef] [PubMed]

274. Malhotra, A.; Shafiq, N.; Rajagopalan, S.; Dogra, S.; Malhotra, S. Thiazolidinediones for plaque psoriasis: A systematic review and meta-analysis. Evid. Based Med. 2012, 17, 171-176. [CrossRef] [PubMed]

275. Mittal, R.; Malhotra, S.; Pandhi, P.; Kaur, I.; Dogra, S. Efficacy and safety of combination acitretin and pioglitazone therapy in patients with moderate to severe chronic plaque-type psoriasis: A randomized, double-blind, placebo-controlled clinical trial. JAMA Dermatol. 2009, 145, 387-393. [CrossRef] [PubMed]

276. Moravek, M.B.; Ward, E.A.; Lebovic, D.I. Thiazolidinediones as therapy for endometriosis: A case series. Gynecol. Obstet. Investig. 2009, 68, 167-170. [CrossRef] [PubMed]

277. Konstan, M.; Hilliard, K.; Bucur, C.; Xue, W.; Schluchter, M.; Divoky, E.; JE, K.; Hilliard, J. Effect of pioglitazone on sputum markers of inflammation in cystic fibrosis [abstract]. Pediatr. Pulmonol. 2008, 43, 310.

278. Kaplan, J.M.; Zingarelli, B.; Krallman, K.; Girdwood, S.T.; Lagory, D.; Mizuno, T.; Fei, L.; Wong, H.R.; Vinks, A.A. Phase 1 safety and pharmacokinetic study on the use of pioglitazone in critically ill patients with sepsis: A randomized clinical trial. Intensive Care Med. 2018, 44, 2006-2008. [CrossRef] [PubMed]

279. Chen, D.L.; Huang, H.J.; Byers, D.E.; Shifren, A.; Belikoff, B.; Engle, J.T.; Arentson, E.; Kemp, D.; Phillips, S.; Scherrer, D.E.; et al. The peroxisome proliferator-activated receptor agonist pioglitazone and 5-lipoxygenase inhibitor zileuton have no effect on lung inflammation in healthy volunteers by positron emission tomography in a single-blind placebo-controlled cohort study. PLoS ONE 2018, 13, e0191783. [CrossRef] [PubMed] 
280. Migliavacca, M.; Assanelli, A.; Ferrua, F.; Cicalese, M.P.; Biffi, A.; Frittoli, M.; Silvani, P.; Chidini, G.; Calderini, E.; Mandelli, A.; et al. Pioglitazone as a novel therapeutic approach in chronic granulomatous disease. J. Allergy Clin. Immunol. 2016, 137, 1913-1915.e2. [CrossRef]

281. Mulvey, C.K.; Ferguson, J.F.; Tabita-Martinez, J.; Kong, S.; Shah, R.Y.; Patel, P.N.; Master, S.R.; Usman, M.H.U.; Propert, K.J.; Shah, R.; et al. Peroxisome proliferator-activated receptor- $\alpha$ agonism with fenofibrate does not suppress inflammatory responses to evoked endotoxemia. J. Am. Heart Assoc. 2012, 1, e002923. [CrossRef]

282. Rhodus, N.; Rohrer, M.; Pambuccian, S.; Keel, S.; Bliss, R.L.; Szabo, E.; Ondrey, F. Phase IIa chemoprevention clinical trial of pioglitazone for oral leukoplakia. In Proceedings of the 89th General Session \& Exhibition of the International Association for Dental Research, San Diego, CA, USA, 16-19 March 2011.

283. Smallridge, R.C.; Copland, J.A.; Brose, M.S.; Wadsworth, J.T.; Houvras, Y.; Menefee, M.E.; Bible, K.C.; Shah, M.H.; Gramza, A.W.; Klopper, J.P.; et al. Efatutazone, an oral PPAR- $\gamma$ agonist, in combination with paclitaxel in anaplastic thyroid cancer: Results of a multicenter phase 1 trial. J. Clin. Endocrinol. Metab. 2013, 98, 2392-2400. [CrossRef] [PubMed]

284. Giordano, T.J.; Haugen, B.R.; Sherman, S.I.; Shah, M.H.; Caoili, E.M.; Koenig, R.J. Pioglitazone therapy of PAX8-PPAR $\gamma$ fusion protein thyroid carcinoma. J. Clin. Endocrinol. Metab. 2018, 103, 1277-1281. [CrossRef] [PubMed]

285. Kebebew, E.; Lindsay, S.; Clark, O.H.; Woeber, K.A.; Hawkins, R.; Greenspan, F.S. Results of rosiglitazone therapy in patients with thyroglobulin-positive and radioiodine-negative advanced differentiated thyroid cancer. Thyroid 2009, 19, 953-956. [CrossRef] [PubMed]

286. Park, K.; Ahn, M.J.; Ahn, J.S.; Lee, J.; Sun, J.M.; Yi, J.H.; Cho, S.H.; Lee, J.Y.; Park, S.; Hwang, D.W. Phase 1b Study of Oral PPAR-gamma Agonist Efatutazone (CS-7017) in Combination With Carboplatin and Paclitaxel in Chemotherapy-Naive Korean Patients With Metastatic or Unresectable Locally Advanced Non-Small Cell Lung Cancer. Eur. J. Cancer 2011, 47, S609. [CrossRef]

287. Kim, S.-W.; Choi, C.-M.; Lee, D.H.; Lee, J.C.; Suh, C.; Lee, J.S. Phase Ib study of oral PPAR $\gamma$ agonist efatutazone (CS-7017) in combination with erlotinib in Korean patients with metastatic or unresectable locally advanced non-small cell lung cancer (NSCLC) who progressed after first-line therapy. J. Clin. Oncol. 2012, 30, e18052.

288. Wigle, D.A.; Mandrekar, S.J.; Allen-Ziegler, K.; Gesthalter, Y.; Holland, P.; Aubry, M.-C.; Limburg, P.J.; Avi, S.; Szabo, E. Pioglitazone as a candidate chemoprevention agent for lung cancer: A pilot window trial in early stage NSCLC. J. Clin. Oncol. 2014, 32, 1581. [CrossRef]

289. Keith, R.L.; Blatchford, P.J.; Merrick, D.T.; Bunn, P.A.; Bagwell, B.; Dwyer-Nield, L.D.; Jackson, M.K.; Geraci, M.; Miller, Y.E. A randomized phase II trial of pioglitazone for lung cancer chemoprevention in high risk current and former smokers. Cancer Prev. Res. 2019, 12, 721-730. [CrossRef]

290. Marshall, J.; Shuster, D.E.; Goldberg, T.R.; Copigneaux, C.; Chen, S.; Zahir, H.; Dutta, D.; Saleh, M.N.; Pishvaian, M.J.; Varela, M.S.; et al. A randomized, open-label phase II study of efatutazone in combination with FOLFIRI as second-line therapy for metastatic colorectal cancer (mCRC). J. Clin. Oncol. 2014, 32, 535. [CrossRef]

291. Smith, M.R.; Manola, J.; Kaufman, D.S.; George, D.; Oh, W.K.; Mueller, E.; Slovin, S.; Spiegelman, B.; Small, E.; Kantoff, P.W. Rosiglitazone versus placebo for men with prostate carcinoma and a rising serum prostate-specific antigen level after radical prostatectomy and/or radiation therapy. Cancer 2004, 101, 1569-1574. [CrossRef]

292. Mueller, E.; Smith, M.; Sarraf, P.; Kroll, T.; Aiyer, A.; Kaufman, D.S.; Oh, W.; Demetri, G.; Figg, W.D.; Zhou, X.-P.; et al. Effects of ligand activation of peroxisome proliferator-activated receptor $\gamma$ in human prostate cancer. Proc. Natl. Acad. Sci. USA 2000, 97, 10990-10995. [CrossRef] [PubMed]

293. Vogelhuber, M.; Feyerabend, S.; Stenzl, A.; Suedhoff, T.; Schulze, M.; Huebner, J.; Oberneder, R.; Wieland, W.; Mueller, S.; Eichhorn, F.; et al. Biomodulatory treatment of patients with castration-resistant prostate cancer: A phase II study of imatinib with pioglitazone, etoricoxib, dexamethasone and low-dose treosulfan. Cancer Microenviron. 2015, 8, 33-41. [CrossRef] [PubMed]

294. Murray, J.A.; Khanim, F.L.; Hayden, R.E.; Craddock, C.F.; Holyoake, T.L.; Jackson, N.; Lumley, M.; Bunce, C.M.; Drayson, M.T. Combined bezafibrate and medroxyprogesterone acetate have efficacy without haematological toxicity in elderly and relapsed acute myeloid leukaemia (AML). Br. J. Haematol. 2010, 149, 65-69. [CrossRef] [PubMed] 
295. Murray, J.; Pratt, G.; Jacob, A.; Clark, F.; Blundred, R.; Fox, S.; Bishop, R.; Wheatley, K.; Khanim, F.; Bunce, C.; et al. Single arm phase II trial assessing the safety, compliance with and activity of Bezafibrate and medroxyProgesterone acetate $(\mathrm{BaP})$ therapy against myeloid and lymphoid cancers. Contemp. Clin. Trials Commun. 2019, 14, 100361. [CrossRef] [PubMed]

296. Rousselot, P.; Prost, S.; Guilhot, J.; Roy, L.; Etienne, G.; Legros, L.; Charbonnier, A.; Coiteux, V.; Cony-Makhoul, P.; Huguet, F.; et al. Pioglitazone together with imatinib in chronic myeloid leukemia: A proof of concept study. Cancer 2017, 123, 1791-1799. [CrossRef] [PubMed]

297. Sepmeyer, J.A.; Greer, J.P.; Koyama, T.; Zic, J.A. Open-label pilot study of combination therapy with rosiglitazone and bexarotene in the treatment of cutaneous T-cell lymphoma. J. Am. Acad. Dermatol. 2007, 56, 584-587. [CrossRef] [PubMed]

298. Molyneux, E.; Merrick, B.; Khanim, F.L.; Banda, K.; Dunn, J.A.; Iqbal, G.; Bunce, C.M.; Drayson, M.T. Bezafibrate and medroxyprogesterone acetate in resistant and relapsed endemic Burkitt lymphoma in Malawi; an open-label, single-arm, phase 2 study (ISRCTN34303497). Br. J. Haematol. 2014, 164, 888-890. [CrossRef]

299. Hart, C.; Vogelhuber, M.; Hafner, C.; Landthaler, M.; Berneburg, M.; Haferkamp, S.; Herr, W.; Reichle, A. Biomodulatory metronomic therapy in stage IV melanoma is well-tolerated and may induce prolonged progression-free survival, a phase I trial. J. Eur. Acad. Dermatol. Venereol. 2016, 30, e119-e121. [CrossRef] [PubMed]

300. Reichle, A.; Bross, K.; Vogt, T.; Bataille, F.; Wild, P.; Berand, A.; Krause, S.W.; Andreesen, R. Pioglitazone and rofecoxib combined with angiostatically scheduled trofosfamide in the treatment of far-advanced melanoma and soft tissue sarcoma. Cancer 2004, 101, 2247-2256. [CrossRef]

301. Tontonoz, P.; Singer, S.; Forman, B.M.; Sarraf, P.; Fletcher, J.A.; Fletcher, C.D.M.; Brun, R.P.; Mueller, E.; Altiok, S.; Oppenheim, H.; et al. Terminal differentiation of human liposarcoma cells induced by ligands for peroxisome proliferator-activated receptor $\gamma$ and the retinoid X receptor. Proc. Natl. Acad. Sci. USA 1997, 94, 237-241. [CrossRef]

302. Demetri, G.D.; Fletcher, C.D.M.; Mueller, E.; Sarraf, P.; Naujoks, R.; Campbell, N.; Spiegelman, B.M.; Singer, S. Induction of solid tumor differentiation by the peroxisome proliferator-activated receptor- $\gamma$ ligand troglitazone in patients with liposarcoma. Proc. Natl. Acad. Sci. USA 1999, 96, 3951-3956. [CrossRef] [PubMed]

303. Debrock, G.; Vanhentenrijk, V.; Sciot, R.; Debiec-Rychter, M.; Oyen, R.; Van Oosterom, A. A phase II trial with rosiglitazone in liposarcoma patients. Br. J. Cancer 2003, 89, 1409-1412. [CrossRef] [PubMed]

304. Burstein, H.J.; Demetri, G.D.; Mueller, E.; Sarraf, P.; Spiegelman, B.M.; Winer, E.P. Use of the peroxisome proliferator-activated receptor (PPAR) $\gamma$ ligand troglitazone as treatment for refractory breast cancer: A phase II study. Breast Cancer Res. Treat. 2003, 79, 391-397. [CrossRef] [PubMed]

305. Yee, L.D.; Williams, N.; Wen, P.; Young, D.C.; Lester, J.; Johnson, M.V.; Farrar, W.B.; Walker, M.J.; Povoski, S.P.; Suster, S.; et al. Pilot study of rosiglitazone therapy in women with breast cancer: Effects of short-term therapy on tumor tissue and serum markers. Clin. Cancer Res. 2007, 13, 246-252. [CrossRef] [PubMed]

306. Bogazzi, F.; Rossi, G.; Lombardi, M.; Raggi, F.; Urbani, C.; Sardella, C.; Cosci, C.; Martino, E. Effect of rosiglitazone on serum IGF-I concentrations in uncontrolled acromegalic patients under conventional medical therapy: Results from a pilot phase 2 study. J. Endocrinol. Investig. 2011, 34, e43-e51. [CrossRef] [PubMed]

307. Robison, N.J.; Campigotto, F.; Chi, S.N.; Manley, P.E.; Turner, C.D.; Zimmerman, M.A.; Chordas, C.A.; Werger, A.M.; Allen, J.C.; Goldman, S.; et al. A phase II trial of a multi-agent oral antiangiogenic (metronomic) regimen in children with recurrent or progressive cancer. Pediatr. Blood Cancer 2014, 61, 636-642. [CrossRef] [PubMed]

308. Pishvaian, M.J.; Cotarla, I.; Wagner, A.J.; Deeken, J.F.; He, A.R.; Hwang, J.J.; Demetri, G.D.; Halim, A.; Copigneaux, C.; Marshall, J. Final reporting of a phase I clinical trial of the oral PPAR-gamma agonist, CS-7017, in patients with advanced malignancies. J. Clin. Oncol. 2010, 28, 2526. [CrossRef]

309. Du, Q.; Yang, S.; Wang, Y.-J.; Wu, B.; Zhao, Y.-Y.; Fan, B. Effects of thiazolidinediones on polycystic ovary syndrome: A meta-analysis of randomized placebo-controlled trials. Adv. Ther. 2012, 29, 763-774. [CrossRef]

310. Gupta, A.; Jakubowicz, D.; Nestler, J.E. Pioglitazone therapy increases insulin-stimulated release of d-Chiro-Inositol-containing Inositolphosphoglycan mediator in women with polycystic ovary syndrome. Metab. Syndr. Relat. Disord. 2016, 14, 391-396. [CrossRef] 
311. Tfayli, H.; Ulnach, J.W.; Lee, S.; Sutton-Tyrrell, K.; Arslanian, S. Drospirenone/Ethinyl estradiol versus rosiglitazone treatment in overweight adolescents with polycystic ovary syndrome: Comparison of metabolic, hormonal, and cardiovascular risk factors. J. Clin. Endocrinol. Metab. 2011, 96, 1311-1319. [CrossRef]

312. Glintborg, D.; Højlund, K.; Andersen, N.R.; Hansen, B.F.; Beck-Nielsen, H.; Wojtaszewski, J.F.P. Impaired insulin activation and dephosphorylation of glycogen synthase in skeletal muscle of women with polycystic ovary syndrome is reversed by pioglitazone treatment. J. Clin. Endocrinol. Metab. 2008, 93, 3618-3626. [CrossRef] [PubMed]

313. Glintborg, D.; Hermann, A.P.; Rasmussen, L.M.; Andersen, M. Plasma osteoprotegerin is associated with testosterone levels but unaffected by pioglitazone treatment in patients with polycystic ovary syndrome. J. Endocrinol. Investig. 2013, 36, 460-465.

314. Ortega-González, C.; Luna, S.; Hernández, L.; Crespo, G.; Aguayo, P.; Arteaga-Troncoso, G.; Parra, A. Responses of serum androgen and insulin resistance to metformin and pioglitazone in obese, insulin-resistant women with polycystic ovary syndrome. J. Clin. Endocrinol. Metab. 2005, 90, 1360-1365. [CrossRef] [PubMed]

315. Cho, L.W.; Kilpatrick, E.S.; Keevil, B.G.; Coady, A.M.; Atkin, S.L. Effect of metformin, orlistat and pioglitazone treatment on mean insulin resistance and its biological variability in polycystic ovary syndrome. Clin. Endocrinol. (Oxf.) 2009, 70, 233-237. [CrossRef] [PubMed]

316. Li, X.-J.; Yu, Y.-X.; Liu, C.-Q.; Zhang, W.; Zhang, H.-J.; Yan, B.; Wang, L.-Y.; Yang, S.-Y.; Zhang, S.-H. Metformin vs thiazolidinediones for treatment of clinical, hormonal and metabolic characteristics of polycystic ovary syndrome: A meta-analysis. Clin. Endocrinol. (Oxf.) 2011, 74, 332-339. [CrossRef] [PubMed]

317. Ibáñez, L.; Diaz, M.; Sebastiani, G.; Sánchez-Infantes, D.; Salvador, C.; Lopez-Bermejo, A.; de Zegher, F. Treatment of androgen excess in adolescent girls: Ethinylestradiol-cyproteroneacetate versus low-dose pioglitazone-flutamide-metformin. J. Clin. Endocrinol. Metab. 2011, 96, 3361-3366. [CrossRef] [PubMed]

318. El-khayat, W.; Abdel Moety, G.; Al Mohammady, M.; Hamed, D. A randomized controlled trial of clomifene citrate, metformin, and pioglitazone versus letrozole, metformin, and pioglitazone for clomifene-citrate-resistant polycystic ovary syndrome. Int. J. Gynecol. Obstet. 2016, 132, 206-209. [CrossRef] [PubMed]

319. van de Weijer, T.; Havekes, B.; Bilet, L.; Hoeks, J.; Sparks, L.; Bosma, M.; Paglialunga, S.; Jorgensen, J.; Janssen Mirian, C.H.; Schaart, G.; et al. Effects of bezafibrate treatment in a patient and a carrier with mutations in the PNPLA2 gene, causing neutral lipid storage disease with myopathy. Circ. Res. 2013, 112, e51-e54. [CrossRef] [PubMed]

320. Tan, N.S.; Wahli, W. Nuclear hormone receptors and epidermal differentiation. In Lipids and Skin Health; Pappas, A., Ed.; Springer International Publishing: Cham, Switzerland, 2015; pp. 91-106.

321. Elijah, I.E.; Børsheim, E.; Maybauer, D.M.; Finnerty, C.C.; Herndon, D.N.; Maybauer, M.O. Role of the PPAR- $\alpha$ agonist fenofibrate in severe pediatric burn. Burns 2012, 38, 481-486. [CrossRef]

322. Jeschke, M.G.; Kraft, R.; Emdad, F.; Kulp, G.A.; Williams, F.N.; Herndon, D.N. Glucose control in severely thermally injured pediatric patients: What glucose range should be the target? Ann. Surg. 2010, 252, 521-528. [CrossRef]

323. Cree, M.G.; Zwetsloot, J.J.; Herndon, D.N.; Qian, T.; Morio, B.; Fram, R.; Sanford, A.P.; Aarsland, A.; Wolfe, R.R. Insulin sensitivity and mitochondrial function are improved in children with burn injury during a randomized controlled trial of fenofibrate. Ann. Surg. 2007, 245, 214-221. [CrossRef] [PubMed]

324. Bruckert, E.; Duchêne, E.; Bonnefont-Rousselot, D.; Hansel, B.; Ansquer, J.-C.; Dubois, A.; Gaymard, B. Proof of concept study: Does fenofibrate have a role in sleep apnoea syndrome? Curr. Med. Res. Opin. 2010, 26, 1185-1192. [CrossRef] [PubMed]

325. Liu, A.; Kim, S.H.; Ariel, D.; Abbasi, F.; Lamendola, C.; Cardell, J.; Xu, S.; Patel, S.; Tomasso, V.; Mojaddidi, H.; et al. Does enhanced insulin sensitivity improve sleep measures in patients with obstructive sleep apnea: A randomized, placebo-controlled pilot study. Sleep Med. 2016, 22, 57-60. [CrossRef] [PubMed]

326. Richir, M.C.; Ellger, B.; Teerlink, T.; Siroen, M.P.C.; Visser, M.; Spreeuwenberg, M.; Girbes, A.R.J.; van der Hoven, B.; van den Berghe, G.; Wilhelm, A.J.; et al. The effect of rosiglitazone on asymmetric dimethylarginine (ADMA) in critically ill patients. Pharmacol. Res. 2009, 60, 519-524. [CrossRef] [PubMed]

327. Doggrell, S. Do peroxisome proliferation receptor- $\gamma$ antagonists have clinical potential as combined antiobesity and antidiabetic drugs? Expert Opin. Investig. Drugs 2003, 12, 713-716. [CrossRef] [PubMed]

328. Gou, Q.; Gong, X.; Jin, J.; Shi, J.; Hou, Y. Peroxisome proliferator-activated receptors (PPARs) are potential drug targets for cancer therapy. Oncotarget 2017, 8, 60704-60709. [CrossRef] [PubMed] 
329. Cheng, H.S.; Lee, J.X.T.; Wahli, W.; Tan, N.S. Exploiting vulnerabilities of cancer by targeting nuclear receptors of stromal cells in tumor microenvironment. Mol. Cancer 2019, 18, 51. [CrossRef]

330. Tan, E.H.P.; Sng, M.K.; How, I.S.B.; Chan, J.S.K.; Chen, J.; Tan, C.K.; Wahli, W.; Tan, N.S. ROS release by PPAR $\beta / \delta$-null fibroblasts reduces tumor load through epithelial antioxidant response. Oncogene 2018, 37, 2067-2078. [CrossRef] [PubMed]

331. Montagner, A.; Wahli, W.; Tan, N.S. Nuclear receptor peroxisome proliferator activated receptor (PPAR) $\beta / \delta$ in skin wound healing and cancer. Eur. J. Dermatol. 2015, 25, 4-11.

(C) 2019 by the authors. Licensee MDPI, Basel, Switzerland. This article is an open access article distributed under the terms and conditions of the Creative Commons Attribution (CC BY) license (http://creativecommons.org/licenses/by/4.0/). 